Dep. de Lenguajes y Sistemas Informáticos e Ingeniería de Software Escuela Técnica Superior de Ingenieros Informáticos Universidad Politécnica de Madrid
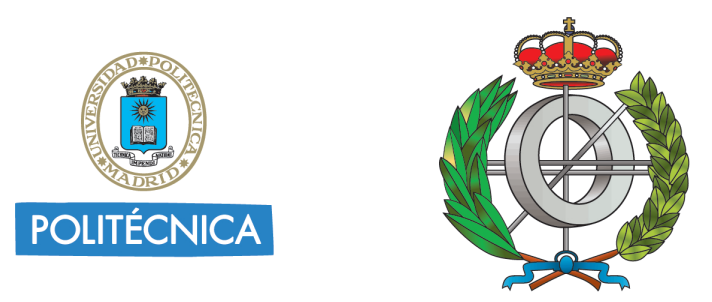

\title{
Modeling the visualization and exploration of document collections with user and purpose-based adaptation
}

Ph.D DISSERTATION

\author{
Author: \\ Cristian Moral Martos \\ Computer Science Engineer \\ Supervisors: \\ Angélica de Antonio Jiménez \\ Ph.D in Computer Science \\ Xavier Ferré Grau \\ Ph.D in Computer Science
}

Madrid, November 2016 

Tribunal nombrado por el Magnífico y Excelentísimo Sr. Rector de la Universidad Politécnica de Madrid.

Presidente: Paloma Díaz Pérez

Secretario: Ricardo Imbert Paredes

Vocales: Salvador Sánchez Alonso

Ángel Rodríguez Martínez de Bartolomé

Matthieu Poyade

Suplentes: Sonia Pamplona Roche

Adriana Peña Pérez-Negrón
Catedrática de la Universidad Carlos III de Madrid (UC3M)

Profesor Contratado Doctor en la Universidad Politécnica de Madrid (UPM)

Profesor Titular de la Universidad de Alcalá (UAH)

Profesor Titular de la Universidad Politécnica de Madrid (UPM)

Director del Programa de Máster de Visualización Médica y Anatomía Humana en The Glasgow School of Arts (Reino Unido)

Profesora Ayudante en la Universidad a Distancia de Madrid (UDIMA)

Profesora Titular de la Universidad de Guadalajara (México)

Realizado el acto de lectura y defensa de la Tesis Doctoral el día 02 de Noviembre de 2016 en Boadilla del Monte, acuerda otorgarle la calificación de:

El Presidente

El Secretario 

A ti mamá.

Sé que estarás profundamente orgullosa de mi, y sólo por eso ha merecido la pena todo el esfuerzo y sacrificio de estos años. 

"We all have dreams. But in order to make dreams come into reality, it takes an awful lot of determination, dedication, self-discipline, and effort." Jesse Owens

"I am a great believer in luck, and I find the harder I work, the more I have of it." Thomas Jefferson 



\section{Acknowledgments / Agradecimientos}

En primer lugar, quiero darle las gracias a mis directores de tesis, Angélica y Xavi. Gracias por haberme acompañado, ayudado, animado y motivado a lo largo de todos estos años. Gracias por confiar en mi, por apostar por mi. Gracias por vuestra infinita paciencia, por tener siempre, bajo cualquier circunstancia y a pesar del agobio y del estrés de estos años, una increíble disposición y una enorme sonrisa. Para mi sois un ejemplo de vocación y capacidad de trabajo. No podía haber tenido a mejores maestros y compañeros en este viaje.

A lo largo de estos años, por suerte, he contado con muchos compañeros que me han ayudado y acompañado en este viaje. En primer lugar, gracias a todos los compañeros doctorandos del Laboratorio Decoroso Crespo: Jackeline, Daniel, Juan Luís, Óscar, Graciela, Pamela y Sonia. No puedo olvidarme de Diego (y por extensión de su mujer Valeria), que en estos años ha sido mi compañero de despacho, de comidas y de debates. Aunque en breve estarás lejos, espero que sigamos solucionando el mundo con nuestras tertulias políticas y filosóficas. También gracias a todos los alumnos que han pasado por el laboratorio, y especialmente a aquellos que, de forma directa o indirecta, han participado en el desarrollo de esta tesis: Alberto, Mario, David, Christian, Luís, Hector Dany, Joaquín y Hebert. Seguro que hay muchos más: aunque no os mencione explícitamente, también gracias a vosotros.

Me gustaría dar mi mayor agradecimiento a mis compañeros "profes" más cercanos: Ricardo, Jaime y Nelson. Gracias por vuestras charlas, por vuestro positivismo, por vuestro incansable disposición para arrimar el hombro y ayudar siempre que os he pedido algo, siempre de buen grado y sin el menor interés propio. Sois un claro ejemplo de lo que es tener pasión por su trabajo. Obviamente, gracias también a mi compañera de despacho, Elena: aunque llevamos poco tiempo juntos en nuestra segunda casa, tengoq ue agradecerte enormemente tus ánimos y haber compartido conmigo mis preocupaciones y agobios en estos meses. Sé que no me podía haber tocado mejor compañera de despacho. Y por último, a mis dos compañeros de asignatura, Loïc y Pilar, gracias por vuestros consejos y por vuestra paciencia en estos meses que he sido más quisquilloso que de costumbre. 
No puedo olvidarme de mis compañeros del Center for Human-Computer Interaction (Virginia Tech), Doug, Felipe, Bireswar, Mahdi, Panagiotis, Siroberto, y Gurjot. Gracias por acogerme y por hacerme sentir parte del equipo.

Quiero dar un especial agradecimiento a todos aquellos que, de forma desinteresada, accedisteis a participar en el estudio que ha dado lugar a esta tesis: Jackeline, Rodrigo, Graciela, Diego, Jaime, Jacinto, Manuel, Paco, Lupe, Pamela, Ben, Valeria, Nelson, Ricardo, Sonia, Marisa, Natalia, Sira, y Tomás. Sin vuestra ayuda, este trabajo no hubiese sido posible. Obviamente, también me gustaría agradecerle su trabajo y ayuda a los revisores externos de mi tesis, Óscar y Matthieu, y a los miembros del tribunal de mi tesis, Paloma, Ricardo, Salvador, Ángel, Matthieu, Sonia y Adriana, por aceptar participar en la lectura y defensa de mi tesis.

A mis amigos, los de verdad, los que siempre han estado ahí y lo siguen estando, les debo un incondicional agradecimiento. En primer lugar, a mis amigos de la Universidad: Víctor, Raúl, Ari, Alberto, Dani, Silvia, Arcos, Mario, Loreto, Sergio, Tania, David, Antonio, María y Mari. Indudablemente, gracias también a mis amigos "Everianos": Isa (Rapun), Marta, Fidel, Miguel, y Raúl. También gracias a mis mejores amigos, Javi y Raquel, que a pesar de estar físicamente lejos, siempre han demostrado estar muy cerca. No querría olvidarme de otros muchos amigos que han sido imprescindibles en éstos últimos años y a lo largo de mi vida (Fer, Marta "Granada", Payán, Nuri, Natalia, Manolo, Eli, Álvaro, Ramón, Mario Palmero, Tania, David), pero me temo que tengo demasiado poco espacio para nombraros a todos. Tengo la gran fortuna de contar con multitud de amigos, pero el espacio es limitado, así que me disculpo de antemano si me dejo a alguien. Gracias a todos por aguantarme durante estos años, por entender mis ausencias físicas y mentales, por ser mono-temático, por haber sido un poquito menos yo en estos años. Las quedadas, vacaciones, fiestas y charlas con vosotros han sido uno de los combustibles que me ha ayudado a no rendirme.

El mayor agradecimiento, sin lugar a duda, es a mi familia. En primer lugar a mi padre y a mi madre, por sacrificarlo todo en la vida para permitirme a mi y a mis hermanos que pudiéramos ser lo que quisiésemos en la vida. Gracias por enseñarme el valor del esfuerzo y del sacrificio y por inculcarme que para ser alguien en la vida, ante todo hay que ser buena persona. Sois los mejores padres que se pueden tener, y sin vosotros no habría podido alcanzar esta meta. Gracias también a Elsy por su constante apoyo y preocupación durante estos años. El otro apoyo incondicional durante la realización de esta tesis, y en la mi vida en general, son mis hermanos. A mi hermano Sebas y a mi cuñada Geli, gracias por vuestro apoyo y ánimo, y por estar siempre (y por demostrarlo) tremendamente orgullosos de mi. A mi hermana Yolanda y a mi cuñado Juan, no hay suficientes palabras para agradeceros todo lo que habéis hecho 
por mi. Todo esto empezó gracias a vosotros. A mi hermano Kiko, gracias por haber sido siempre mi figura a seguir. Si hoy me dedico a la informática, es gracias a ti. A mi hermano Marc, gracias por la ingenua admiración que siempre demuestras que sientes por mi, y por ser para mi un ejemplo de valentía y de esfuerzo. No puedo no darle las gracias a todos mis sobrinos, Adrià, Olga, Nerea, Paula y Gael. Sois lo más bonito que tenemos en la familia, y no sabéis cuánto me han ayudado vuestros inocentes pero sinceros gestos, abrazos y besos durante estos años. Os quiero a todos.

Y por último, a ti, que me has acompañado día a día durante estos años, que has aguantado mis cambios de humor, que me has apoyado incondicionalmente, que has conseguido hacerme reír incluso en los momentos más críticos, que a pesar de no entender casi nada de las "cosas de informáticos" que contiene esta tesis te has empeñado en intentar entenderla, a ti que me has demostrado y demuestras un amor sin fin, sólo puedo pedirte perdón por estos últimos años y darte el mayor de los agradecimientos. 



\begin{abstract}
Seeking information is an essential activity in the field of research. However, due to the huge amount of information that already exists, and that is increased every day, it is difficult to find the specific information that a researcher actually needs. Many software tools have appeared in the last years to facilitate information-seeking activities, but most of them are based on the classic "best-match" approach. However, a "one-size-fits-all" solution is limited in order to effectively fulfill the user's information needs, especially in the research domain, where huge document collections are managed, and very specific information is usually required to achieve the user's purpose.

Instead, information seeking and exploration systems should effectively adapt to all the aspects that may influence the information-seeking process, like the user, the type of data being used, the context of the seeking activity, or the purpose the user aims to achieve. An essential precondition for adaptation is the existence of a clear model of this process that considers all the concepts that intervene, and how they interrelate. However, such a model is still missing.

To fill this gap, in this research we have carried out a complete inductive qualitative study allowing us to comprehensively understand how the process is performed by researchers and which are the relevant concepts and relationships that intervene in it. The research has been contextualized in the computer science field to ensure that the possible variability in the information-seeking practices in different domains does not bias the obtained information.

Based on the results of this qualitative study, we propose representing the concepts and relationships that emerged in the analysis of the process through a set of holistic and extensive conceptual models. In order to facilitate their understanding, a pictorial representation has been created using a standard, easy-to-understand and widely used representation language (UML). First of all, we propose a conceptual model of the information-seeking process, where high-level concepts, like document, task, or purpose, are not only present, but are also modeled in detail.

On the other hand, due to the huge amount of documents that are usually involved in seeking activities, information visualization has become an essential aspect of the process, as it potentially can transmit information (like relationships) in a very intuitive
\end{abstract}


and effective way. For this reason, the concepts and relationships specifically related to the information visualization activities have also been described through a conceptual model.

Finally, the researcher's characteristics and preferences that are relevant for information seeking and exploration are also described in a conceptual model.

In all cases, the models have been designed to reflect the complexity of the process, and are also flexible enough to be easily modified or extended.

Once the processes and actors have been fully modeled, we propose a fuzzy logic approach to allow a dynamic and adaptive calculation of the relevance of certain information elements (like authors or documents) depending on the user preferences and on the interrelationships that exist among them (as specified in the conceptual model).

In order to point out the usefulness of the proposed solution, we present some of its practical applications. First of all, the models provide a complete framework that can be used to comprehensively analyze, describe and compare in detail existing information systems. Additionally, models can also be used to guide the design of new information systems and some prototypes developed with the model guidance are presented to prove the feasibility of such application of our proposal. 


\section{Resumen}

La búsqueda de información es una de las principales actividades en el ámbito de la investigación. No obstante, debido a la gran cantidad de información que ya existe, junto con la que se produce cada día, resulta especialmente difícil hallar la información que realmente necesita el investigador. En los últimos años han aparecido multitud de herramientas informáticas que buscan facilitar la búsqueda de información, pero la mayoría de ellas usan el enfoque clásico basado en hallar "la mejor coincidencia". Sin embargo, este tipo de soluciones "de talla única" tienen una efectividad limitada a la hora de cubrir las necesidades de información del usuario, especialmente en al ámbito de la investigación, dónde se manejan grandes colecciones de documentos y se requiere de datos muy específicos para alcanzar el objetivo de la búsqueda.

Sin embargo, los sistemas de información deberían adaptarse de manera efectiva a todos aquellos aspectos que puedan influir en el proceso, como el usuario, el tipo de dato usado, el contexto en el que se realiza la actividad o el propósito del usuario. Para que esto ocurra, es condición esencial que exista un modelo completo del proceso que contemple todos los conceptos y relaciones que intervienen en él. Sin embargo, dicho modelo no existe.

En este trabajo hemos llevado a cabo un completo estudio cualitativo e inductivo que nos ha permitido comprender en detalle cómo buscan información los investigadores, y cuáles son los principales conceptos y relaciones que interviniente en el proceso de búsqueda. El estudio se llevó a cabo únicamente con investigadores en informática para asegurar que la variabilidad entre los distintos dominios no afectase a los resultados.

En base a dichos resultados, hemos representado todos los conceptos y relaciones que emergieron del análisis del estudio cualitativo mediante una serie de completos y holísticos modelos conceptuales. Para facilitar su comprensión, se ha creado una representación pictórica mediante el uso de un lenguaje de representación estándar, fácil de entender y ampliamente usado (UML). En primer lugar, proponemos un modelo conceptual del proceso de búsqueda de información, en el cual se representan y detallan los conceptos de más alto nivel (documentos, tareas, objetivos... ).

Por otro lado, la visualización de la información, es un concepto de alto nivel que es imprescindible modelar ya que permite transmitir más información (por ejemplo las 
relaciones) de forma más intuitiva y efectiva. Por este motivo, también proponemos un modelo conceptual de la visualización de información.

Por último, también modelamos las principales características y preferencias del usuario que son relevantes en el proceso de búsqueda. En todos los casos, los modelos han sido diseñados para reflejar la complejidad del proceso, pero también para ser flexibles y permitir que puedan añadirse nuevos conceptos, o modificar o eliminar aquellos ya existentes.

Tras esto, proponemos un sistema de lógica difusa para calcular dinámica y adaptativamente la relevancia de algunos conceptos (como un autor o un documento) en base a las preferencias del usuario y las relaciones mutuas que existen entre dichos elementos (tal y como se especifica en el modelo conceptual del proceso de búsqueda).

Con el objetivo de mostrar la utilidad de la solución propuesta, se presentan algunas de sus aplicaciones prácticas, como servir como marco de referencia para analizar, describir y comparar sistemas de información ya existentes, o para ser usados para guiar el diseño de nuevos sistemas de información. Como prueba de dicha utilidad, se explican dos prototipos que se han desarrollado usando los modelos como guía. 


\section{Contents}

Abstract xiii

Resumen $\quad$ Xv

List of Figures $\quad$ xxi

List of Tables $\quad$ xxvii

1 Introduction and motivation 1

1.1 Assumptions . . . . . . . . . . . . . . . . . . . 3

1.2 Research objectives . . . . . . . . . . . . . . . . . 3

1.3 Research approach . . . . . . . . . . . . . . . . . 3

1.4 Proposed solution . . . . . . . . . . . . . . . . . . . 5

1.4.1 Qualitative Study . . . . . . . . . . . . . . 5 5

1.4.2 Conceptual models . . . . . . . . . . . . . . 6

1.4.3 Relevance estimation . . . . . . . . . . . . . . 8

2 A qualitative study of the research-oriented information seeking pro$\begin{array}{ll}\text { cess in Computer Science } & 11\end{array}$

2.1 Methodology . . . . . . . . . . . . . . . . . . . . 12

2.1.1 Focus group . . . . . . . . . . . . . . . 13

2.1.1.1 Research team ................ 13

2.1.1.2 Research sample . . . . . . . . . . . . . . . . . 14

2.1.1.3 Study design . . . . . . . . . . . . . . . . 15

2.1.1.4 Data Analysis . . . . . . . . . . . . . 17

2.1 .2 Interviews . . . . . . . . . . . . . . . . . 18

2.1.2.1 Research team . . . . . . . . . . . . . . . 19

2.1.2.2 Research sample . . . . . . . . . . . . . . . . 19

2.1.2.3 Study design . . . . . . . . . . . . . . . . . . 19

2.1.2.4 Data analysis . . . . . . . . . . . . 22 
2.2 Refining the coding system . . . . . . . . . . . . . . . 24

2.2.1 Triangulation of the data . . . . . . . . . . . . 24

2.2 .2 Iterative process . . . . . . . . . . . . . . . . . . 25

2.2.3 Theoretical Saturation . . . . . . . . . . . . . . 30

2.3 Qualitative study results . . . . . . . . . . . . . . 32

3 Information-Seeking Process Model 35

3.1 Obtaining of the models . . . . . . . . . . . . . . 36

3.2 Information-Seeking Activity . . . . . . . . . . . . . . . 38

3.3 Documents . . . . . . . . . . . . . . . . . . . . 42

3.3.1 Explicit Document Data . . . . . . . . . . . . . . 45

3.3.2 External entities related to a document . . . . . . . . . . . . 47

3.3.3 Implicit Document Data . . . . . . . . . . . . . . . . 49

3.4 Topic . . . . . . . . . . . . . . . . . . 50

3.4.1 Identification of topics . . . . . . . . . . . . . . 51

3.4.1.1 Use of predefined definition of topics . . . . . . . . 51

3.4.1.2 Personal definition of topics . . . . . . . . . . 51

3.4.1.3 Using a significant representative . . . . . . . . . . 52

3.4.1.4 Emerging definition of topics . . . . . . . . . . . 52

3.4 .2 Topic representation . . . . . . . . . . . . . . . 53

3.4.2.1 Using a label . . . . . . . . . . . . . . 54

3.4.2.2 Using a vectorial representation . . . . . . . . . 54

3.4.3 Determining the topics addressed by a document . . . . . . . . 57

3.5 Information-Seeking Tasks . . . . . . . . . . . . . . . . . 59

3.5.1 Filtering Task . . . . . . . . . . . . . 61

3.5.2 Exploration Task . . . . . . . . . . . . . 63

3.5.3 Reading Task . . . . . . . . . . . . . . . . . . . . . 64

3.5.4 Storage \& Management Task . . . . . . . . . . . . . . . . . 64

3.6 Context . . . . . . . . . . . . . . . 66

3.6.1 Interaction details . . . . . . . . . . . . . . 66

3.6.2 Temporal details . . . . . . . . . . . . . . . . . . 69

3.6 .3 Workspace . . . . . . . . . . . . . . 69

3.6 .4 Work style . . . . . . . . . . . . . . . 70

3.7 Related works . . . . . . . . . . . . . . . . 71

4 Information Visualization Model $\quad 81$

4.1 Information visualization activity . . . . . . . . . . . . . 83

4.2 Device . . . . . . . . . . . . . . . . . . . . . . . 87 
4.3 Visual representations . . . . . . . . . . . . . . . . . . . . . 90

4.4 Visualization dimensions . . . . . . . . . . . . . . . . . . . . . . . . . . . . 95

4.5 Information visualization tasks . . . . . . . . . . . . . . . . . . . . 99

4.6 Inter-document relationships . . . . . . . . . . . . . . . . . 104

4.7 Related works . . . . . . . . . . . . . . . . . . . 107

5 Model of Computer Science researchers 113

5.1 Main components of the researcher's model . . . . . . . . . . . . . . 115

5.1 .1 Relevant knowledge . . . . . . . . . . . . . . . 115

5.1 .2 Personal characteristics . . . . . . . . . . . . . . 118

5.1 .3 Personal preferences . . . . . . . . . . . . . . . . 120

5.1.3.1 General preferences . . . . . . . . . . . . . . 122

5.1.3.2 Context-related preferences . . . . . . . . . . 123

5.1.3.3 Visualization-related preferences . . . . . . . . . 125

5.1.3.4 Preferences related to information-seeking tasks . . . . 126

5.1.4 History of CS researcher's usage of the information-seeking system 132

5.2 CS Researcher's topics of interest . . . . . . . . . . . . . . . . 140

6 Adaptive relevance estimation: A Fuzzy Logic approach 143

6.1 Fuzzy logic . . . . . . . . . . . . . . . . . . . . . . . . . . . 145

6.2 Objective relevance based on indicators . . . . . . . . . . . . . . . . . 148

6.2.1 Document's relevance based on the amount of times it has been cited . . . . . . . . . . . . . . . . . . . . . 148

6.2.2 Author's relevance based on the amount of documents he/she has written . . . . . . . . . . . . . . . . . . 150

6.2.3 Author's relevance based on his/her impact metrics . . . . . . . 150

6.2.4 Publication venue's relevance based on its impact metrics . . . . 156 6.2.4.1 Journal's relevance based on its impact metrics . . . . 157 6.2.4.2 Conference's relevance based on its impact metrics . . 161

6.2.5 Relevance of a publication venue based on the amount of documents it has published . . . . . . . . . . . . . . 161

6.2.6 Relevance of a research group based on the amount of authors affiliated to it . . . . . . . . . . . . . . . . . . . 162

6.3 Researcher-dependent relevance . . . . . . . . . . . . . . 163

6.3.1 Document's relevance based on the usage history of it by the researcher ....................... . 163

6.3.2 Document's relevance based on its thematic similarity with researcher's topics of interest . . . . . . . . . . . . . . . 172 
6.3.3 Explicit relevance assigned by the researcher . . . . . . . . . . . 173

6.4 Inter-concepts influence . . . . . . . . . . . . . . . . . . . . . . 174

6.5 Final relevance . . . . . . . . . . . . . . . . . 176

6.5.1 Document's relevance . . . . . . . . . . . . . . 176

6.5.2 Author's relevance . . . . . . . . . . . . . . . . . . 191

6.5.3 Publication venue's relevance . . . . . . . . . . . . 196

6.5.4 Research group's relevance . . . . . . . . . . . . . . . . . 199

6.6 Time-dependence of relevance . . . . . . . . . . . . . . . . . 203

$\begin{array}{lll}7 & \text { Practical applications } & 207\end{array}$

7.1 Use for formal characterization of information systems . . . . . . . . 207

7.2 Use for information systems comparison . . . . . . . . . . . . . 209

7.3 Use for designing an information system . . . . . . . . . . . . . . . . 209

7.3.1 Design and implementation of an ontology . . . . . . . . . . 215

7.3.2 Design and implementation of an information visualization proto-

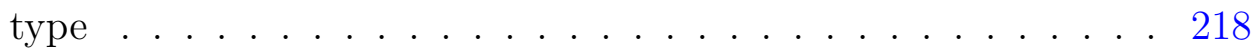

7.3.2.1 AD-DOC . . . . . . . . . . . . 218

7.3.2.2 Journal Advisor . . . . . . . . . . . . . . . . 220

7.4 Framework for future work . . . . . . . . . . . . . . . . 225

7.4.1 Studying the researcher's classification strategies and the use of workspaces . . . . . . . . . . . . . . . . . 225

7.4.2 Studying the impact of multi-environment information systems . 226

8 Discussion of the results $\quad 229$

9 Conclusions and future work $\quad 233$

9.1 Achievement of the objectives . . . . . . . . . . . . . . . 233

9.2 Dissemination of results . . . . . . . . . . . . . . . . . . . 237

9.3 Future work . . . . . . . . . . . . . . . . . . . . . . . . 238

$\begin{array}{ll}\text { References } & 245\end{array}$

$\begin{array}{ll}\text { Appendix A Categorized coding system } & 255\end{array}$

$\begin{array}{ll}\text { Appendix B Stopwords list } & 299\end{array}$

$\begin{array}{lll}\text { Appendix C Full conceptual models } & 303\end{array}$

Appendix D Multi-component rules used to calculate the final relevances309 


\section{List of Figures}

1.1 Overview of the proposed solution . . . . . . . . . . . . . . 6

2.1 Steps followed to carry out the qualitative study . . . . . . . . . . . . . 12

2.2 Focus Group steps . . . . . . . . . . . . . . . . . . . . . . 17

2.3 First round of interviews . . . . . . . . . . . . . . . . . . . 21

2.4 Second round of interviews . . . . . . . . . . . . . . . . . . . 22

2.5 First tentative coding system . . . . . . . . . . . . . . 26

2.6 Second coding phase . . . . . . . . . . . . . . . . 27

2.7 First refinement iteration: comparison of the coders' codification . . . . 28

2.8 Second refinement iteration: individual refinement . . . . . . . . . . . . 28

2.9 Third refinement iteration: refinement by the other coders . . . . . . . 29

2.10 Evolution of the inter-coders agreement during the refinement process . 29

2.11 Evolution of the coding system . . . . . . . . . . . . . . . 30

2.12 Generation of codes along the interviews . . . . . . . . . . . . . . . . 32

2.13 Hierarchical organization of the codes . . . . . . . . . . . . . 33

3.1 Main concepts intervening in an information-seeking process . . . . . . 39

3.2 Document collection . . . . . . . . . . . . . . . . . . . . . . 43

3.3 Types of research documents . . . . . . . . . . . . . . . . . . 44

3.4 Basic and abstract composition of a research document . . . . . . . . . 45

3.5 Explicit data contained in a research document . . . . . . . . . . . 45

3.6 Data included in bibliographic references . . . . . . . . . . . . . . 46

3.7 Explicit data that are specific to a given type of research document . . 47

3.8 Other concepts related to research documents . . . . . . . . . . . . . . 48

3.9 Impact metrics in the research domain . . . . . . . . . . . . . . . . . . 49

3.10 Data thata re implicitly contained in research documents . . . . . . . . 50

3.11 Topics in the research domain . . . . . . . . . . . . . . . 50

3.12 Example of vectorization of 3 documents using the Vector Space Model 54

3.13 Example of similarity calculation using the cosine metric . . . . . . . . 58

3.14 Similarity matrix of the four documents presented in the example . . . 59 
3.15 Types of information-seeking tasks . . . . . . . . . . . . . . 60

3.16 Single and chained information-seeking tasks . . . . . . . . . . . . . 61

3.17 Filtering task . . . . . . . . . . . . . . . . . . 62

3.18 Exploration task . . . . . . . . . . . . . . . . . . 63

3.19 Reading task . . . . . . . . . . . . . . . . 65

3.20 Storage \& management task . . . . . . . . . . . . . . . 65

3.21 Main components of the context . . . . . . . . . . . . . . . . 67

3.22 Means of access . . . . . . . . . . . . . . . . . 67

3.23 Wilson's revised general model of information behaviour . . . . . . . . . 74

3.24 Krikelas' information behaviour model . . . . . . . . . . . . . . . . . . . 75

3.25 Scholarly research activity model from Benardou, Constantopoulos, Dallas, and Gavrilis . . . . . . . . . . . . . . . . 76

3.26 Comparing the obtained ISP conceptual model vs. models existing in the literature . . . . . . . . . . . . . . . . . . 8 80

4.1 Information visualization activity . . . . . . . . . . 83

4.2 Example of information seeking and visualization system: 3D Explorer (First workspace). . . . . . . . . . . . . . . . . .

4.3 Example of information seeking and visualization system: 3D Explorer (Second workspace) . . . . . . . . . . . . . . . . . 86

4.4 Devices used to visualize and manipulate information . . . . . . . . . . 88

4.5 Visual representations of the elements displayed in the visualization . . 90

4.6 Example of information seeking and visualization system: Calimaco. . . 92

4.7 Example of use of other visual representations . . . . . . . . . . . . . 93

4.8 Main features of the visual representations . . . . . . . . . . . . . . 94

4.9 Modalities of visual representations . . . . . . . . . . . . . . . 95

4.10 Some visualization dimensions used to illustrate the visual representations 95

4.11 HSL model . . . . . . . . . . . . . . . . . . . . . . . . . 96

4.12 Some tasks allowing to manipulating the displayed information and the visualization . . . . . . . . . . . . . . . . . . 100

4.13 Example of information seeking and visualization system: Google Scholar102

4.14 Calimaco: Increasing the intra-cluster force from zero to maximum value 103

4.15 Effects that can occur when performing an information visualization task 103

4.16 Inter-documents Relationship . . . . . . . . . . . . . . . 105

4.17 Reference Model for visualization . . . . . . . . . . . . . . . . . . . . . 110

4.18 Mapping of concepts between proposed model and reference model . . . 111

5.1 Main aspects that define a CS researcher . . . . . . . . . . . 116 
5.2 Types of research-related knowledge a CS researcher can have . . . . . 116

5.3 CS researcher's profiles based on their seniority in the research domain 116

5.4 Personal characteristics of a CS researcher . . . . . . . . . . . . . 118

5.5 Personal preferences of a CS researcher . . . . . . . . . . . . . . . 121

5.6 CS researcher's preferences related to the information-seeking activity as a whole . . . . . . . . . . . . . . . . . 122

5.7 CS researcher's preferences related to the context in which are carried out the information-seeking activities . . . . . . . . . . . . . . 123

5.8 CS researcher's preferences related to the visualization of the information 125

5.9 CS researcher's preferences related to the performance of the informationseeking tasks . . . . . . . . . . . . . . . . 127

5.10 Example of classification: Depth Structure vs. Breadth Structure . . . 131

5.11 Actions recorded in the information-seeking history . . . . . . . . . . . 134

5.12 Weighted vector representing the relevant terms for the CS researcher . 142

6.1 Example of fuzzy functions for the linguistic terms "young" and "old" of the variable "age" . . . . . . . . . . . . . . . . . . . . . . . . . 146

6.2 Membership functions for the fuzzy input variables related to the author's impact metrics . . . . . . . . . . . . . . . . . . . 152

6.3 Membership functions for the output variable "relevance of the author based on his/her impact metrics" . . . . . . . . . . . . . . . . . . . . . . 153

6.4 Resulting area of the variable "Shneiderman's relevance based on his impact metrics" . . . . . . . . . . . . . . . . . . . . . . . . . 155

6.5 Resulting area of the variable "Brusilovsky's relevance based on his impact metrics" . . . . . . . . . . . . . . . . . . 155

6.6 Resulting area of the variable "Ahn's relevance based on her impact metrics" 156

6.7 Membership functions for the input variables related to impact metrics of a journal . . . . . . . . . . . . . . . . . . . . 158

6.8 Membership functions for the output variable "relevance of a journal based on its impact metrics" . . . . . . . . . . . . . . . . . . . . . . . . 158

6.9 Resulting area of the variable "relevance of journal 1 based on its impact metrics" when classified in JCR quartile $Q 1$. . . . . . . . . . . 160

6.10 Resulting area of the variable "relevance of journal 1 based on its impact metrics" when classified in JCR quartile Q2 . . . . . . . . . . . . 160

6.11 Resulting area of the variable "relevance of journal 2 based on its impact metrics" . . . . . . . . . . . . . . . . . 160

6.12 Resulting area of the variable "relevance of journal 3 based on its impact metrics" . . . . . . . . . . . . . . . . . . . . 161 
6.13 Membership functions for the input variable "rate of times a document has been opened by the researcher" . . . . . . . . . . . . . . . . . . . . . 164

6.14 Membership functions for the fuzzy input variables related to annotations and highlightings performed by the researcher . . . . . . . . . . 164

6.15 Membership functions for the input variable "document has been printed" 165

6.16 Membership functions for the input variable "rate of times the document is discarded" . . . . . . . . . . . . . . . . . . . 166

6.17 Membership functions for the input variable "the document has been deleted from the storage system" . . . . . . . . . . . . . . . 167

6.18 Membership functions of the output fuzzy variable "document's relevance based on the action history of the researcher" . . . . . . . . . . . . . . . 169

6.19 Resulting area of the variable "document's relevance based on the action history of the researcher" (Example 1) . . . . . . . . . . . . . .

6.20 Resulting area of the variable "document's relevance based on the action history of the researcher" (Example 2) . . . . . . . . . . . . . .

6.21 Resulting area of the variable "document's relevance based on the action history of the researcher" (Example 3) . . . . . . . . . . . . . .

6.22 Resulting area of the variable "document's relevance based on the action history of the researcher" (Example 4) . . . . . . . . . . . . .

6.23 Membership functions for the input variable "document's thematic similarity with researcher's topics of interest" . . . . . . . . . . . . . . . . . 172

6.24 Membership functions for the input variable "explicit relevance assigned by the researcher" . . . . . . . . . . . . . . . . . . . 174

6.25 Dependencies between concepts . . . . . . . . . . . . . . . . 175

6.26 Membership functions for the input variable "mean relevance of citation to document" . . . . . . . . . . . . . . . . . . . . . . 177

6.27 Membership functions for the target output variable "document's relevance" 180

6.28 Resulting area of the target output variable "document $D_{1}$ relevance" for researcher $R_{1} \ldots \ldots \ldots \ldots \ldots \ldots \ldots \ldots$

6.29 Resulting area of the target output variable "document $D_{2}$ relevance" for researcher $R_{1}$

6.30 Resulting area of the target output variable "document $D_{3}$ relevance" for researcher $R_{1} \ldots \ldots \ldots \ldots \ldots \ldots \ldots$

6.31 Resulting area of the target output variable "document $D_{1}$ relevance" for researcher $R_{2} \ldots \ldots \ldots \ldots \ldots \ldots \ldots \ldots \ldots \ldots \ldots$

6.32 Resulting area of the target output variable "document $D_{2}$ relevance" for researcher $R_{2}$. . . . . . . . . . . . . . . . . . . . . . 187 
6.33 Resulting area of the target output variable "document $D_{3}$ relevance" for

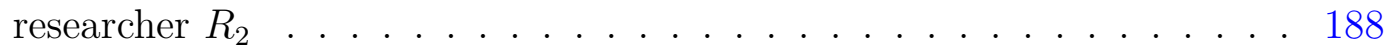

6.34 Membership functions for the target output variable "document $D_{1}$ relevance" for researcher $R_{3} \ldots \ldots \ldots \ldots$. . . . . . . . . . . . 189

6.35 Membership functions for the target output variable "document $D_{2}$ relevance" for researcher $R_{3}$. . . . . . . . . . . . . . . . . . . . 190

6.36 Membership functions for the target output variable "document $D_{3}$ relevance" for researcher $R_{3} \ldots \ldots \ldots \ldots$

6.37 Membership functions for the input variable "mean relevance of documents written by the author" . . . . . . . . . . . . . . . . . 192

6.38 Membership functions for the target output variable "author's relevance" 194

6.39 Membership functions for the input variable "mean relevance of documents published by the venue" . . . . . . . . . . . . . . . . . . . . 197

6.40 Membership functions for the target output variable "publication venue's relevance" . . . . . . . . . . . . . . . . . . . . . . . 198

6.41 Membership functions for the input variable "research group's relevance" 201

6.42 Membership functions for the target output variable "research group's relevance" . . . . . . . . . . . . . . . . . . 202

7.1 Description of the information-seeking tasks supported by Google Scholar using the conceptual model. . . . . . . . . . . . . . . . . . 208

7.2 Implementation of the classes defined in the document's model using Protégé . . . . . . . . . . . . . . . .

7.3 Implementation of the relationships defined in the document's model using Protégé . . . . . . . . . . . . . . . . . .

7.4 Illustration of some documents in AD-DOC, using the position to reflect the publication date. . . . . . . . . . . . . .

7.5 Illustration of some documents in AD-DOC, using the position to reflect the publication date, and collapsing the representaiton of documents with similar publication dates. . . . . . . . . . . . .

7.6 Illustration of some documents in AD-DOC, using the position to reflect the publication date, color for the main author, and shape for the topic. 221

7.7 Journal Advisor: information visualization system to help the researcher the best journal to publish a new paper. . . . . . . . . . . . . . . 222

7.8 Journal Advisor: information visualization system to help the researcher the best journal to publish a new paper. . . . . . . . . . . . . . . . 223

7.9 Journal Advisor: definition of groups to reduce the amount of visualization dimension values needed. . . . . . . . . . . . . . 
C.1 Document sub-model . . . . . . . . . . . . . . . . . . . . . . . 304

C.2 Information-seeking task sub-model . . . . . . . . . . . . . . . . . 305

C.3 Context sub-model . . . . . . . . . . . . . . . . . 306

C.4 Information visualization model . . . . . . . . . . . . . . . 307

C.5 Researcher model . . . . . . . . . . . . . . . . . . . . . 308 


\section{List of Tables}

2.1 Examples of actions performed over the coding system in the last iteration. 31

3.1 Example of frequency of occurrence of terms in documents . . . . . . 58

6.1 Summary of the components used to calculate the relevance of the different entities implied in research-oriented information-seeking activities 204

7.1 Use of the model as framework to describe Google Scholar . . . . . . . 210

7.2 Use of the model as framework to describe Calimaco . . . . . . . . . . 212 



\section{Chapter 1}

\section{Introduction and motivation}

We live in a digital era where it seems easy to find any piece of information in the Internet, where millions of people and organizations produce, share and consume tons of data every second. However, the existence of this huge amount of information greatly hinders the aim of finding the information that a user actually needs. It is difficult to identify which information is reliable and which one is erroneous, incomplete or even false.

Information-seeking tasks have benefited from this great availability of information in the last 20 years, but the problem of identifying the relevant information that has enough quality has worsened. To a large degree, this is due to the approach used to design information systems. Despite technology has evolved a lot in the last years, the classic best-match approach is still predominant. Many efforts have been put on defining new algorithms that improve this matching process, but this approach still has many shortcomings due to the complexity of the information-seeking process, where several aspects, besides the terms that form a query, have to be taken into account. This implies that information systems should be able to identify these aspects in order to better understand which are the actual needs of the user and adapt its behavior and functionality to them.

This problem has even more relevance if the information-seeking activity is carried out in a research domain. The information-seeking process is of high relevance for research activities, since the quality of the found information directly affects the quality of the overall research activity. However, the amount of information that is available in the research domain keeps growing dramatically day by day due to the advances in publishing and accessing the information that has brought the popularization of the Internet. This has caused that thousands of new researchers from all around the world can make their publications visible and accessible for everybody. In order to respond to this enormous demand, hundreds of new journals and conferences have appeared in 
Introduction and motivation

the last years, increasing a lot the number of available and potentially useful sources of information. As a result, nowadays there may be hundreds of researchers, journals and conferences that address a given topic, which obviously allows to advance science more quickly and collaboratively, but also adds a tremendous difficulty in finding the desired information with the desired quality. Moreover, in this domain, even if there are important commonalities that can be gathered and are relevant for supporting the task of researchers, there is also a high degree of variability between many aspects - like the seniority or preferences of the researcher, the context in which the information is sought, or the information need that wants to be fulfilled, among others - regarding the specific information-seeking strategies followed to achieve a specific goal. Then, it is essential to have a clear representation of the process in order to design information systems that properly and effectively support the information-seeking activities.

Identifying all the elements that form part of the information-seeking process and how they interrelate will provide a deeper understanding of the tasks involved in it and the challenges that face the researchers when seeking information.

At the beginning of this research, an information visualization prototype named Calimaco (de Antonio, Moral, Klepel, \& Abente, 2012, 2013a, 2013b) was developed. The prototype served us to confirm the actual relevance of the research topic, and to obtain some information from real users about the information-seeking and visualization processes. The prototype, which was developed as a 3D digital environment and was manipulated by the user through in-air gestures, made use of some visualization aspects to display some information about the documents. To be more concrete, thematic similarity was illustrated through proximity in the 3D space, and thematic clusters were displayed using colors. Apart from evaluating if allowing the users to modify the spatial proximity of the documents in the 3D space according to their similarity with the rest of the documents - inter-documents force-- or to the cluster they belonged to - intra-cluster - led to better results than not allowing it, the observation of the participants during the experiment — who was video-recorded-, and the collection of the comments made by the participants both during and after the tests, allowed us realize that, even if all participants agreed that the system was very interesting and could be of great utility when refined and improved, each of them found difficult different aspects of the visualization, each of them preferred some aspects with respect to others, some found the prototype very easy to use, while others were not even able to accomplish some of the tasks asked in the test. Because of this, it was assumed that a one-size-fits-all approach was not able to satisfy the needs of all the participants, nor to attract them. 


\section{$1.1 \quad$ Assumptions}

The main assumption is that an information system designed for supporting the exploration, visualization and management of document collections has to be able to adapt, at lest, to the specific user who is using it, to the specific purpose of this user, and to the context in which he/she is using it. This assumption is clearly supported by Brusilovsky $(1996,2001)$, who states that in contexts where the user population is diverse in terms of goals, previous knowledge and preferences, as it occurs in researchoriented information-seeking activities, it is practically impossible to design a system satisfying them all, and then an adaptive system, that takes into account these aspects of the user, has to be provided.

Another assumption is that it is possible to propose a model flexible enough to deal with the variability and dependence on other aspects that derive from this need of adaptation.

The last assumption is that capturing the models in a graphical representation is better than explaining them only by text, as it provides, with a naked eye, an overview of the full model in a complete, unambiguous and intuitive way.

\section{$1.2 \quad$ Research objectives}

Below, are presented the research objectives that are expected to be achieved in this thesis:

1. to study in detail what the research-oriented information-seeking process consists of in a specific field - computer science. This implies determining which are the main actors, concepts and relationships that intervene in a research-oriented information-seeking activity;

2. to represent all the previous aspects in a simple and intuitive way, but without losing information or details;

3. to define some automatic mechanisms to adapt the information system to the user's preferences and capabilities;

4. to validate the usefulness of the generated representations.

\subsection{Research approach}

In the literature can be found several authors that have investigated the informationseeking process and behavior (Ellis, 1989; Leckie, Pettigrew, \& Sylvain, 1996; Ellis \& 
Introduction and motivation

Haugan, 1997; Meho \& Tibbo, 2003; Makri, Blandford, \& Cox, 2008), but none of them has offered a comprehensive description of the process, where all the aspects that intervene in it have been taken into account. In fact, many of the most relevant papers and books addressing the topic mainly focus on the researcher from a psychological point of view (Wilson, 1981; Kuhlthau, 1991; Marchionini, 1997; Niedźwiedzka, 2003; Foster, 2004; Godbold, 2006). It is not pretended in this work to further investigate this humanistic approach, but from a more practical point of view.

In addition, almost all the models existent in the literature are described in textual mode (Bates, 1989; Ellis, 1989; Kuhlthau, 1991; Ellis \& Haugan, 1997; Marchionini, 1997; Cheuk \& Dervin, 1999; Meho \& Tibbo, 2003; Foster, 2004; Freund, Toms, \& Waterhouse, 2006; Makri et al., 2008) which requires from the user reading, analyzing and processing the whole model in order to get an idea of it. This restricts its use and reuse capabilities, as the reader still has to spend efforts to fully understand the model. In this work, on the contrary, the aim is to provide a comprehensive, flexible, expandable, reusable and easy-to-understand model of the information-seeking process.

Nonetheless, regardless the point of view or type of the model, in general authors have run a inductive qualitative study to derive their models from scratch (Ellis, 1989; Kuhlthau, 1991; Marchionini, 1997; Cheuk \& Dervin, 1999; Foster, 2004; Freund et al., 2006; Benardou, Constantopoulos, Dallas, \& Gavrilis, 2010). Only a few authors have used a previous model as framework to carry out their qualitative studies (Meho \& Tibbo, 2003; Niedźwiedzka, 2003; Godbold, 2006; Makri et al., 2008).

In this research, models have been derived using an inductive qualitative study mainly because there are no previous models describing in an holistic way and from a conceptual point of view how computer science (CS) researchers seek information. In fact, only two information-seeking models related to the computer science domain have been found (O'Brien \& Buckley, 2005; Freund et al., 2006), but none of them describes the process in a research context. So, in order to avoid using a bad description of the process due to differences between domains, it was decided to thoroughly analyze the domain to be studied - research-oriented information-seeking performed by CS researchers - in order to derive a specific model, which is a common approach in this field. In fact, even if some authors have proposed models that are supposed to be general and domain-independent (Krikelas, 1982; Bates, 1989; Wilson, 1981; Marchionini, 1997; Niedźwiedzka, 2003; Foster, 2004; Godbold, 2006), many of them have proposed models that specifically describe the process in a given domain (Ellis, 1989; Kuhlthau, 1991; Ellis, Cox, \& Hall, 1993; Ellis, 1993; Leckie et al., 1996; Ellis \& Haugan, 1997; Cheuk \& Dervin, 1999; Meho \& Tibbo, 2003; O’Brien \& Buckley, 2005; Freund et al., 2006; Makri et al., 2008; Benardou et al., 2010) 


\subsection{Proposed solution}

The initial purpose of this research was to design an information system that would be able to adapt to any external aspect, like the user, the context or the information need to be fulfilled, in a transparent, effective and efficient way. The idea was to demonstrate that an adaptive information system can support an information-seeking activity much better then a one-size-fits-all solution. However, before working on this purpose, it was needed to comprehensively formalize the process, as this was not done previously and it was considered an essential pre-requisite in order to effectively design an adaptive information system. In this work, then, we have laid the foundations for designing an adaptive information system.

As reflected in Figure 1.1, the solution proposed in this thesis consists of three parts:

1. A qualitative study has been run in order study the information-seeking process performed by CS researchers. This study produced two results: a categorized list of aspects that are relevant and should be addressed, and a list of 169 codes that have emerged from the performance of an inductive coding of the data collected during the study.

2. The previous lists of topics and codes have been used to propose a summary allowing to explain the information-seeking process performed by CS researchers. In this case, the summary has been materialized by a set of models that describe the information-seeking process from a conceptual point of view. To reach this goal, both the identified topics and codes have been categorized and grouped according to their relationships, as defined in methodology used to analyze the collected data - Grounded Theory.

3. As a first approach to the information system's adaptation, an innovative approach has been proposed to estimate the relevance of some aspects that are essential in the research domain - i.e. documents, authors, publication venues, research groups and specific terminology. The calculation is made using a fuzzy logic approach, as it was considered the best option to represent a concept - relevance - that is very abstract and dependent on the user's interpretation.

\subsubsection{Qualitative Study}

As mentioned before, a qualitative study was run in order to study the informationseeking process performed by real CS researchers. The use of rigorous tools is needed to properly analyze qualitative data, and to ensure the correctness of the results. In Chapter 2 is presented one of these tools, a coding system, that has emerged from 


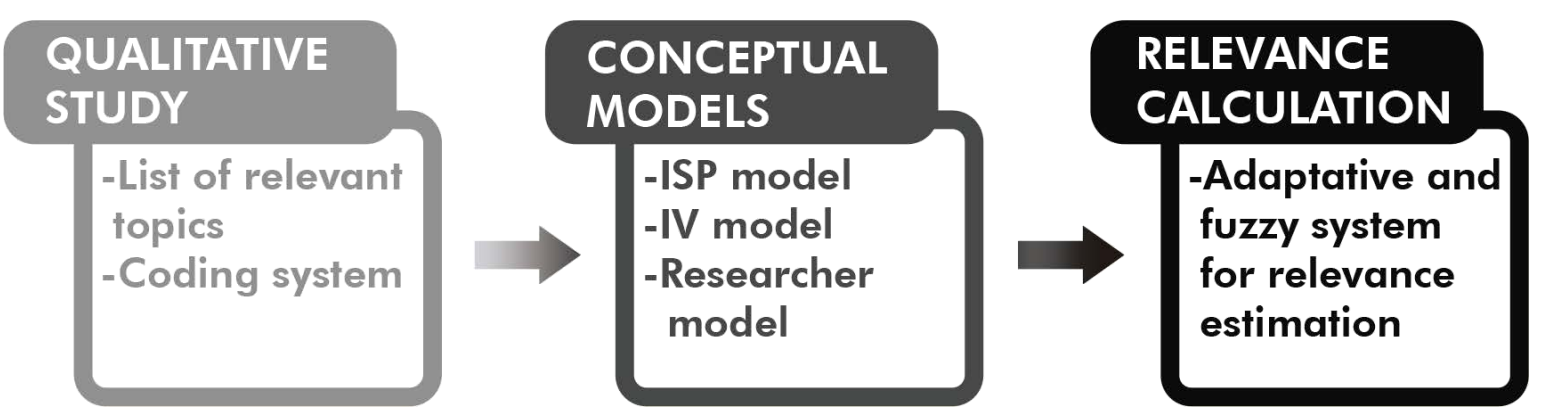

Figure 1.1 Overview of the proposed solution

the analysis of the data collected during the qualitative study. The coding system is presented as a list of codes that have been hierarchically grouped and ordered according to the aspects they are related to.

\subsubsection{Conceptual models}

The coding system derived from the analysis of the data collected during the qualitative study has been used as a framework to elaborate a set of pictorial UML-based conceptual models that illustrate the main concepts emerged in the analysis, and how they interrelate. A pictorial model, like a UML-based model, provides the information in a conceptual and visual form. This kind of representation can serve to transmit the relevant information to stakeholders more clearly, due the excellent human capacity to process visual information (Järvelin \& Wilson, 2003). Conceptual models are a way of representing elements in a particular domain, and they can serve to provide training to novices in the field, or to provide support to the tasks represented in different ways, either by means of technology or via specialized professionals working in the field, like library and information sciences researchers and staff. In fact, this kind of representation allows making explicit and visual, and in a self-explanatory way, all the concepts and relationships these professionals have to manage. Conceptual models can also serve as a tool for software designers, guiding the design process along the user view of the relevant elements that have to be considered. In this direction, Preece, Rogers, and Sharp (2015, p.42) state that "most interface applications are actually based on well-established conceptual models". In this research, this last option is especially of interest, as the final aim is to design an information system that fully supports the information-seeking process.

In Chapter 3 are presented the conceptual models that represent the pillar aspects that have to be taken into account when modeling an information-seeking process. First of all, a general model detailing which are the high-level aspects that intervene during an information-seeking activity is provided. Among them are the documents 
used during the information-seeking process. This concept is essential as documents contain the information needed to achieve the information-seeking purposes. Then, the main tasks that can be undertaken by the user to manipulate these documents and achieve his/her information goal are also modeled. Finally, it is also provided a model of the context in which the information-seeking activity is carried out.

As the long-term purpose of this research is to design an information system, there are two main technological aspects that have to be studied. First of all, it has to be defined how the information contained in the documents is going to be processed and which tasks are going to be offered to the user in order to find the desired information. This part, usually known as information retrieval, has been widely investigated in the last decades. As a result, there are several very efficient and precise techniques. At the highest level, in fact, it is possible nowadays to find many search engines, both generalist and research-oriented, that return a list of documents sorted according tot he degree of similarity with the query terms posed by the user. However, these engines often return an unmanageable amount of results, and this greatly hinders the user finding what he/she needs.

The second technological aspect that has to be studied is how the information is computationally displayed to the user. In the literature, many authors have established the basis of the visualization of information, but from a generalist and theoretical point of view. However, it is not the same visualizing millions of simple data representing, for example, the amount of times a word has been cited in social networks during a certain period, than illustrating the different types of non-numerical data contained in complex entities, like documents, their interrelationships, or their use during a period of time. In the first case, the visualization has to facilitate the processing of the data as a whole through the recognition, for example, of the patterns they form, or by their density. In the second case, on the contrary, the visualization is much more complex as several dimensions of data have to be considered, and the final purpose is to find a subset of individual documents or to obtain a very specific information. In this case, then, even if patterns can be used to achieve this goal, they are not the main aspect of the visualization, but only one more functionality. Then, there is still much work to do to investigate how to visualize and manipulate a great amount of documents in the research domain, especially if a user-centered approach wants to be followed, as visualization and interaction clearly depend on the users. That's why this work focuses on this second technological aspect, as reflected in the model of the information visualization explained in Chapter 4.

Both at the seeking and visualization levels, the user is one of the essential and indispensable aspects that have to be considered. Users seek information in order to 
Introduction and motivation

obtain enough information to achieve a given purpose. Then, it is essential to represent in the model which are the possible purposes a user can have in an information-seeking activity. Additionally, as the actor of the process is the user, it is also imperative to know which are the main characteristics of the user, as the process varies according to them. In fact, most of the information-seeking models existing in the literature specifically focus on the user. Intuitively, the best approach would seem to try to model the main aspects that are common to most users when seeking information in order to obtain a generic model. However, obtaining information to fulfill a need is a very personal activity that relies on several individual aspects, like his/her previous knowledge, his/her previous experience, his/her cognitive capabilities, or the specific preferences he/she has. This implies, then, analyzing not only the explicit information provided by the user to the system - for example the terms he/she uses in the queries-, but also tracking all the actions he/she performs in the informations system, which kind of use he/she makes of each of the documents managed in the system, and which kind of visualization he/she prefers to use, among others. At the end, the final purpose is to allow the system inferring which are the characteristics, capabilities and preferences of the user, so that it can adapt both the visualization and interaction to him/her. In Chapter 5 is presented a complete model containing illustrating all these aspects for a specific type of user: researchers in the computer science field.

finally, in Chapter 7 are presented some examples of practical applications of the proposed models, like using them to describe or compare existing information systems, to guide the design of an ontology containing the knowledge related to part of the information-seeking process, or to serve as framework for designing and developing a new information system allowing to achieve a set of information-seeking purposes.

\subsubsection{Relevance estimation}

User modeling is a very common approach when designing and developing information systems, especially interactive systems. In this research, the thematic interests of the CS researchers have to be clearly represented in the model, as they have a major influence on the identification of the information that he/she can consider relevant or not. Knowing the relevance of these aspects is then essential to adapt the information system's visualization and interaction to the user, and then to increase its usability and to improve his/her user experience. In Chapter 6 is proposed a fuzzy logic system designed to estimate the relevance of the elements that is mainly used in research for a given CS researcher: documents, authors, publication venues and research groups. Fuzzy logic has been chosen as it is a suitable approach to manage uncertain situations that are too abstract or subjective to be uniquely specified, like the relevance, which 
is an abstract concept that is difficult to be concreted, especially taking into account the inner uncertainty and complexity associated to humans and their decision-making processes. 



\section{Chapter 2}

\section{A qualitative study of the research-oriented information seeking process in computer science}

The information-seeking process is a very familiar activity for researchers, but it is difficult to formalize. In this research, the first approach was to informally ask some CS researchers how they seek for information during their research activities. Some of them were unable to explain how they look for, select, classify and archive papers for their researches. Either they had interiorized and mechanized the process to such a degree that they did not remember how they usually perform it, or they considered the process unquantifiable because it depends on many external factors. There were some of them who attempted to propose a definition of the process, but there was a high variability between them. In both cases, the results would have probably been wrong, incomplete or forced.

In order to overcome this lack of definition and the potential subjectivity, a qualitative study was run so as to increase the understanding of the process and to objectivize the process description as much as possible. To be more explicit, in this qualitative study we aim at answering the following research question: Which are the concepts that intervene in an information-seeking activity and how they interrelate?

In the following sections is explained the design of the qualitative study, detailing which qualitative techniques have been carried out, which kind of results have been obtained, and how they have been analyzed. At the end, a categorized coding system containing many relevant concepts and relationships intervening in the informationseeking activities carried out in the research field is derived from this analysis.

The design, performance, and results of this study are presented in this chapter, and can also be consulted in (Moral, de Antonio, Ferre, \& Lara, 2015). 


\subsection{Methodology}

Figure 2.1 illustrates the list of activities that have been performed in the qualitative study.

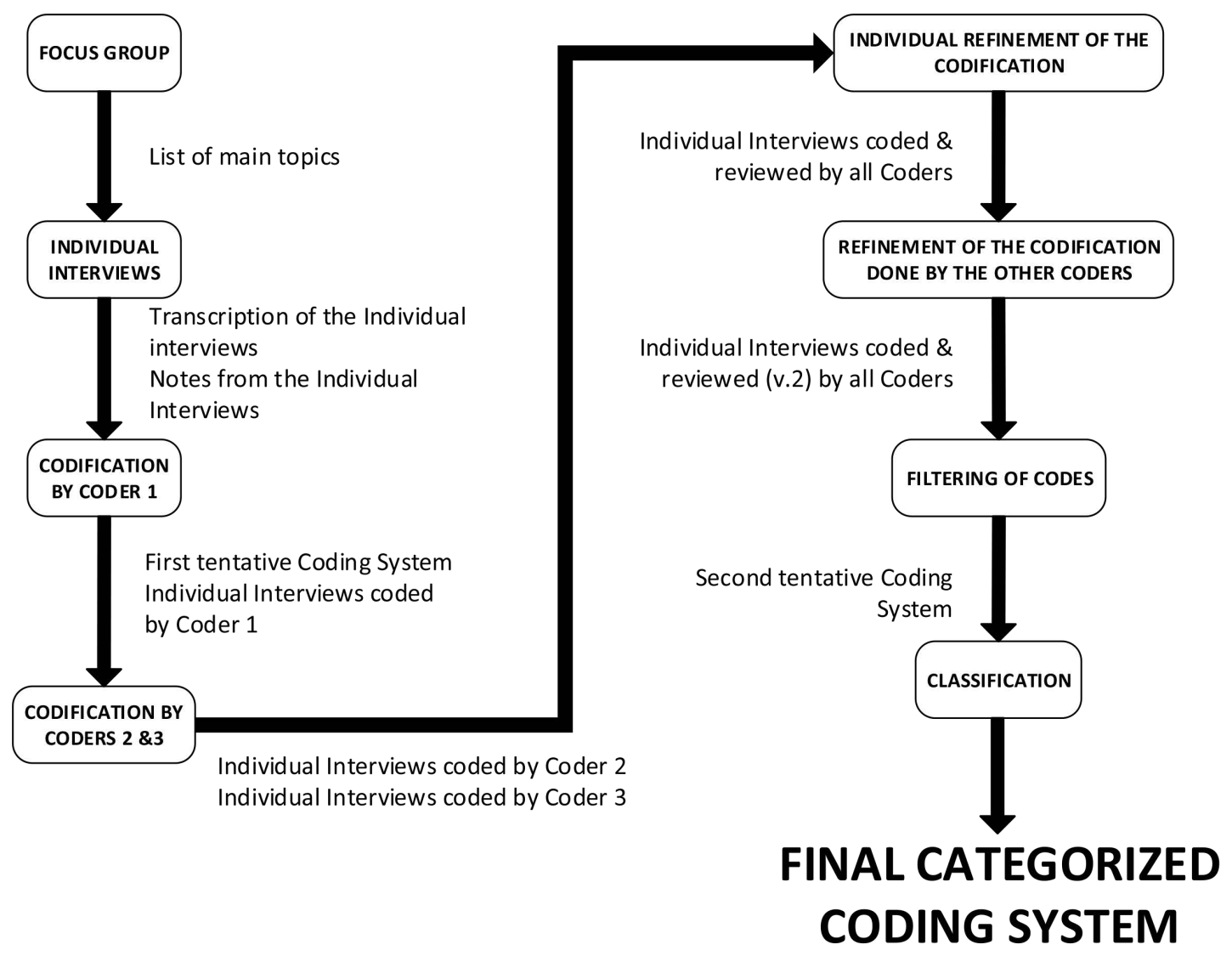

Figure 2.1 Steps followed to carry out the qualitative study

First of all, it was decided to run a focus group (Krueger \& Casey, 2015) formed by CS researchers, in order to provide them with a relaxed environment where they could share and contrast their ideas and opinions. In this way, CS researchers who initially were unable to define the process could discover similarities with other CS researchers so that they could better realize how they seek for information. In turn, the discussion would help identifying the main aspects and ideas that are related with the information-seeking process.

At this point, these main aspects and ideas were used as a starting point to develop a questionnaire that served as a guide for running individual interviews to CS researchers. Basing the questionnaire on a previous group interview with CS researchers decreased the risk that important ideas might be omitted in the interview design. Additionally, in order to expand the range of responses to the fullest, and to collect as much information as possible, the group of participants in the focus group and in the interviews were 
totally disjoint. This helped improving the completeness and validity of the study as data was obtained from multiple sources. The interviews were the main source of data collection for the formalization of the information-seeking process in the context of computer science research.

It is important to highlight that both the focus group and the individual interviews were conducted in Spanish, and then the data were also collected in Spanish. In order to facilitate and internationalize the results of the study, both the tools - namely the guides, questions, and keywords - used during the qualitative study and the results obtained from the qualitative analysis have been reliably and thoroughly translated, ensuring that both the content and the meaning were the same.

During the whole process, the achievement of a high level of quality in both the design and performance of the qualitative study and the obtained results was established as an essential and leading criterion. To reach this goal, the criteria proposed by Tong, Sainsbury, and Craig (2007) have been used as a guideline to report the results that emerged from both the focus groups and the interviews. For that reason, explicit and detailed information is provided in this chapter about the personal characteristics of the people who run the qualitative study and their relationship with the participants; the selection of the participants; how and where were collected the data; how the data were analyzed; and how the results were reported. Some issues that, according to Miles, Huberman, and Saldana (2014), have to be addressed in order to ensure the quality of the obtained results both during the design and conduct of a qualitative study and when reporting the results, were also considered. To be more specific, the confirmability of the results - e.g., the methods and procedures followed are explained in detail一, the reliability of the results - e.g., the research question has been made clear, and the CS researchers' role and status have been explicitly described-, the internal validity of the results - e.g., results have been triangulated-, the external validity of the results - e.g., details of the sample have been provided and the boundaries and scope of the results for generalization have been defined-, and the application of the results - e.g., the results are available to potential future users and they potentially can help to answer the research question posed.

\subsubsection{Focus group}

\subsubsection{Research team}

As the number of participants in the focus group was relatively large, the study was led jointly by the author of this Ph.D. research, and by one of its supervisors. 
The role of facilitator was undertaken by the supervisor, who is a senior researcher and full professor at the University, female, aged between 45 and 50, and who has a large experience running qualitative studies. This ensured the proper development of the focus group. Her job consisted in guiding the discussion to ensure that participants do not deviate from the topic being investigated. To do this, the facilitator can pose some general questions to launch the conversation or to go deeper into an interesting thought or idea mentioned by one or more participants (Kitzinger, 1994). This does not mean that the facilitator poses questions and the participants just answer them, but rather the opposite. Participants have a high degree of freedom to redirect the discussion to any topic they consider interesting. The facilitator's role is to ensure that this deviation still keeps the discussion on track. The second essential aim of the facilitator is to manage the speaking times of the participants, so everybody can express his/her opinion. This is extremely important in order to avoid having answers only from dominant participants, to the detriment of shy or low-confident participants (Kitzinger, 1995). Additionally, results are richer if all the participants give their opinion and participate in the discussion.

On the other hand, the author of this Ph.D. research - male, between 25 and 30 years old, with no previous experience in running qualitative studies - took the role of the notetaker. The purpose of the notetaker is to annotate things that go beyond the speech itself, items of interest that can provide more details to the words of the interviewees (Powell \& Single, 1996). Into this category falls the so-called non-verbal communication - the tone and volume of the voice, or the gestures and postures the speakers make during speech, among others. In this case, the P.h.D was considered the best one to take the notes, as he was the one going to later analyze them together with the participants comments. The notetaker remained silent during the session in order not to break the group dynamics and to avoid interfering in the facilitator's work.

\subsubsection{Research sample}

The research sample was composed of 9 participants. The selection was performed under a set of strict restrictions in order to obtain not only relevant, but also significant results.

All participants were required to have a professional background in the same field: computer science. This meant that all participants, one way or another, were involved in some kind of research in this field. It was tried to consider as many profiles as possible, and then both senior and junior CS researchers were selected. The first group was represented by five university professors, all of them with a $\mathrm{Ph}$. D. in computer science, while the second one was formed by four Ph.D. students in computer science. 
As computer science can be divided into many specific areas, it was also tried to cover many of them in the focus group. To reach this goal, each of the CS researchers belonged to a different department inside the Computer Science School of the Polytechnic University of Madrid (UPM) ${ }^{1}$, and then some of these areas were covered: Computer Systems Architecture and Technology ${ }^{2}$, Artificial Intelligence ${ }^{3}$, Linguistics Applied to Science and Technology ${ }^{4}$, Computer Languages and Systems and Software Engineering ${ }^{5}$, and Applied Mathematics ${ }^{6}$. In turn, the Ph.D. students were researching a variety of topics - Software Engineering, Virtual Environments, Data Mining and Intelligent Software Agents. In demographic terms, participants were aged from 27 to 53 years old, with three female and six male.

All participants were contacted via email. The message was standard for all the candidates and the purpose of the focus group and how it would take place was explained in general terms. Potential participants were also informed that there would not be any kind of compensation or incentive, apart from helping in the investigation been performed. At the end of the email, they were requested to indicate their interest in participating in the study. The ones that affirmatively answered to it were replied with a message of gratitude and a request to choose the most suitable date for them to participate.

After selecting the most popular date, one of the participants had to cancel her participation because of incompatibility with the schedule, but she proposed another participant with a similar profile in terms of field of research, age and level of expertise.

All the participants - except one Ph.D. student - and the team members running the study knew each other to some extent, either as coworkers, because they were have been member of the same research laboratory, or because they have attended some courses taught by another participant.

\subsubsection{Study design}

\subsection{Introduction}

The facilitator welcomed everybody and thanked them for their participation. In order to provide some context, she reviewed the origin and purpose of the research and explained, in general terms, the objectives and the procedure of a focus group.

As a gold standard for the whole session, the facilitator asked all the participants to be as sincere as possible. She made it clear that no answer would be considered as a

\footnotetext{
${ }^{1}$ http://etsiinf.upm.es

${ }^{2}$ http://www.datsi.fi.upm.es/

${ }^{3}$ http://www.dia.fi.upm.es/

${ }^{4}$ http://www.fi.upm.es/dlacyt

${ }^{5}$ http://www.dlsiis.fi.upm.es/

${ }^{6}$ http://www.dma.fi.upm.es/
} 
A qualitative study of the research-oriented information seeking process in CS

bad answer but, on the contrary, all answers would be good, interesting and relevant for the research. Finally she stated very clearly that in any case, none of them or their methods would be questioned, and then asked them to feel comfortable, recognizing that there was no pressure.

\subsection{Open-ended questions}

The discussion started with the following question: 'How do you seek for information while carrying out a research?' During the nearly two hours of the session, the facilitator intervened very few times to help participants to remain focused, or to motivate some of them to participate.

The facilitator used a set of keywords previously defined by the research team as a guide. These keywords referred to general concepts that were considered potentially related to the topic. Some examples are stages, objectives, tasks, context, user profile, tools, workspace, search, filtering, classification, visualisation or interaction. With these keywords, it was expected to obtain answers to questions like: Which are the stages of an information-seeking process? Which are the problems and deficiencies you usually have to face while looking for information? What else would you like a system to do to help you during the information-seeking processes? However, no predefined questions were used - except the first one used as a trigger - in order to allow the discussion to flow and to avoid prejudicing the participants' opinions.

\subsection{Setting}

The session took place in a meeting room of the Computer Science School of the UPM, which is the common workplace of both the participants and the research team. Participants, facilitator and notetaker sat at a round table in order to facilitate the communication and provide a feeling of equality, so as to promote participation. As the focus group was expected to finish just before lunch time, some finger food and beverages were provided during the discussion to help participants feel comfortable and focused.

\subsection{Data collection}

In order to allow both the facilitator and the notetaker to be focused on the discussion, the session was audio-recorded using a smartphone. Before starting the session, all participants were informed of the recording and were asked for permission. The facilitator also informed the group that the recording would be only used to analyze the discussion and that, in no case individual opinions would be identified in any published report or subsequent work. At the end, around 103 minutes of audio were recorded. 
No further interviews were made with the participants to corroborate their discussion and the final transcripts were not returned to the participants. Participants were not asked to provide any feedback on the findings.

\subsubsection{Data Analysis}

Once the session was transcribed, the both the author of this Ph.D research and its supervisors analyzed and discussed the content of the focus group - see Figure 2.2.

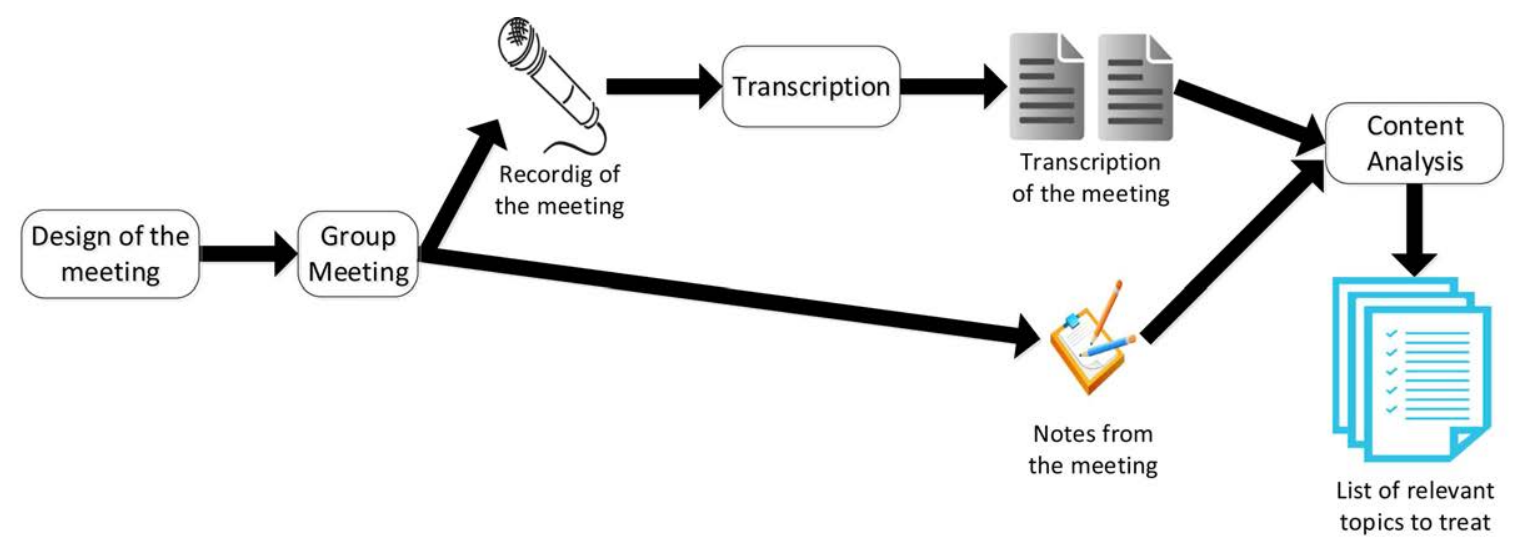

Figure 2.2 Focus Group steps

The intent was to identify which aspects are involved in the information-seeking process. The analysis consisted of grouping together related ideas or comments so as to draw a preliminary conceptual map of the main aspects that should be considered while studying the information-seeking process. At the end, 13 concepts related to the information-seeking process were identified:

1. Archiving

Comments related to the activity of archiving of the articles during the informationseeking process.

2. Corpus

Comments related to the set of results obtained after a search process.

3. Search process

Comments related to the process of looking for results that may cover an information need.

4. Reading process

Comments related to the process of reading the articles selected after the informationseeking process. 
5. Exploration process

Comments related to the process of exploration of the results obtained from the search process.

6. Wishes

Comments related to things the user would like to happen during the informationseeking process.

7. Difficulties

Comments related to difficulties found during the information-seeking process.

8. Collaborative work

Comments related to the information-seeking process performed collaboratively in a team.

9. Workspace

Comments related to the organization and use of the physical and digital space during the information-seeking process.

10. Tasks

Comments related to tasks undertaken during the information-seeking process.

11. Meta-information

Comments related to meta-information used during the information-seeking process.

12. User profile

Comments related to the profile of the user with respect to the information-seeking process.

13. Reference manager

Comments related to reference managers used during the information-seeking process.

\subsubsection{Interviews}

In order to deepen the aspects identified in the focus group and increase the knowledge about the information-seeking process, a set of individual interviews and face-to-face was carried out in order to allow each participant to explain in detail how he/she seeks information while researching.

Before running the interviews, a semi-structured questionnaire was developed to guide the sessions, using the list of relevant aspects identified in the focus group as a guide. Most of the questions were open-ended in order to allow wide and unbounded 
answers from interviewees, but also in order to avoid biasing the participants by unintentionally leading their answers. As an example, the first question 'How do you seek for scientific papers while doing research?' was very general and open-ended, allowing the user to express almost anything related to the studied process. Some more specific questions were also posed in order to obtain more details about concrete aspects, but even in these cases the interviewees were able to express their ideas openly as they were asked to explain more in detail their answers: 'Do you think the information-seeking process varies according to the context? Please explain your answer'. Additionally, the interviewer had the freedom to pose new questions to delve into interesting comments, or to clarify incomplete or unclear answers, thus making the interview more flexible, in order to obtain as much information from the interviewees as possible (Bernard, 2006; Crabtree \& Miller, 1999).

\subsubsection{Research team}

In this case, the interviews were conducted only by the author of this Ph.D. research. This helped maintaining the consistency during the interviewing process as it avoided possible differences because of having more than one interviewer collecting the data.

\subsubsection{Research sample}

The criteria followed to recruit participants were exactly the same as in the focus group: senior and junior CS researchers from different areas of the computer science field, covering a range of ages - in this case from 29 to 65 years old. In order to avoid interviewing biased participants, all the CS researchers that participated in the focus group were considered ineligible for this second qualitative technique. Again, potential participants were contacted via email using a standard message, explaining to them the purpose of the interview and how it would take place, and informing them that participation was unpaid. Among those who answered the email indicating they were interested in participating, 5 females and 3 males were selected.

Once again, the interviewer and the interviewees knew each other to some extent, either because the interviewer had previously attended some course taught by the interviewee, or because both worked in the same research lab.

\subsubsection{Study design}

\subsection{Introduction}

The interviewee was first welcomed and thanked for his/her participation, and then the 
A qualitative study of the research-oriented information seeking process in CS

interviewer introduced him/her to the purpose of the research. Details were provided about how the interview would proceed.

The interviewer also asked the participants to be as sincere as possible, stating clearly that neither him/her nor his/her methods were being evaluated,and that the only aim was to figure out how the information-seeking process is carried out from different perspectives.

\subsection{Open-ended questions}

Even if 18 predefined questions were used to guide the interview - see Appendix $\mathrm{A}-$, the interviewee was allowed and encouraged to explore new topics and express everything he/she considered relevant for the question or for any other topic he/she considered related and/or interesting. The main goal was to bring to the surface all the concepts, problems, suggestions, difficulties, tasks, and so on, related to his/her information-seeking processes. As a result, the interviewee was able to develop his/her ideas and thoughts as much as he/she wanted.

To reinforce this goal, the interviewer was allowed to pose unplanned questions not present in the script when needed in order to dig deeper into an idea, to clarify an ambiguous answer, or to nail down an interesting comment.

\subsection{Setting}

The location and schedule for the interviews was agreed individually with each of the participants according to their availability and preferences. Five weeks were needed to perform all the interviews, and seven of the eight interviews took place in the interviewee's workplace, while one of them was carried out in the interviewer's workplace.

Only the interviewer and the interviewee were present during the interview to avoid external influences that could disturb the participant.

\subsection{Data collection}

As the interview was expected to be quite long, the session was audio-recorded using a smartphone, while the interviewer was focused on obtaining as much information as possible from the interviewee. Recording the interview also allowed the interviewer to take notes regarding non-verbal communication that could complete some answers. As in the focus group, all participants were informed of the recording at the beginning of the session and were asked for permission. The interviewees were also informed about the planned use of the recording, which would only be analyzing his/her answers. Finally, they were informed that their name would not appear in any report or subsequent work without their explicit permission. 
In this case, the interview was pilot-tested. In fact, two pilots were run. The first one was a controlled pilot where the interviewee was one of the supervisors of this $\mathrm{Ph} . \mathrm{D}$. research. The aim of this pilot interview was to set up all the materials and try out the whole procedure, and to ensure that every relevant aspect has been considered and nothing was left to improvisation.

Once the procedure was verified and refined according to the first pilot, the interviews with real participants were run. After conducting four interviews, the interviewer transcribed them in order to perform a first analysis evaluating how rich and complete the answers were, and if the questions were clear enough and covered the topic broadly. The analysis was made only by skimming the transcriptions of the interviews. This analysis, together with the experience of the interviewer, gave rise to reformulation and reordering for some of the questions of the questionnaire that were ambiguous or hard to understand for the interviewees. Nonetheless, no questions were added or deleted, but only reorganized. The content and the semantic of the questionnaire was exactly the same - see Figure 2.3.

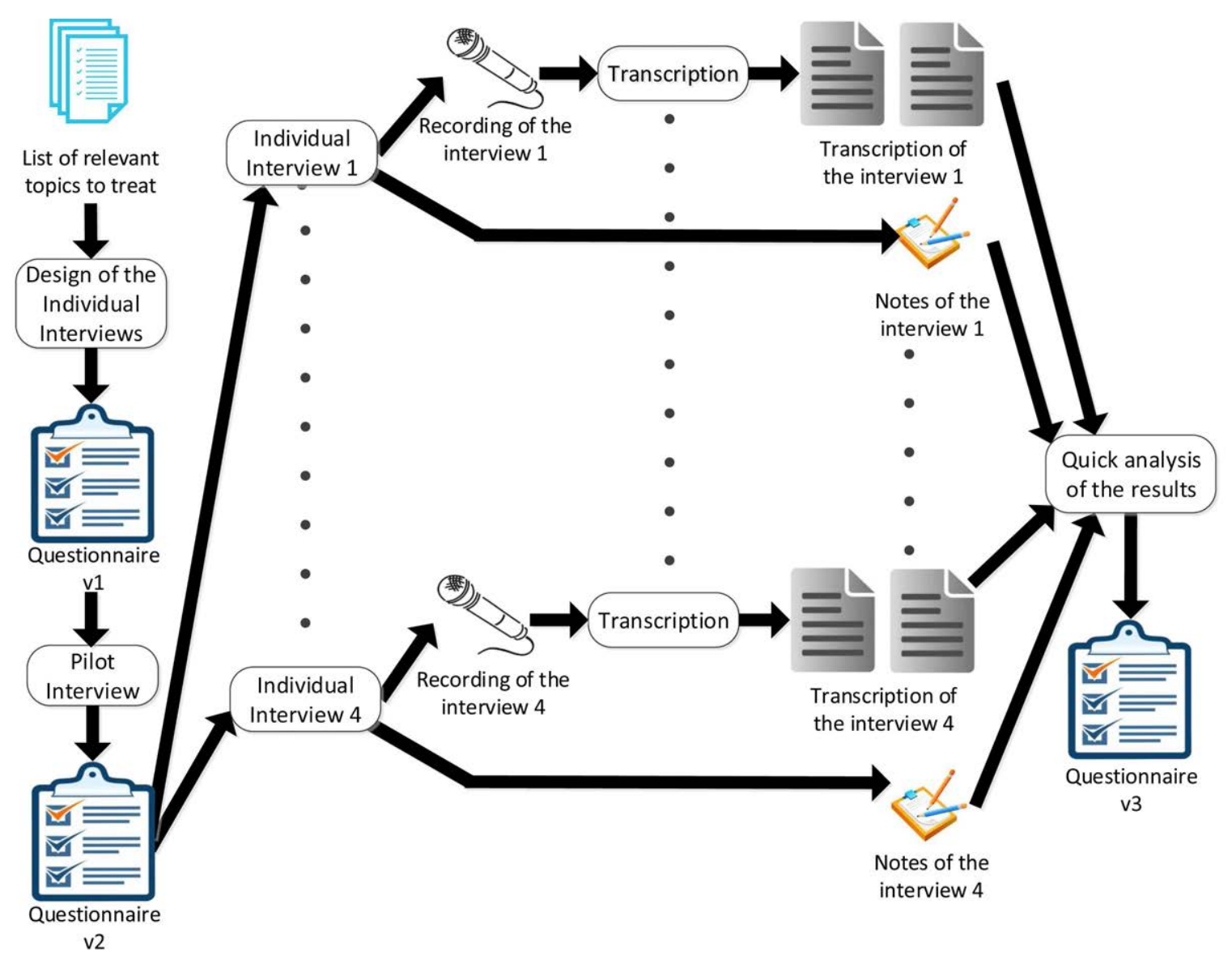

Figure 2.3 First round of interviews 
After this, four more CS researchers were interviewed with the updated questionnaire - see 2.4. In both cases, each interview lasted around one hour, even if they a time limit was not set and each interviewee had as much time as desired to express his/her ideas.

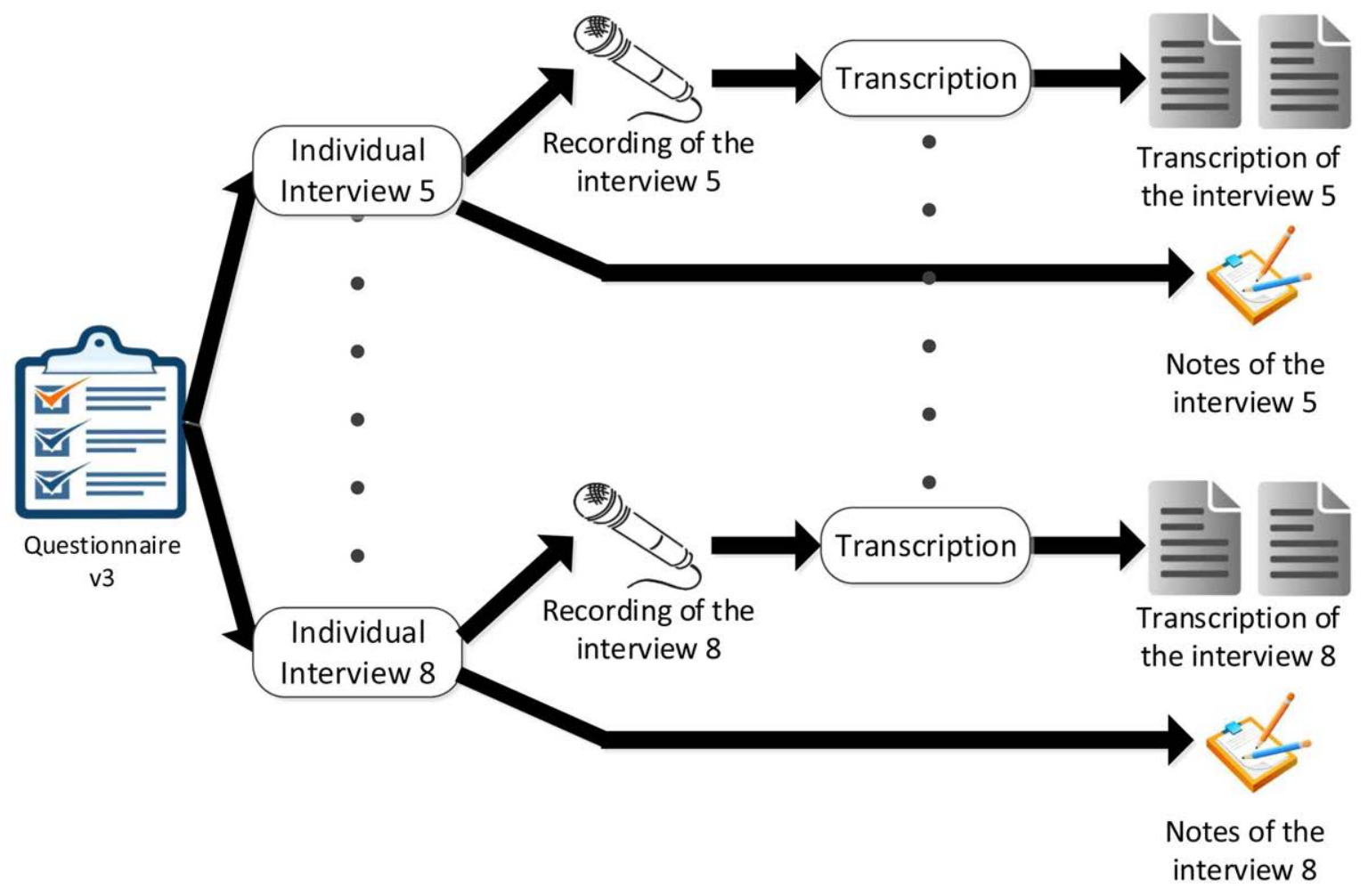

Figure 2.4 Second round of interviews

The eight interviews produced around 450 minutes of audio recording, and the transcription of the answers given by the participants resulted in around 40 pages of free-text, containing around 15.000 words.

Apart from this, no further feedback was obtained from the participants - neither from further interviews, revision of the interviews' transcriptions, nor comments regarding the findings.

\subsubsection{Data analysis}

Amongst the available methods used to analyze qualitative studies, Grounded Theory (Glaser \& Strauss, 2009) was used as it allows starting the analysis from scratch. Grounded theory is an inductive approach allowing concepts to emerge from natural language content, without a starting point of pre-defined concepts or hypothesis. In this approach, the aim is to make a theory emerge from the data, but not to prove it (Corbin \& Strauss, 2014).

The analysis was performed through a systematic and iterative approach based on the assignment of codes to text fragments that contained relevant phenomena. 
According to Saldaña (2013, p.3), " a code in qualitative inquiry is most often a word or short phrase that symbolically assigns a summative, salient, essence-capturing, and/or evocative attribute for a portion of language-based or visual data". Then, the main aim of the coding in qualitative study is to concentrate in a smaller form the most relevant information contained in a text, audio, picture or video. This is essential to make emanate the underlying relevant content, to simplify the understanding of the raw data, and to allow relating different parts of raw data based on the message they transmit. In qualitative research in general, and in the grounded theory approach in concrete, this process is essential as grouping the codes that are related allows identifying which are the main concepts that are addressed in the raw data, and how they relate. At the end, the overview of these concepts and their interrelations allows deriving a set of statements or conclusions that implicitly exist in the raw data and give an answer to the question stated in the qualitative study.

As an example, one of the interviewees mentioned that "Once I consider that an article may be relevant, when I read it, I take some notes that I write on a shared document we have in the research team so that everybody can read them.". In this case, coders assigned three specific codes to this text fragment:

- The user takes textual notes in a separate document - code 152 of the coding list, see Appendix A-;

- Information-seeking process is performed collaboratively - code 166 of the coding list, see Appendix A-;

- The user makes use of a shared document to take notes - code 168 of the coding list, see Appendix A.

In grounded theory, the codes assignment and categorization is performed iteratively in order to refine the analysis, typically following these four stages:

1. Open or emerging coding system

Text is coded from scratch, without using any kind of theoretical framework or published code list. One code is assigned to each unique phenomenon.

2. Development of concepts

Similar codes are grouped under concepts.

3. Grouping concepts into categories

Similar concepts are grouped into categories. Each category has a detailed description. 


\section{Formation of a theory}

Identification of connections or co-relations between concepts and categories in order to infer or predict a theory.

During recent decades, many authors have proposed models of the informationseeking process. While some of them are rather general (Kuhlthau, 1991; Wilson, 1981, 1997, 1999b), many of them only consider the information-seeking process in specific fields like social sciences (Ellis, 1989; Meho \& Tibbo, 2003), physics (Cox, 1991), chemistry (Hall, 1991), engineering (Hertzum \& Pejtersen, 2000) or advocacy (Makri et al., 2008). Even if many of them also use grounded theory as the qualitative tool to formalize a theory (Ellis et al., 1993), none of them specifies which coding system they have used. In addition, to the best of our knowledge, no models have been proposed for the research-oriented information-seeking process in computer science, and there is no published coding system that could be useful as a base upon which to create an adapted one. Therefore a new coding system had to be developed in order to formalize a model for the information-seeking process in computer science. This coding system could also be of value for other researchers who would like to perform a qualitative study related to this topic, or even to use as a starting point for other fields of study.

\subsection{Refining the coding system}

\subsubsection{Triangulation of the data}

Qualitative studies are inherently subjective because of their nature. There is no scientific and straightforward method to analyze text or speech, and then results, inevitably, depend to a greater or lesser extent on the researcher who carries out the codification.

Being aware of this limitation, individual subjectivity while coding was minimized as much as possible in order to provide as objective as possible results. To do this, the interviews' transcript were coded in parallel by three different coders. The first coder, the author of this Ph.D research, was the one who carried out the interviews and transcribed them, and may have had a higher risk for bias. To compensate for this, the other two coders did not participate in the qualitative study until all the interviews had been conducted and transcribed.

The two coders in charge of the validation of the coding system were recruited because of their closeness to the topic and because of their experience in conducting qualitative studies. One of them is one of the supervisors of this Ph.D. research, while the other is an active member of the research group to which the author of this Ph.D. 
research is affiliated to. Both coders have a similar profile: senior university professors and researchers in a computer science school, whose field of research is human-computer interaction, both around 40 years old. To avoid possible differences in interpretation of the interviews because of the gender, one of the coders was male and the other one was female.

\subsubsection{Iterative process}

The codification process consisted of several phases. To begin with, the first coder developed a preliminary version of the coding system tagging the interviews' transcriptions totally from scratch - see Figure 2.5. The assignment of codes was performed using ATLAS.ti ${ }^{7}$, a software tool for analyzing data from qualitative studies. As an interpretive approach was chosen to analyze the qualitative data, codes had to emerge from the text. Therefore, the coder labeled each sentence - or group of closely related sentences - with keywords that reflected the concepts or ideas emanating from the text. Initially, many of the codes that emerged were ad-hoc, redundant or hard to understand. An example is the code 'DIFFICULTIES - Find interesting articles or authors that do not have too much impact or are not known experts in the field' that was used to label the portion of text 'It is difficult to find somebody who is not very well known in the field or does not have published any article with a high impact, but is working in the same topic as I am'. It seemed obvious that both the code and the text were almost the same, and then the code would be hardly reusable in other cases, offering little scope for re-use.

As the first coder encoded the interviews, he acquired some perspective that allowed him to refine the initial codes and where they were used. Each iteration resulted in a new refinement to the coding system, where new codes were added and former codes were deleted or reformulated. As a result, when the coder concluded his work, the coding system contained 189 codes.

In the second phase, the other two coders were given the transcriptions of the interviews alongside with the coding system, and were asked to code them individually and separately - see Figure 2.6. No guidelines or rules were given to these coders to avoid influencing them. The only direction they were given was to identify bad codes - ambiguous, incomprehensible, misspelled - or relevant parts of text where no code was suitable to express the underlying idea, if any. Furthermore, in order to avoid any external influence or preconceived ideas, transcriptions were anonymized. Coders were asked to revise and refine their codification until they thought it was accurate and comprehensive.

\footnotetext{
${ }^{7}$ http://www.atlasti.com/
} 


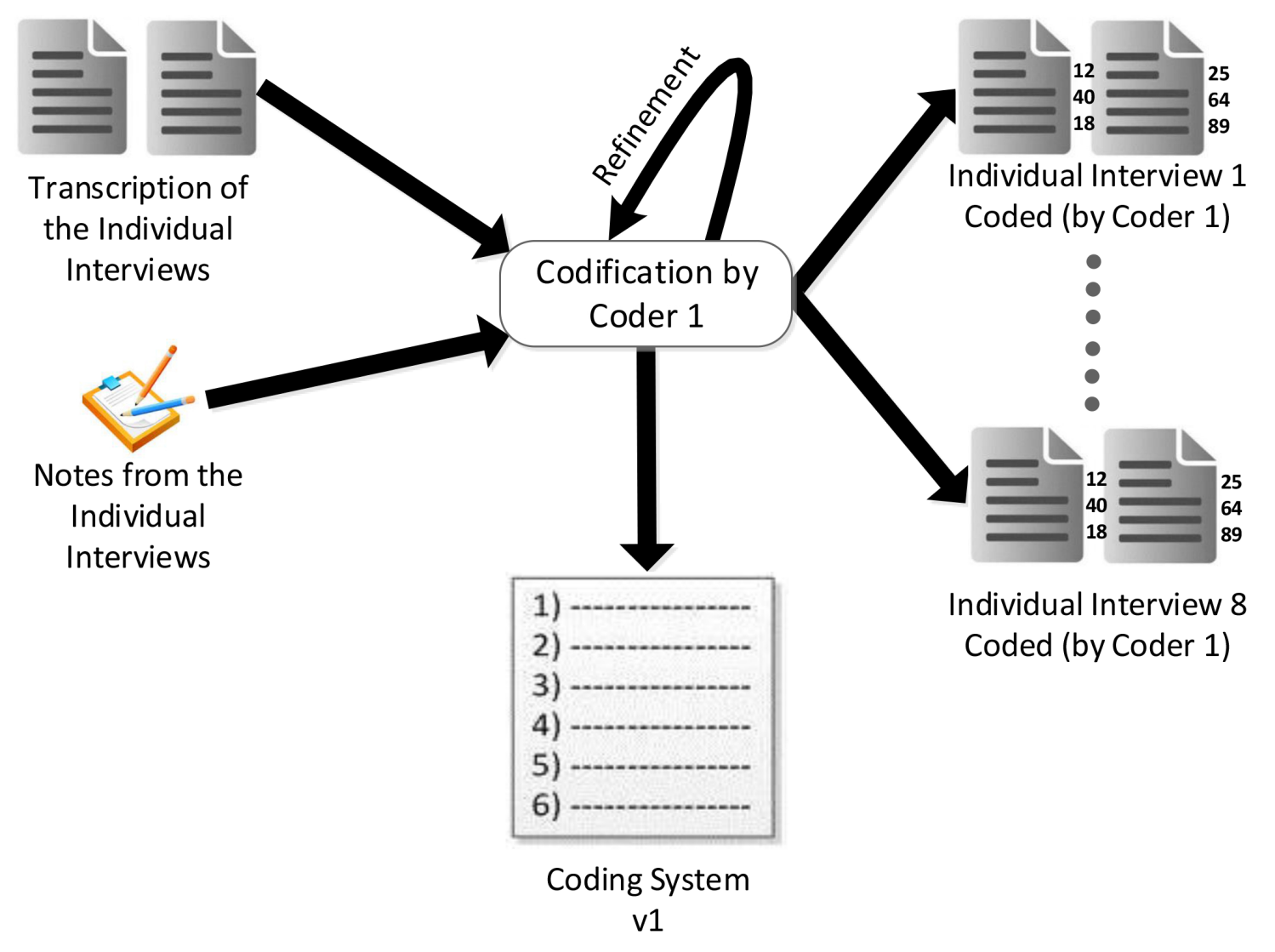

Figure 2.5 First tentative coding system

Once all the interviews were coded by all the coders, the rate of agreement was computed to determine the validity of the coding system - see Figure 2.7. The computation was made taking into account the rate of times the text fragments have been coded the same way. In this phase, the mean agreement rate of the three coders was $18.88 \%$. In general terms, this rate may seem very low, but considering that the codification is made for text without any kind of structure nor delimitation, that three different researchers have individually coded this text, that the codification was subjected to a high degree of subjectivity, and that a non-verified preliminary version of the coding system was used, the yardstick changes. For those reasons, the proportion of times that at least two of three coders have used the same codes to tag the same chunk of text was adopted as agreement rate. This means that, if at least two coders decided individually and separately to use the same code to describe a fragment of text, then the code was descriptive and meaningful enough to describe one of the phenomena existing int he raw data. In this second iteration, the mean rate of agreement of at least two of the three coders was $40.87 \%$, which is significantly higher than in the rate of full agreement. 


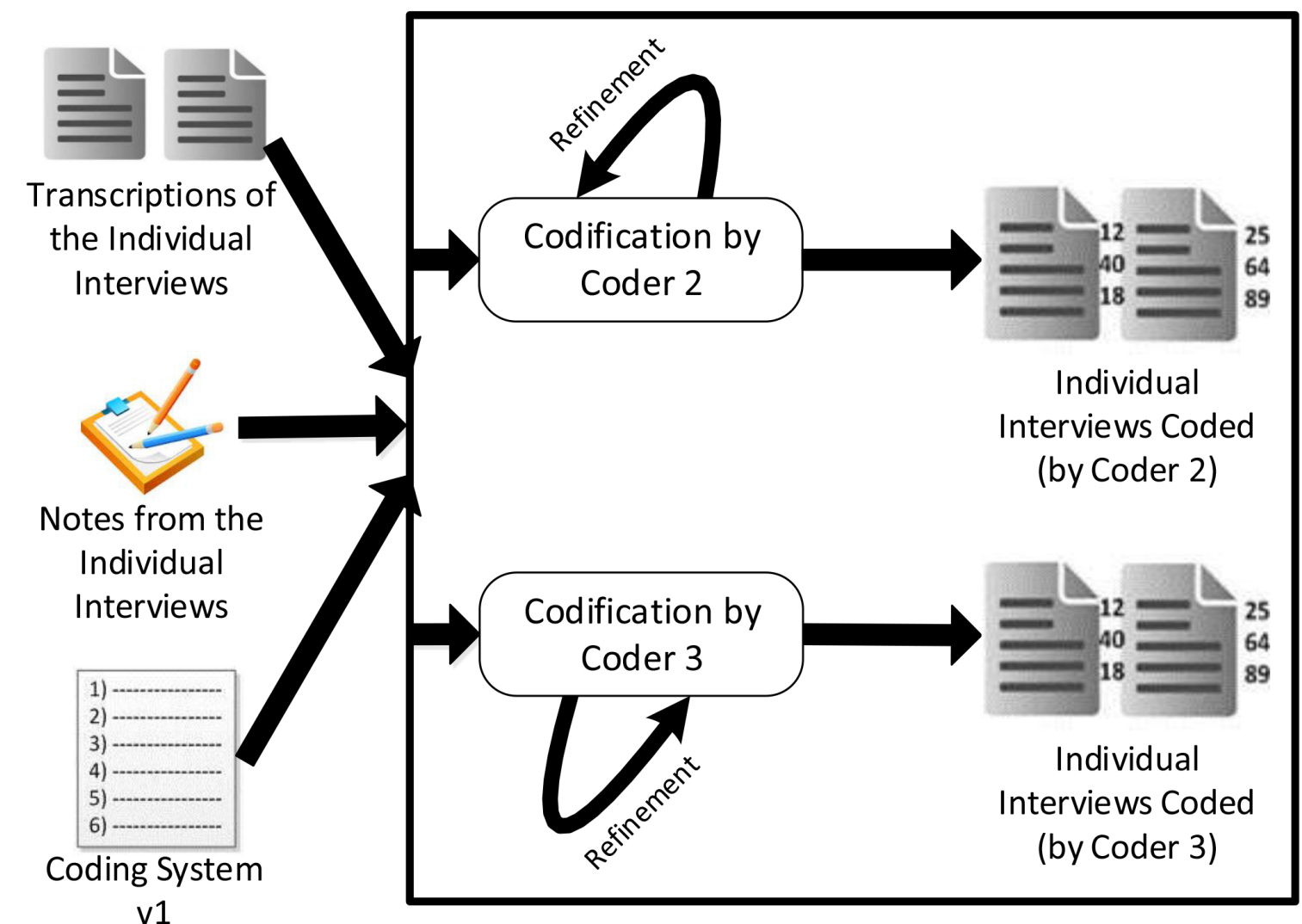

Figure 2.6 Second coding phase

A third iteration was planned from the beginning, where the three sets of coded interviews, each one coded by each of the coders, were used as starting point. The main objective in this phase was to identify if differences in codification were due to errors or misunderstandings while coding, or because of differences in interpretation. Each coder received his/her set of coded interviews together with the list of text fragments that had been coded differently to what the two other coders have done. The coders did not know which codes were used by the other coders to code these text fragment. Each coder, then, had to evaluate, again individually, why they were the only ones using these codes. As a result, coders were able to reconsider their decision and use another code they considered more appropriate, or on the contrary they reaffirmed their decision and maintained the original code - see Figure 2.8. After this revision, the mean agreement rate was $28.53 \%$ for all three coders when all the codifications were considered, while $57.53 \%$ of the codification was the same for at least two of the three coders.

The next step consisted of identifying which fragments of text were still coded differently by one of the coders, but in this case the evaluation was made by the other two coders - see Figure 2.9. At this point, if at least one of these two coders agreed with 


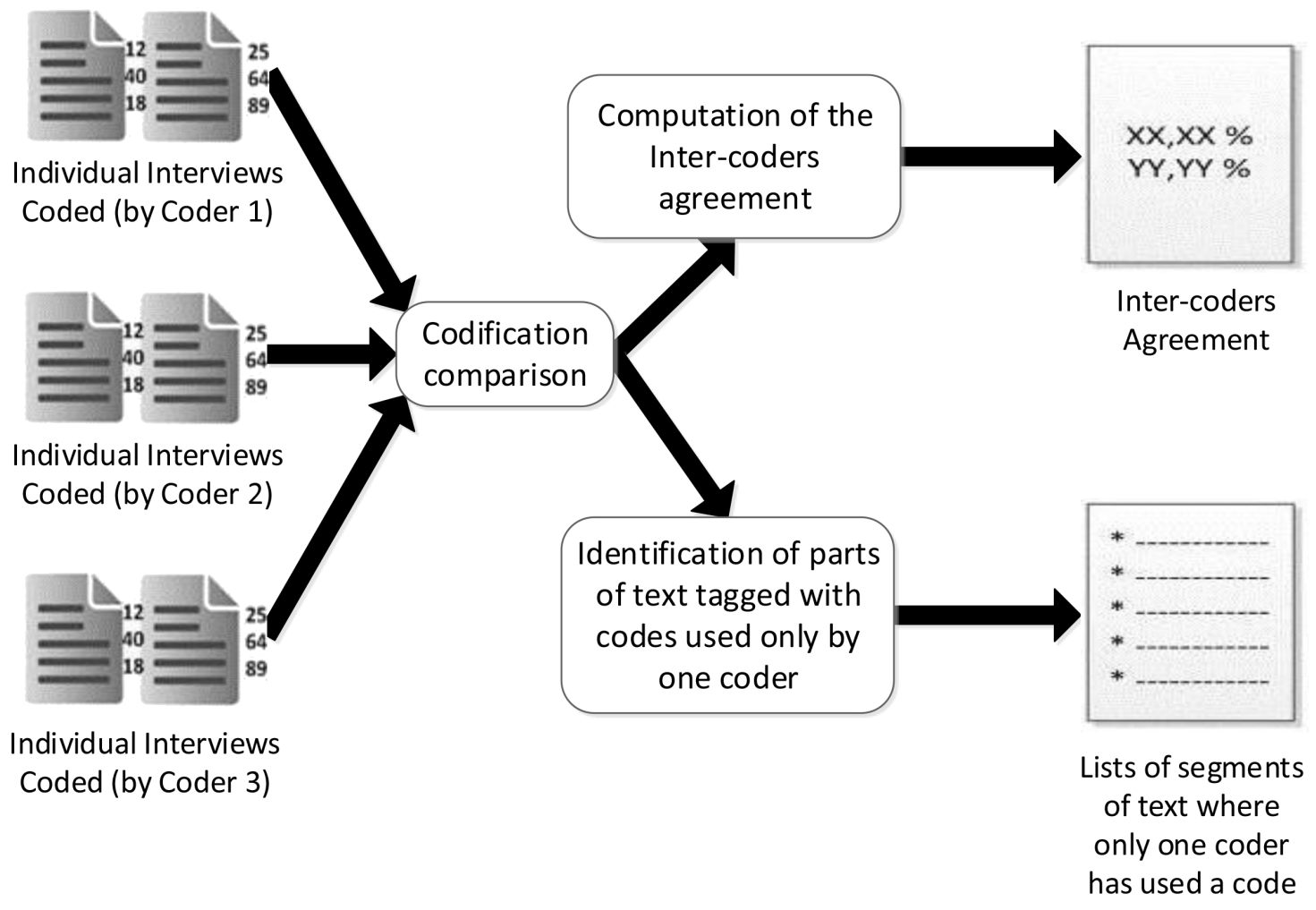

Figure 2.7 First refinement iteration: comparison of the coders' codification

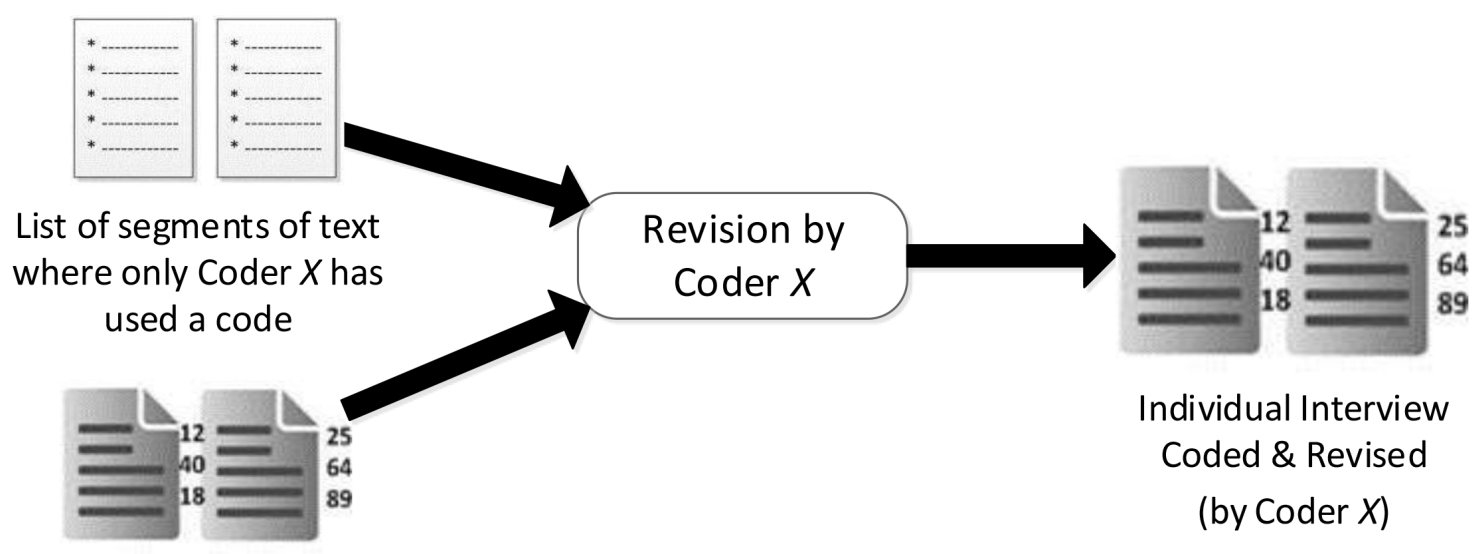

Individual Interviews

Coded (by Coder $X$ )

Figure 2.8 Second refinement iteration: individual refinement

the use of the code, it was validated and considered representative of a phenomenon. Conversely, if both coders were against using the code in that portion of text, the code was discarded. This validation phase resulted in a $31.18 \%$ of agreement between all the coders, and $66.43 \%$ between at least two of the three coders. 


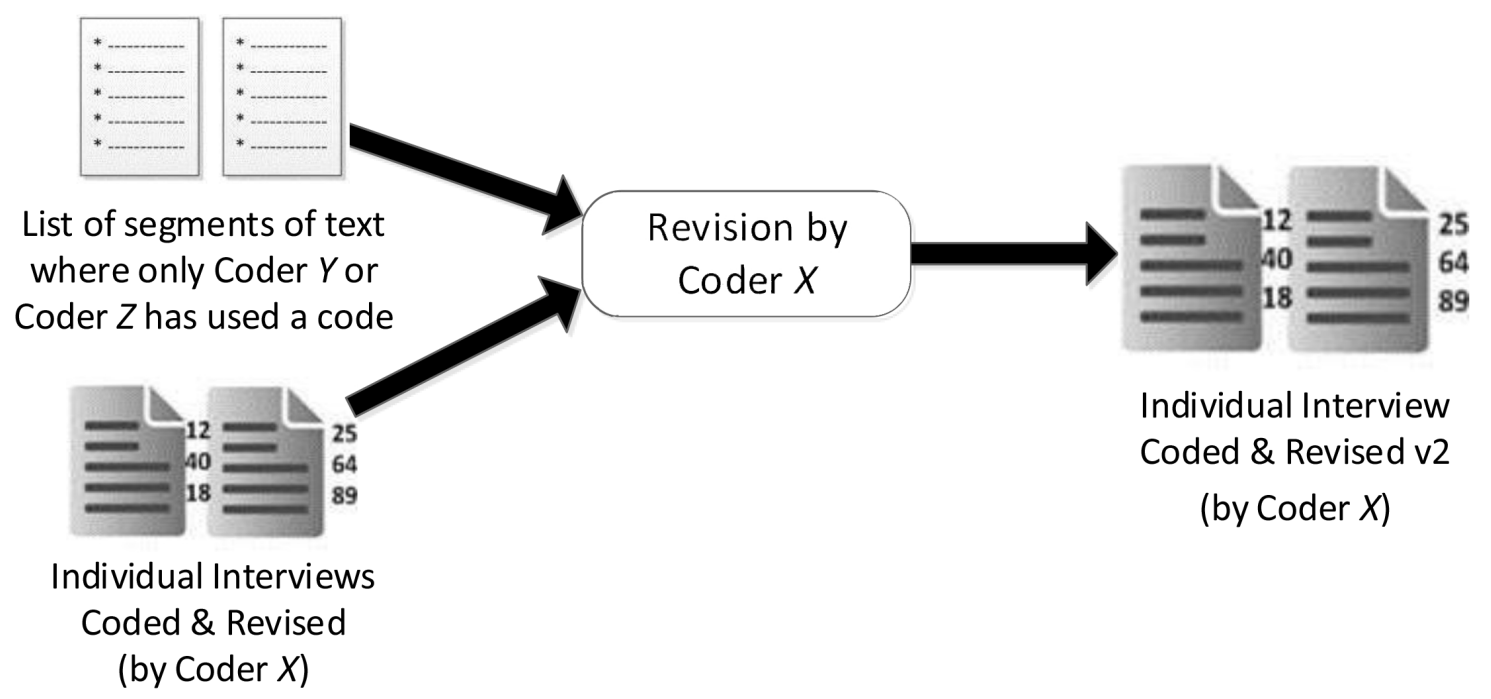

Figure 2.9 Third refinement iteration: refinement by the other coders

Figure 2.10 shows the evolution of both inter-coders agreement rates —rate of codes agreed by all the coders, and rate of codes agreed by at least two of the three codersduring the refinement process.

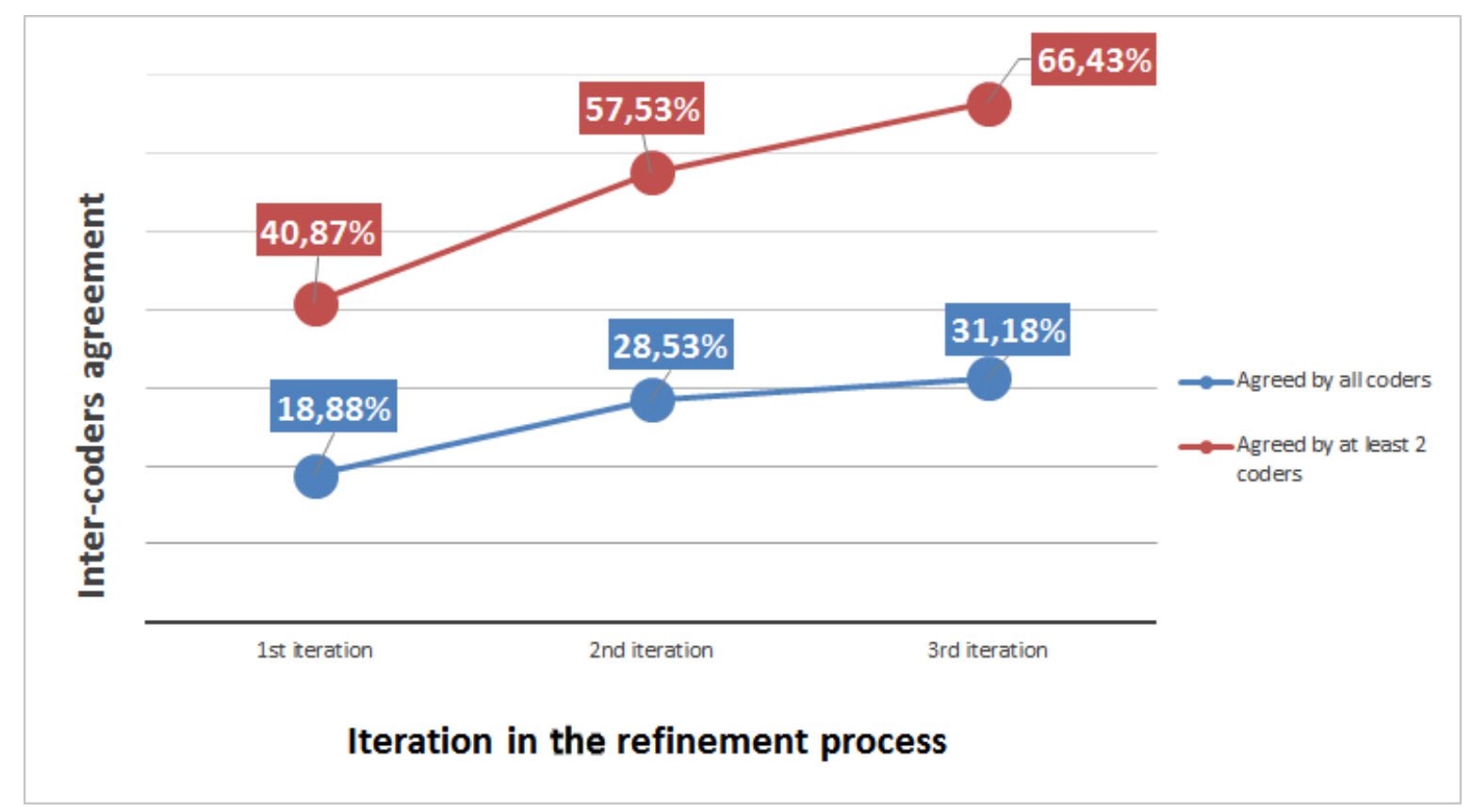

Figure 2.10 Evolution of the inter-coders agreement during the refinement process

Finally, once the coding of the raw has has been agreed, a last iteration was performed to filter the codes that have been little or no used by the coders. This last refinement phase was carried out over several group meetings, where decisions were discussed and agreed by all three coders. The codes that had not been used at all in the final codification of the interviews were considered redundant, erroneous or unneeded, so 
they were deleted from the coding system. Altogether, 13 codes were deleted, with a total of 176 codes left in the coding system. After this step, 17 codes, which had been used at least one time, were considered redundant and merged into 8 new codes. This merge decreased the number of codes to 167 . In some cases, the two validating coders made use of codes that were not included in the first version of the coding system, as any of the existing codes was good enough to summarize a given phenomenon. All three coders also discussed about the proposed new codes that were not present in the first coding system, and those that were considered representative were definitely included int he coding system. The result was that 14 codes were added to the coding system, increasing the total number of codes to 181. Some codes were considered too abstract, so they were divided into more specific codes: two of the former codes were divided each into two new codes, while a third former code gave way to three new codes. From the remaining 185 codes, 31 of them had been only one time used to code a text segment along all the interviews. Between these codes, the three coders determined that 16 of them were unnecessarily used - for example because they were too specific, or because they did not express a relevant idea, and then had to be deleted, while others were representative of very specific and quirky, but also relevant concepts that had to be represented in the coding system. The evolution of the coding system in this last iteration has been depicted in Figure 2.11, and Table 2.1 provides some examples of the actions performed over the codes.

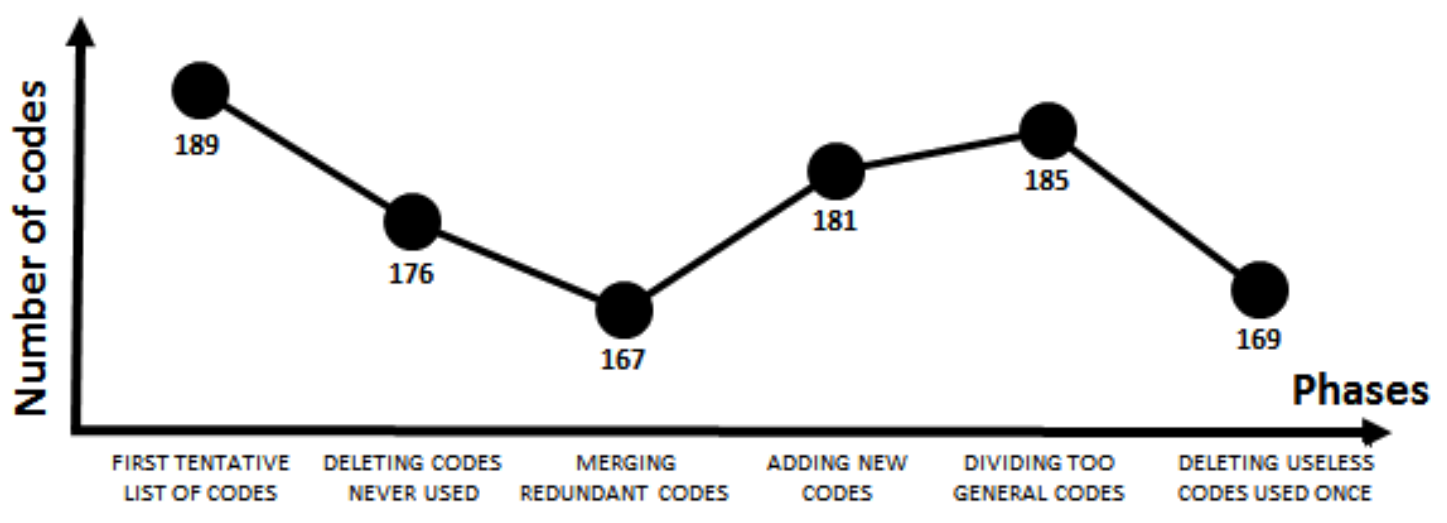

Figure 2.11 Evolution of the coding system

\subsubsection{Theoretical Saturation}

In order to determine how many CS researchers should be interviewed to obtain enough data to perform a complete and proper analysis deriving in relevant and representative results, there were performed as many interviews as needed to achieve the theoretical 
Table 2.1 Examples of actions performed over the coding system in the last iteration.

\begin{tabular}{|c|c|c|}
\hline $\begin{array}{c}\text { Action } \\
\text { Performed }\end{array}$ & Initial Code(s) & Resulting Code(s) \\
\hline $\begin{array}{l}\text { DELETING } \\
\text { CODES NEVER } \\
\text { USED }\end{array}$ & $\begin{array}{l}\text { WISHES: Integrate all } \\
\text { the available information. }\end{array}$ & - \\
\hline $\begin{array}{l}\text { MERGING } \\
\text { REDUNDANT } \\
\text { CODES }\end{array}$ & $\begin{array}{l}\text { WORKSPACE: Relevant } \\
\text { articles are clearly } \\
\text { differentiated. } \\
\text { WORKSPACE: Relevant } \\
\text { articles are kept at hand. }\end{array}$ & $\begin{array}{l}\text { WORKSPACE: Relevant articles } \\
\text { for the current task are kept at } \\
\text { hand. }\end{array}$ \\
\hline $\begin{array}{l}\text { ADDING NEW } \\
\text { CODES }\end{array}$ & - & $\begin{array}{l}\text { SEARCH - SOURCES OF } \\
\text { INFORMATION: Local } \\
\text { Repository. }\end{array}$ \\
\hline \multirow{2}{*}{$\begin{array}{l}\text { DIVIDING TOO } \\
\text { GENERAL } \\
\text { CODES }\end{array}$} & \multirow{2}{*}{$\begin{array}{l}\text { WISHES: Suggestions } \\
\text { should be displayed only } \\
\text { on demand and in a } \\
\text { non-intrusive way. }\end{array}$} & $\begin{array}{l}\text { USER WISHES - } \\
\text { VISUALIZATION: To display } \\
\text { suggestions only on demand. }\end{array}$ \\
\hline & & $\begin{array}{l}\text { USER WISHES - } \\
\text { VISUALIZATION: To have a } \\
\text { non-intrusive visualization of the } \\
\text { suggestions. }\end{array}$ \\
\hline $\begin{array}{l}\text { DELETING } \\
\text { USELESS } \\
\text { CODES USED } \\
\text { ONCE }\end{array}$ & $\begin{array}{l}\text { INFORMATION- } \\
\text { SEEKING PROCESS: It } \\
\text { is the starting point to } \\
\text { write an article. }\end{array}$ & - \\
\hline
\end{tabular}

saturation of the data - see Figure 2.12. Theoretical saturation "means that no additional data are being found" (Glaser \& Strauss, 2009, p.61) even if more interviews are performed. In this research, two rounds of four interviews were needed to achieve theoretical saturation of the data. The codification of the first interview generated 88 of the 189 codes obtained in the first phase of the coding, before the three refinement 
iterations were performed. From there, the discovering of new codes decreased from interview to interview: 36, 22, 21, 17, 2 and 3 new codes appeared after coding interviews 2 to 7 . Finally, in the eighth interview no new codes were obtained. Then, due to the decreasing evolution of the appearance of new codes, and the no appearance of new codes in the codification of the last interview, it can be stated that theoretical saturation was achieved and it was not required to perform more interviews to collect new data, as theoretically this would have not result in identifying more codes.

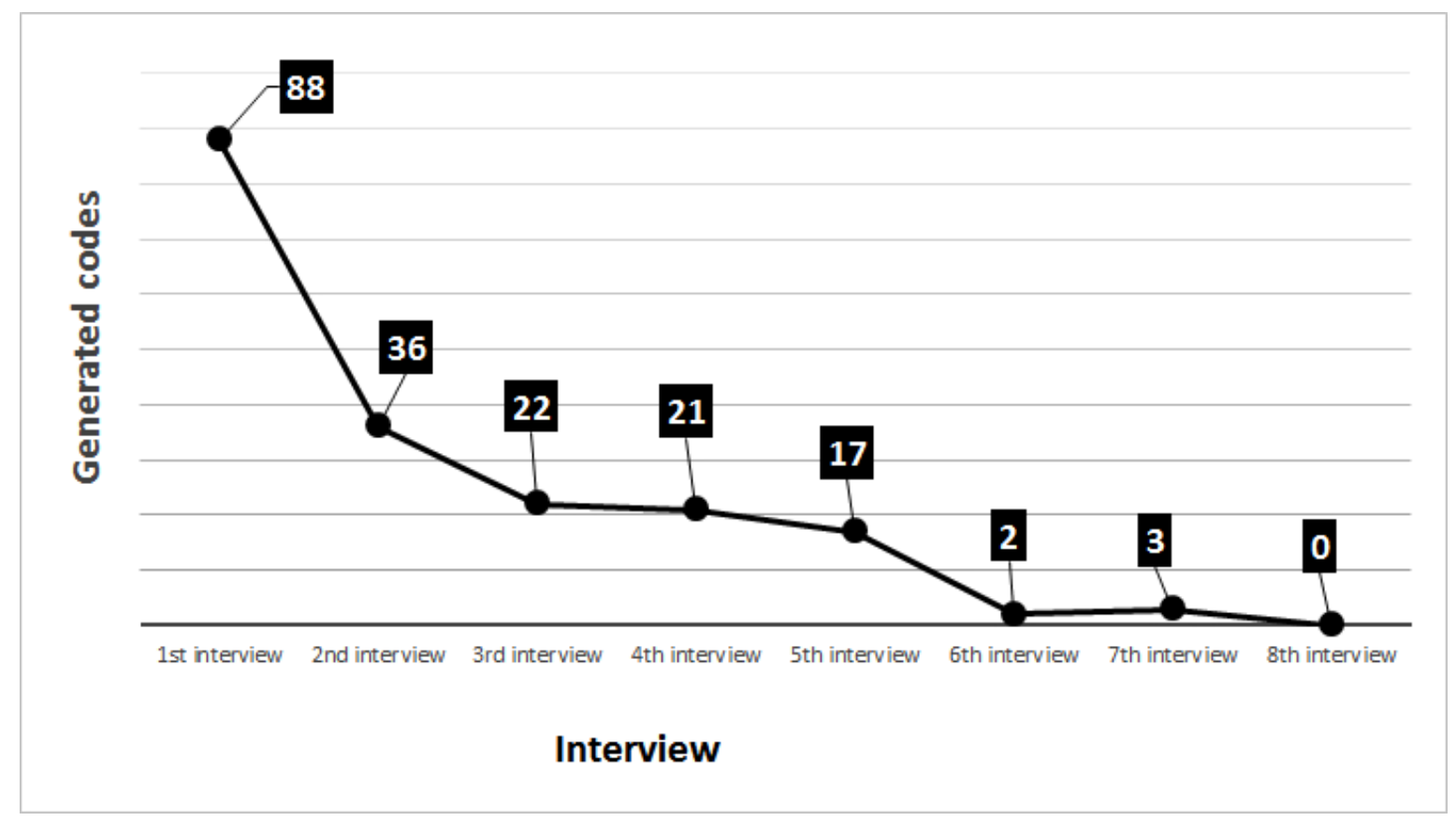

Figure 2.12 Generation of codes along the interviews

\subsection{Qualitative study results}

At the end of the analysis, a coding system that includes 169 codes is proposed. In order to facilitate the understanding and further use of these codes, each of them has a short description associated to clarify its meaning. Additionally, an example of use - extracted from the interviews - is provided for each of the proposed codes, so as to foster their application. Additionally, a hierarchical categorization of the codes is provided in Figure 2.13 to allow potential users of the coding system to locate the desired code(s) more easily. To elaborate these categories, the initial aspects identified in the focus group were taken into consideration, but also the codes themselves and their use while coding the interviews. Some of these categories were in turn divided into more specific subcategories, which allowed better grouping of the codes based on the specific aspect they dealt with. As an example, the category Archiving contains 
three subcategories: Classification criteria, Archiving format -Digital vs. Printed) and File name for digital archiving.

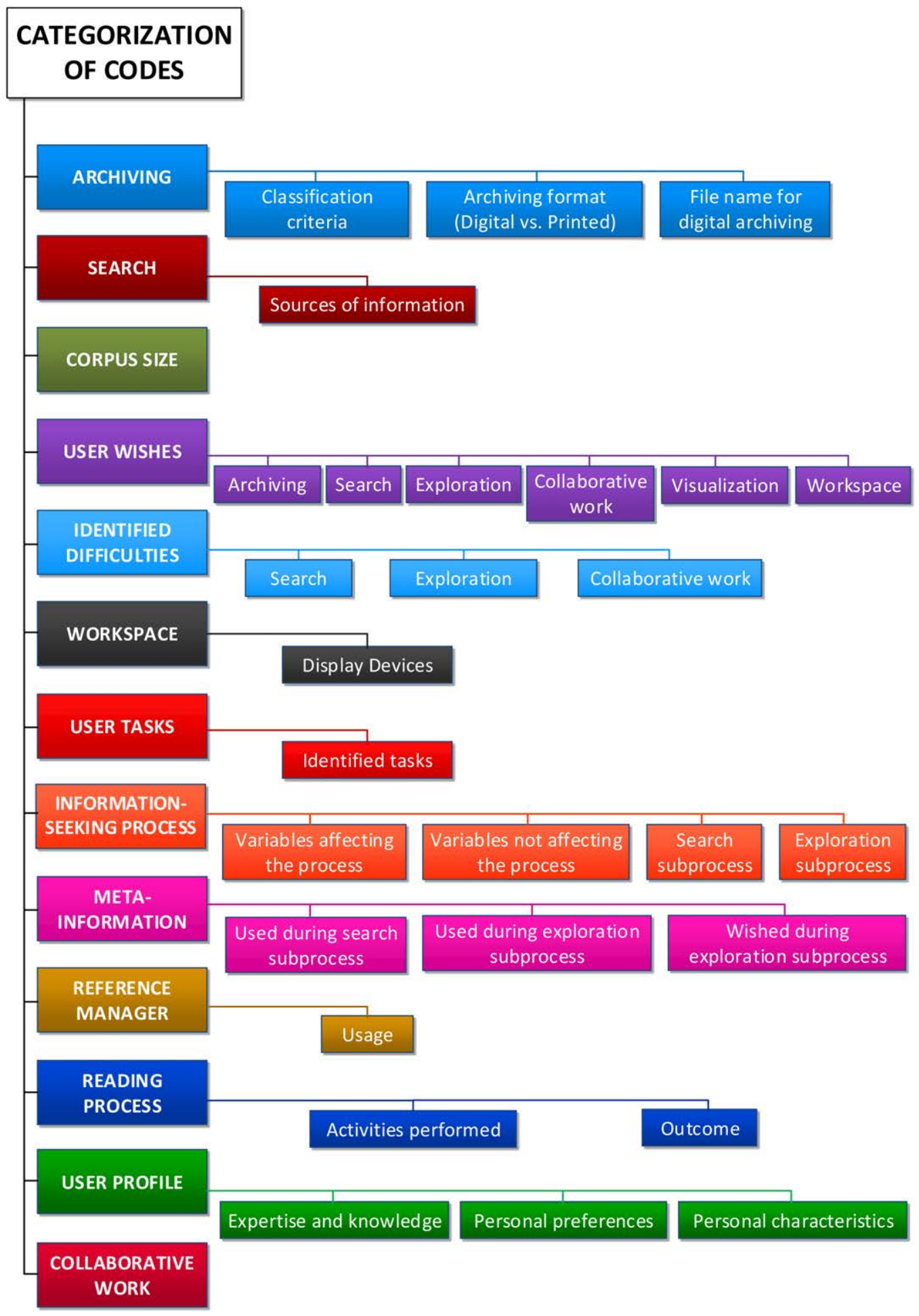

Figure 2.13 Hierarchical organization of the codes

The full categorized list of codes, together with their description and example of use, is provided in Appendix A. 



\section{Chapter 3}

\section{Information-Seeking Process Model}

As mentioned before, seeking and finding relevant information in order to fill an information need is a complex, changing and sometimes chaotic process in which are involved lots of aspects that, in addition, are in many cases related in different ways. The coding system presented in the previous chapter points out many of these aspects and relationships. However, even though the codes are categorized, it may be unpractical to make direct use of them - except if the coding system is used as framework for the analysis of new qualitative studies related with the information-seeking process in the research field - because they are too many and their relationships are not obvious.

To overcome this problem, a set of visual UML-based conceptual models is presented in this chapter in order to represent the concepts and relationships derived from the qualitative study, as they are more flexible, scalable, concise, unambiguous and easy to understand. Due to the complexity of the information-seeking process, it is first proposed a high level model of the information-seeking activity, which is the core element of the information-seeking process. Apart from it, the analysis of the qualitative study has allowed to identify four main concepts that have to be taken into account when modeling an information seeking-activity: the documents used during the activity to fulfill a given information need; the tasks carried out by the user in order to achieve his/her goals; the context in which the activity is carried out; and the characteristics of CS researcher himself/herself. Additionally, as this work focus on information-seeking in the research field, there is a last aspect that is especially relevant: the topic. Indeed, it is essential to properly model the research topics, as they play an important role during the whole process because a CS researcher is interested in a specific set of topics and a document addresses one or more concrete topics, and then the definition of both the documents and the CS researcher is somehow linked to the topic modeling.

Due the great amount of concepts that intervene in the information-seeking process, the model has been subdivided in some sub-models - document, tasks, and context. 
Moreover, to facilitate the reading and understanding of the model, we have split them into smaller parts that explained one by one. However, in Appendix A can be found the full models, in case the reader prefers to have a full view of the representation. Due to its special complexity, and as a system adaptation based on the user is proposed in this thesis, the CS researcher modeling has been addressed separately in Chapter 5.

\subsection{Obtaining of the models}

The creation of these models corresponds to the last step of the grounded theory - see Section 2.1.2.4 in Chapter 2-, which is the methodology we have used to analyze the data collected in the qualitative study. This last stage indicates that relationships between concepts and categories has to be identified in order to make a theory emerge. In our case, the concepts and the relationships are represented, implicitly and explicitly, through the categorized coding system, and the expected theory is a conceptual representation of these concepts and relationships.

To reach this goal, it has been required to translate the knowledge included in the coding system, and the one derived from its use when coding the interviews, to a set of conceptual models. To do so, for each of the codes included in the coding system, and taking into account the contexts in which it has been used, a set of relevant concepts have been derived, together with their relationships.

Let's take as example the same response presented in Chapter 2: "Once I consider that an article may be relevant, when I read it, I take some notes that I write on a shared document we have in the research team so that everybody can read them.". This text fragment was coded with the codes "The user takes textual notes in a separate document", Information-seeking process is performed collaboratively, and "The user makes use of a shared document to take notes". From these codes, the following concepts were derived:

1. Article

2. Relevance

3. Reading

4. Annotation

5. Shared document

6. Research group

7. User

8. Textual note 
9. Separate document

Additionally, the following relationships stemmed from this single answer:

1. The relevance of an article depends on the user

2. The user reads articles

3. The user takes notes when reading an article

4. The notes contain text

5. The notes are taken in a separate document

6. The user belongs to a research group

7. The user performs some kind of collaborative information-seeking tasks

8. The separate document where notes are taken is accessible by the rest of the members of the research group

These concepts and relationships, for example, have fed several models:

- Document's sub-model

- Concepts: 1,6 .

- Relationships: 6 .

- Context's sub-model

- Concepts: 5 .

- Relationships: 7, 8 .

- IS Task's sub-model

- Concepts: 3, 4, 8, 9

- Relationships: 2, 3, 4, 5, 7 .

- Researcher's model

- Concepts: 2, 7 .

- Relationships: 1.

Then, the models have been built-up step by step, trying to cover all the concepts and relationships appearing both in the answers and in the codes used to tag them. An iterative and incremental approach has been followed, in order to insert the new concepts and relationships as they appear, but always maintaining the consistency and 
ensuring its validity for the answers and codes analyzed until that moment. For that reason, it has been needed to include new high-level concepts, usually hypernyms, in order to organize the ones emanating from the codes - as for example the concept information element for the document's sub-model, or the concept personal preference for the CS researcher 's model.

Both in this chapter and in the next two are presented the conceptual models obtained following this approach.

\subsection{Information-Seeking Activity}

Figure 3.1 illustrates the modeling of an information-seeking activity, which is the main high level concept of the information-seeking process, but also the rest of the main concepts intervening of the process that are related to the activity, but only at the highest level. First of all, an information-seeking activity can be defined by the information-seeking tasks — at least one - that are performed by one or more CS researchers in order to find the document(s) included in one or more collections. These documents are those that are considered as relevant to achieve a given purpose. In overview, the model presents information-seeking as a motive-driven activity, that can be decomposed, according to Marsh (2003), as follows:

- An activity is defined by its goal. In the proposed model this aspect is represented through an information-seeking activity that fulfills the information-seeking purposes;

- At a lower level, each of these activities is achieved by performing a set of actions -in this case information-seeking tasks - in order to meet specific goals leading to achieve the activity purpose;

- Finally, Marsh claims that actions are composed of a combination of operations, that are well learned by the user and then are "unconsciously performed processes [...] that are performed without conscious thought or effort" (Marsh, 2003, p. 87). In this work, these operations are not explicitly represented as concepts, but nevertheless its recognition and understanding is the main objective analysis of the context of use observed in the qualitative study — and then they are the basis of the conceptual model-, as they are essential to really understand what the real behavioral, conceptual and operational problems are when seeking information.

This decomposition has been adopted as the presented information-seeking purposes are rather high-level objectives whose complexity depends on a lot of aspects like 
the CS researcher preferences and characteristics, the context in which the activity is undertaken, or the topic being investigated. Nevertheless, the aim of the informationseeking tasks - explained in Section 3.5 - is static and very well defined: a filtering task aims at discarding or selecting a set of documents from a bigger collection that matches a set of criteria, an exploration task allows the CS researcher browsing more in detail a set of documents to determine which of them are actually relevant or to identify some relevant information, the objective of a reading task is to deeply enter into the content of a document, and a storage\&management task allows the CS researcher storing and organizing the documents that are somewhat considered relevant. Then, it makes more sense relating the final information-seeking purpose with an information-seeking activity formed by a set of information-seeking tasks whose performance is interleaved - and then provides more flexibility_-, than to the tasks themselves.

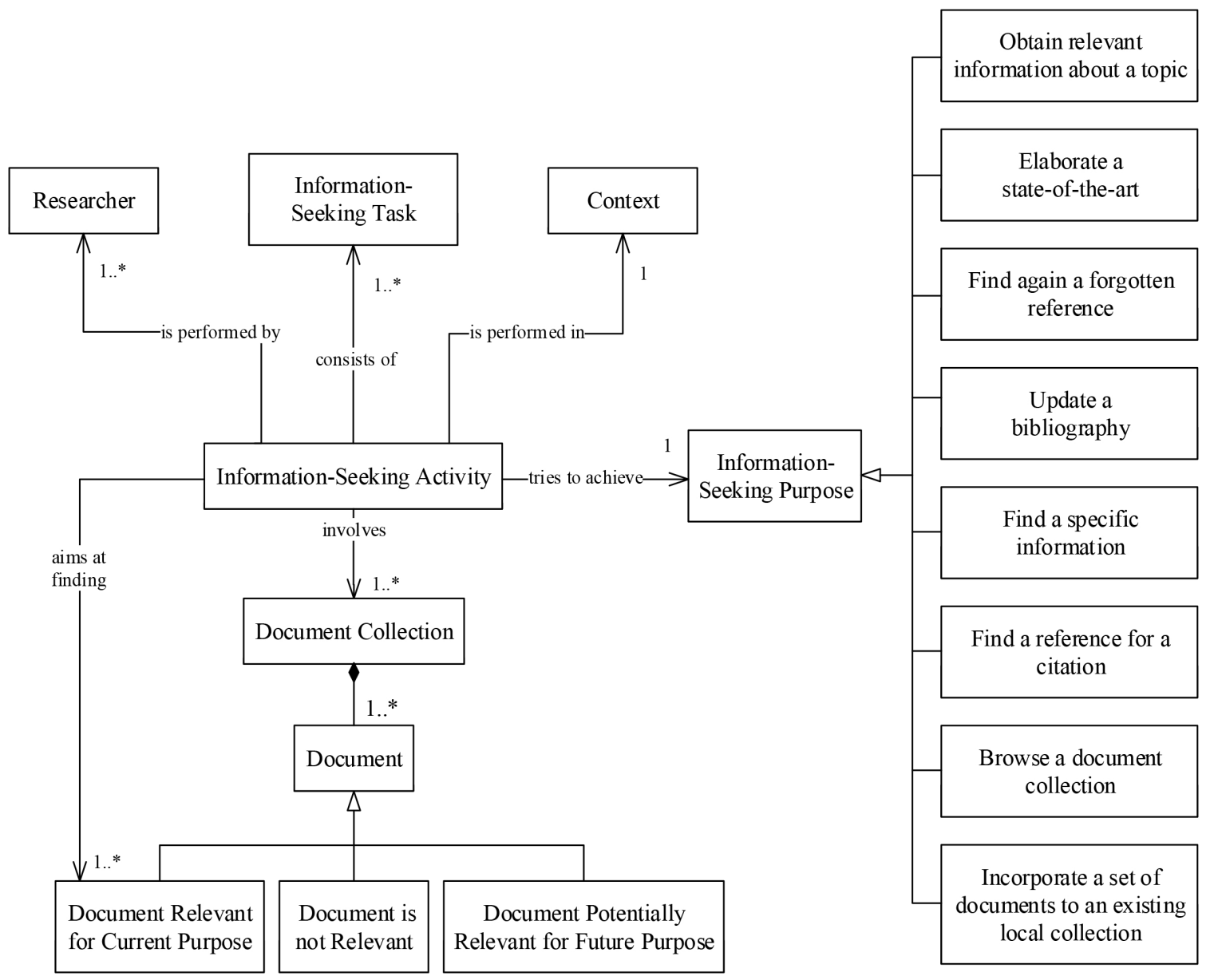

Figure 3.1 Main concepts intervening in an information-seeking process

Most of the literature related to the modeling of the information-seeking behavior -which is the study of the information-seeking process from a more humanistic point of view- defines the existence of an information need as the element that triggers the 
process. However, as Wilson (1981) stated when he presented his first model, using the term information need could lead to confusion as any human need can be divided into three interrelated features, namely physiological, affective, and cognitive aspects. Case (2012) also highlights the difficulty of defining what is a need in general, and more specifically an information need, as users can have many motivations to carry out an information-seeking activity, like seeking answers, reducing uncertainty and/or making sense of a situation. However, regardless the meaning assigned to information need, it is assumed that an information-seeking activity starts when the user becomes aware that he/she has less knowledge than the one he/she needs to solve a problem (Krikelas, 1982). In this approach, instead of making the information-seeking process revolve around this information need, it is led by the resolution of the problem, that is the purpose that wants to be achieved. By doing this, the proposed model can represent information-seeking as an adaptive process, as it depends, at least, on the specific goal of the CS researcher.

Due to the diversity of information-seeking processes, a CS researcher may have to achieve a lot of different purposes. Nonetheless, as mentioned before, in the model have been considered only those purposes that have been mentioned by the interviewees during the study, as they probably are those that are more relevant and usual for them. It is important to differentiate between these purposes because, in fact, each of them has different objectives and specificities implicitly attached. In order to support concrete information-seeking activities it is important to make the main needs of a CS researcher explicit:

a) Obtain relevant information about a topic refers to the commonly initial exploratory phase when the CS researcher needs to delve deeper into a topic. This usually means that he/she lacks or needs to increase the knowledge related to the topic he/she has, like its specific terminology, which are the most relevant publication venues that regularly address it, or which are the most relevant authors who produce relevant scientific documents in the topic. In summary, the CS researcher wants to build a mental model including the main concepts related to a topic.

b) Elaborate a state-of-the-art means trying to find all the relevant documents that are related to a topic in order to draw its current situation in the research field. In this case, the information-seeking activity has to be exhaustive and systematic in order to ensure the completeness of the obtained information.

c) Find again a forgotten reference corresponds to the need of finding the bibliographic reference to a document that the CS researcher has already read - or at least 
explored - before, but without remembering enough specific data - like its title, its author(s) or its publication venue- allowing him/her to directly find it again.

d) Update a bibliography refers to the need of finding documents related to a topic that have been published recently — or from a given date - in order to include updated bibliographic references in a new document to be published.

e) Find a specific information deals with the need of obtaining a very concrete information, like a definition or a formula. It is the most directed and narrowed information-seeking purpose as the kind of output to be obtained is previously known by the CS researcher, and then it is easier for him/her to determine if the result is the expected one or not. Besides, in this case, the CS researcher usually knows - to a greater or lesser extent - how to obtain the desired information - for example where to look for it, which terms to use in the query or which authors should preferably be considered.

f) Find the reference for a citation also represents the need of finding a specific information, which in this case is the bibliographic reference to a document that supports or contradicts - depending on the aim of the citation - a given statement or hypothesis. Even if this information-seeking purpose is also directed, achieving it is not so straightforward because its formulation is usually not so direct, and then it often requires the CS researcher to analyze more in detail one or more full documents - or at least part of them - to determine which ones contain the sought information and then can be cited.

g) Browse a document collection has to do with the aim of exploring a set of documents at a general level. In this case, the CS researcher does not seek for a specific kind of information, but, on the contrary, he/she only wants to know more about a set of documents, like for example which are the main topics they address.

h) Incorporate a set of documents to an existing local collection characterizes the desire of a CS researcher to evaluate a set of documents in order to identify which of them should be kept and added to his/her local collection of documents. In this case, documents are not selected to fill a specific information need, but only to update and thicken the CS researcher's local collection. As an example, when a CS researcher receives a new issue of a research journal, but due to lack of time he/she is not able to read all the articles included in it, he/she may just want to identify which ones might be relevant or interesting for him/her and mark them somehow to be accessed later. For example, storing them in a specific folder of his/her computer, named "To read". 
While seeking information, CS researchers can find documents that are not relevant for his/her current purpose but that can be potentially relevant for future purposes as their contribution is novel and is related, at some level, with his/her topics of interest. Other times, a CS researcher can determine that a given document is not relevant for his/her current purpose, and that there is little chance for it to become relevant for future information-seeking purposes. Identifying this last case can be very useful as knowing that a given document is probably not going to be useful in the future can make the information system avoid showing it, or at least indicate somehow that it has already been processed and tagged as non-relevant in past information-seeking activities.

\subsection{Documents}

Researchers in general, and CS researchers in specific, typically need to handle hundreds or thousands of documents grouped around one or more document collections during their information-seeking activities. Appendix C.1 presents the complete modeling of the document and document collection concepts.

To begin with, as reflected in Figure 3.2, a document collection can be physical -if it only contains paper documents like printed books or printed articles-, or digital - if it only contains a set of digital documents. In the first case, there are physical libraries - for example in a University - where thousands of books, journals and other documents are made available to the users, but there are also physical local collections that are formed by a set of paper documents that have been locally archived over the time by a CS researcher. Analogously, it is common for CS researchers to have a digital local collection formed by a set of digital documents stored over the time, but there are also digital libraries that are made available by most of the main editorials - for example, Elsevier Science Direct ${ }^{1}$, ACM Digital Library ${ }^{2}$, IEEE Xplore Digital Library $^{3}$, or Frontiers ${ }^{4}$. In fact, most of the interviewees asserted that digital libraries are increasingly becoming their main source to seek information, as they contain a huge amount of past and recent publications. Moreover, they allow accessing the documents from anywhere through the Internet and they provide powerful search tools that simplify and cheapen - in terms of time and money - the process of locating and obtaining the desired documents. Finally, specialized forums and websites can also be considered as collections of forum posts and webpages, respectively.

\footnotetext{
${ }^{1}$ http://www.sciencedirect.com

${ }^{2}$ http://dl.acm.org

${ }^{3}$ http://dl.acm.org

${ }^{4}$ http://home.frontiersin.org/about/journals-a-z
} 


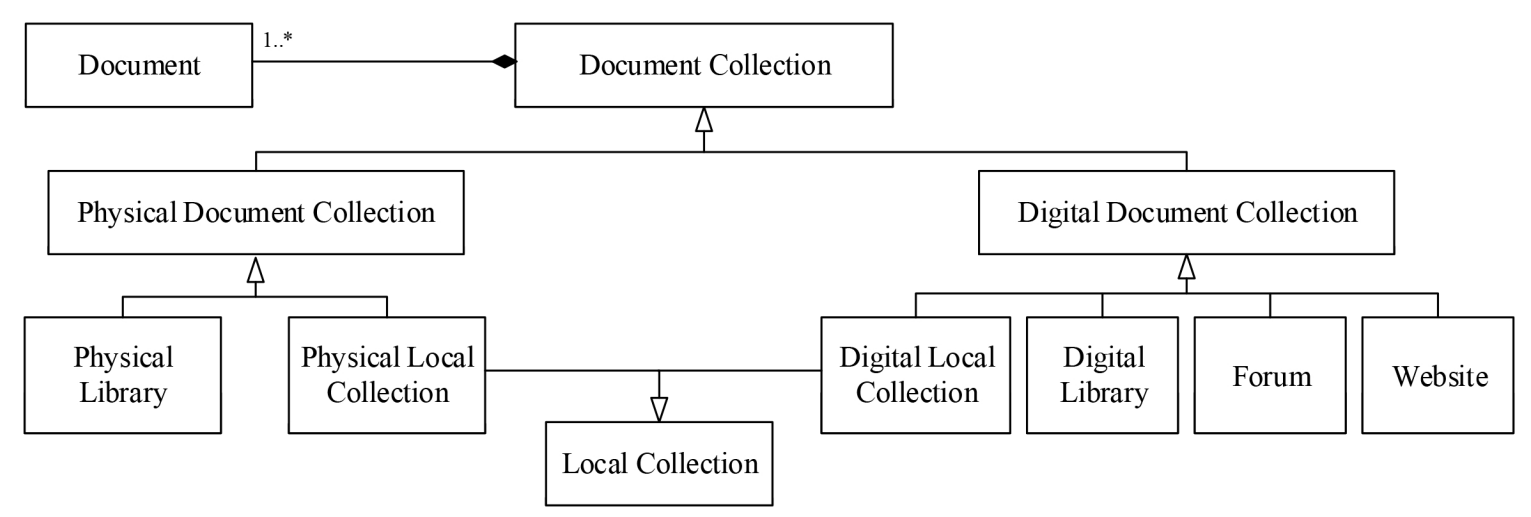

Figure 3.2 Document collection

In research it is also usual to employ style guides that define how to write and cite research documents, but they only cover some of the concepts related to a research document, like which are their sections or which publication details have to appear in a bibliographic reference - some examples are the style guides (American Psychological Association [APA], 2001; Feder, 2006; University of Chicago, 2010). However, the objective of this work is to provide a more detailed description, including also the relationships between the concepts. To some extent, this has been already made for journal articles in the Archiving and Interchange Tag Suite project developed by the U.S. National Library of Medicine (NLM, 2012) where 4 different XML-based tag sets are offered to facilitate the archiving, interchange, publication and authoring of journal articles. Among the hundreds of tags that are defined in the model, some examples are "journal-title", "publisher", "pub-date", "abstract", or "fig". This model, besides defining a lot more concepts related with a journal article, it also reflects some of the relationships that exist between them, like the ones between "publisher" and "publisher name", "pub-date" and "month" and "year", an author — "contrib" — and its affiliation — "aff" — or between an article and its meta-information — "article-meta" — like its "article-id" — for example its DOI - or its "title-id".

Apart from this, in our opinion, considering the variety of document sources is essential to adequately support the information-seeking process in the research domain. Any kind of document containing explicitly written information can be considered as a source of information. According to the interviewees, the document types that are more common in research are articles, academic theses, books, technical reports, forum posts and webpages - see Figure 3.3. In turn, articles can be divided into journal articles and conference papers; there are classical text books consisting of a set of chapters, but also books presented as a compendium of documents - typically journal articles or conference papers - ; and an academic thesis can be a Master thesis — of any kind — or a Ph.D. Dissertation. This subdivision is especially relevant in the case of the articles and 
theses as, even if their format, structure and type of content is very similar, interviewees clearly considered them as different types of documents for some reasons, like the difficulty of publication, the novelty of their contribution, the maturity and reliability of their results in the case of the articles, or the extent of the contribution in the case of the theses. Obviously, these are only some of the types of documents that may be used in the research field, but new ones could safely be added to the sub-model as new types or subtypes of documents, for example, editorial articles, short/long papers, extended abstracts, posters, position papers, or undergraduate thesis.

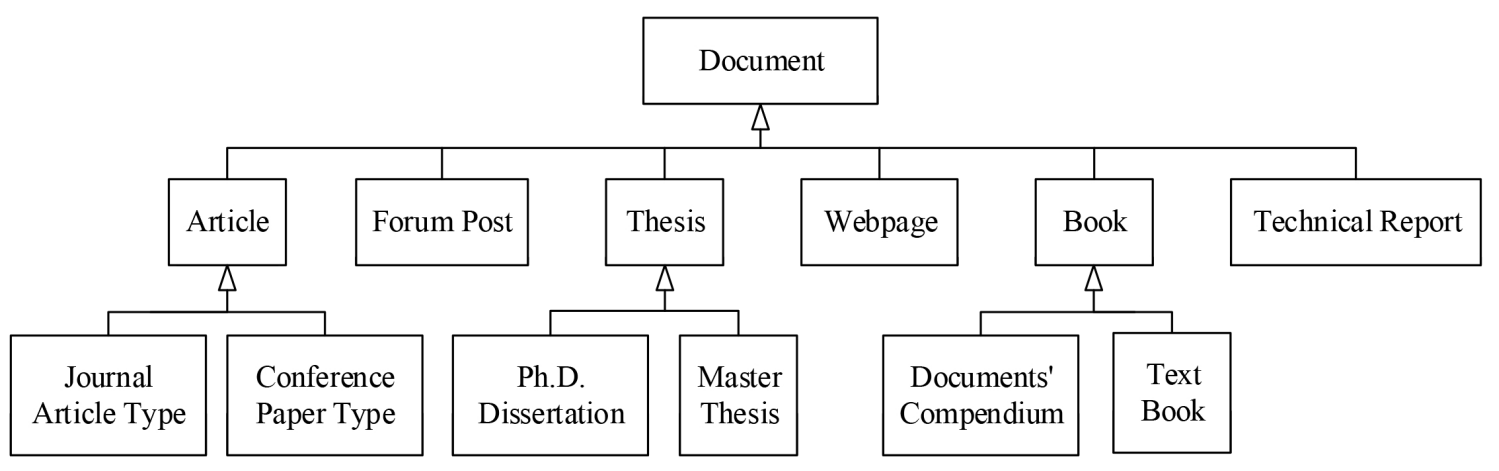

Figure 3.3 Types of research documents

Figure 3.4 illustrates that, at the most basic level, a document consists of a set of terms. These terms, in turn, can be divided into semantically relevant terms - that is those terms that provide relevant information about the topic(s) addressed in the document, like for example the keywords or those that are part of the specific terminology of a topic-, and semantically non-relevant terms, which are the rest. At a more conceptual level, a document can be seen as a set of components, called information elements, that contain relevant information, either indirectly through content elements like tables, equations, and/or figures-, or directly through the information that is written or can be inferred from the document's textual data. These document data allow to identify the document - who has written it, when it has been written, where it has been published, etc. - but also to provide information about its structure - which sections are present, which type of document it is, how long it is, etc.- , or about its contribution - which topic it addresses, what is its contribution, etc.-, among others. Some of this information is explicitly provided by some of the terms explicitly written in the document, while some other can only be implicitly provided, and then have to be inferred from the structure and the content of the document. 


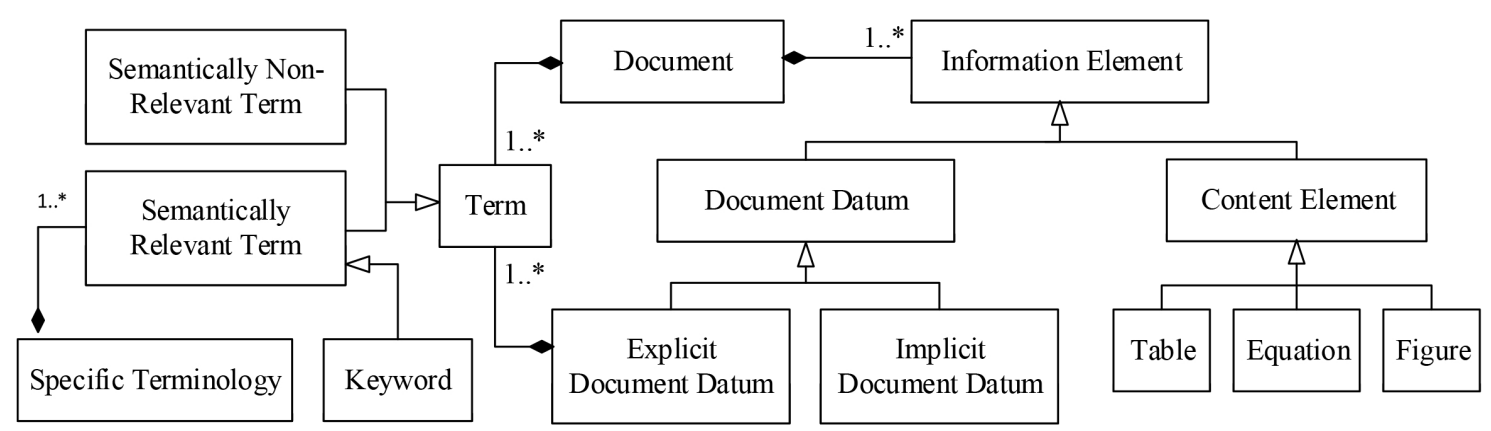

Figure 3.4 Basic and abstract composition of a research document

\subsubsection{Explicit Document Data}

CS researchers usually read and use - to a greater or lesser extent- some of the explicit document data while looking for information for a variety of reasons, as for example to determine the quality of a document. As reflected in Figure 3.5, some of these data are generic and are typically present in any kind of document, while others can only be found in documents of a specific type. In the first group are the name(s) of the author(s), the title and the publication date as primary data, but also a set of bibliographic references, each of them consisting of a subset of data about the document it refers to.

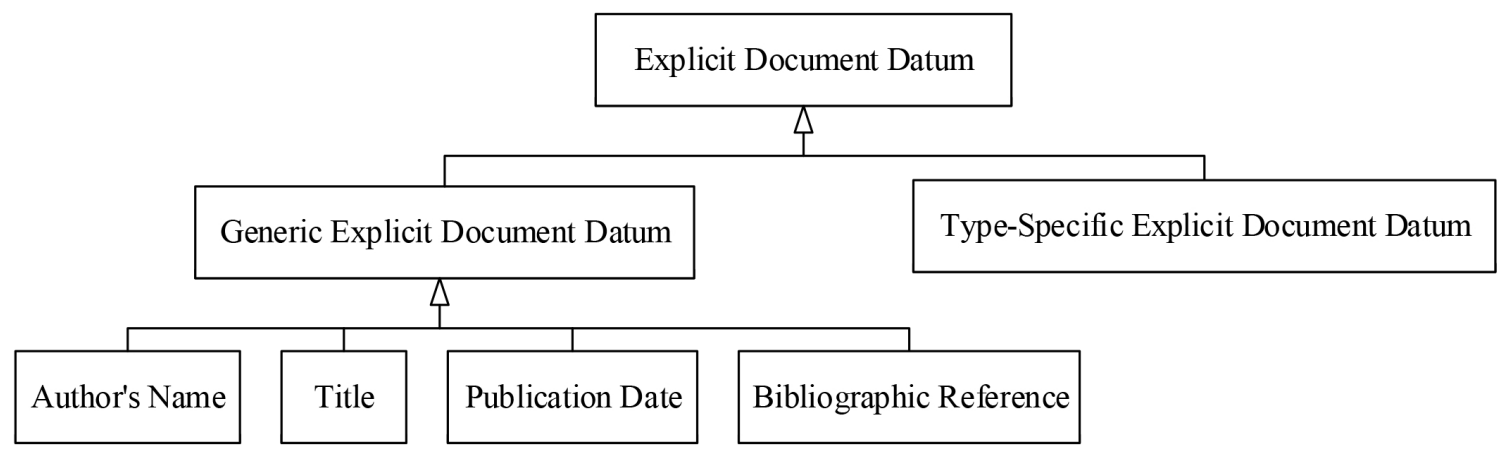

Figure 3.5 Explicit data contained in a research document

The model offers a flexible way to represent bibliographic references - see Figure 3.6 - as, instead of setting which are the fields - in the proposed model they are called publication details - that are standard based on the type of the referenced document, each bibliographic reference can be defined individually, according to the publication details it contains. This is especially relevant, because some supposedly necessary fields are sometimes not present, and sometimes there are additional data that have to be included as publication details. As an example, a bibliographic reference is always supposed to contain a title, one or more authors, and a publication date - among others-, but it can also contain other data that do not appear explicitly nor implicitly 
anywhere, like the last time the availability of a remote source - like a webpage or an open-access digital journal article - was checked, or the URL from where the referred document can be retrieved.

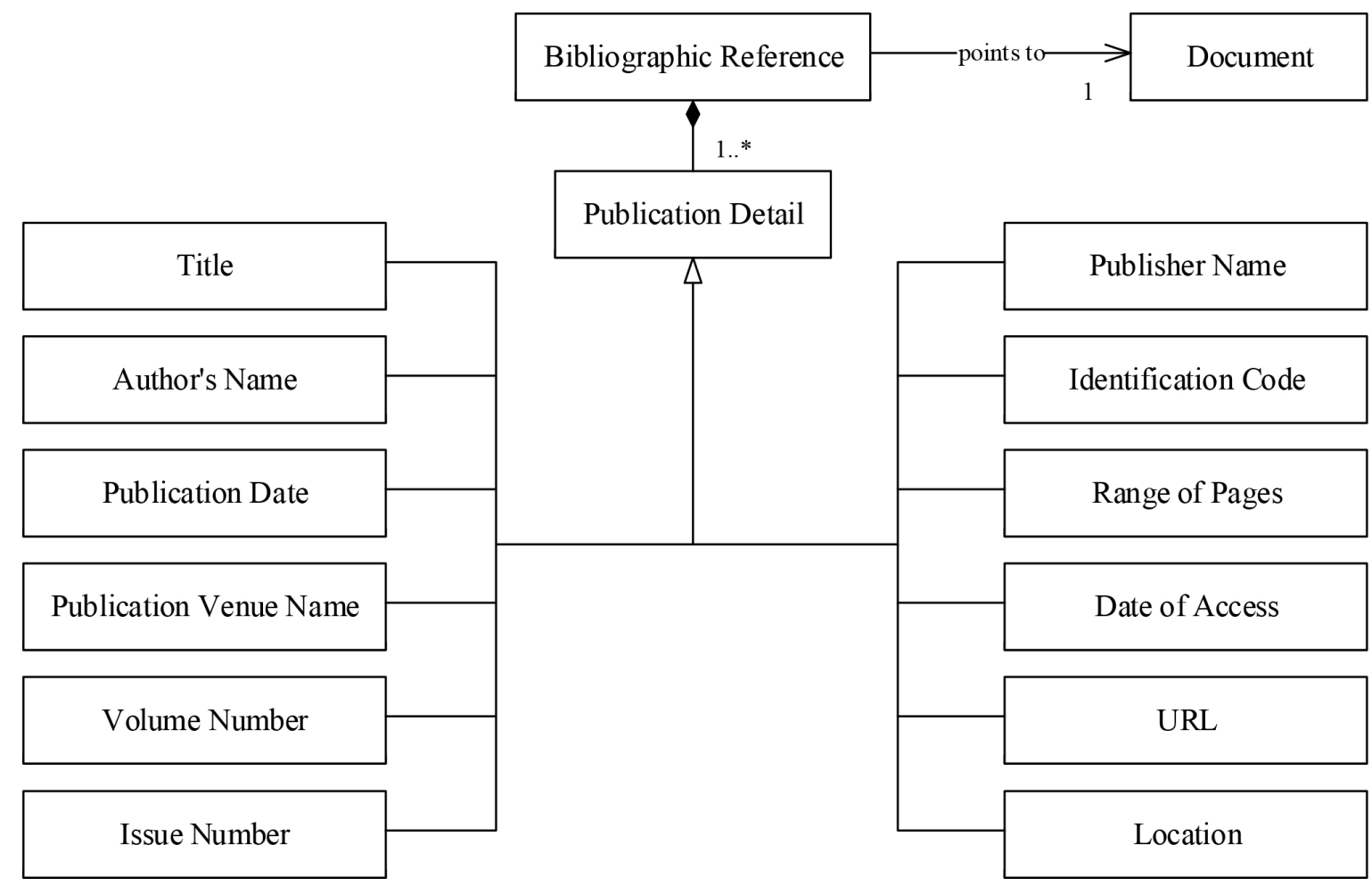

Figure 3.6 Data included in bibliographic references

Beyond generic explicit data, a document can have other data that are specific to its type - see Figure 3.7. In fact, it is common to find explicitly written in an article the name of the venue where it has been published - that is the name of the journal or of the conference proceedings-, together with the name of the research institution to which each author is affiliated. In the case of an academic thesis, the explicit data that can be more commonly found are the name(s) of the supervisor(s) and the name of the university where the thesis has been developed. Finally, both webpages and forum posts have as specific data the URL that gives access to them. In journal articles, conference papers and technical reports it is also possible to find the volume and the range of pages in which the document can be found. As conferences usually are annual, there is only a volume of conference proceedings per year, and then only journal articles and technical reports use to have an issue number associated. Nevertheless, it is not uncommon to have explicitly indicated in a conference paper the location where the conference took place. Finally, these three types of documents and books usually have an identification code explicitly written - a DOI in the case of an article, an ISBN in the case of a book, 
and a report number or ISSN in the case of a technical report-, and are published by a publisher, except technical reports that are typically produced by an organization.

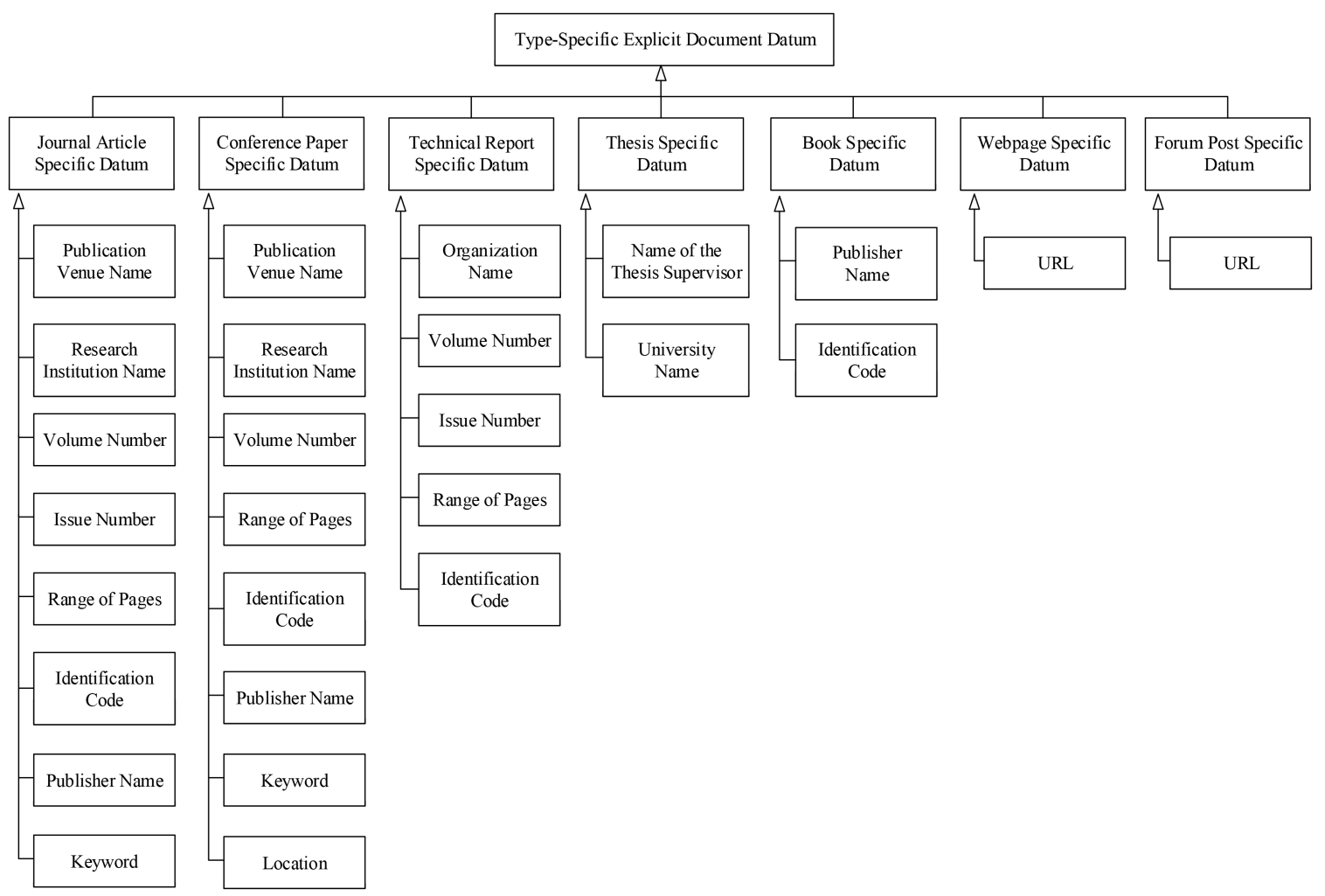

Figure 3.7 Explicit data that are specific to a given type of research document

\subsubsection{External entities related to a document}

Some of these explicit document data indirectly provide two types of information. The first one corresponds to the semantics explained above - for example the authorship of a document-, while the other points to an external and more complete concept. This concept is related at some level with the document in question, but it is clearly different from it. The model, as illustrated in Figure 3.8, contains three of these entities - author, publication venue and research institution - that provide this double information. In fact, a document has the name of its authors explicitly written, and this provides a direct information about the authorship of the document. Each of these names, however, also serves as a link to the author himself/herself, and then to a lot more information about him/her such as his/her current involvement in a research institution, which can be different from the affiliation of the author at the time of writing the document. In fact, over time, an author may have been affiliated to different research institutions. Therefore, author's name - as it appears written in the document - and 
the author himself/herself are modeled separately, as the latter concept groups much more information about the author than the first one.

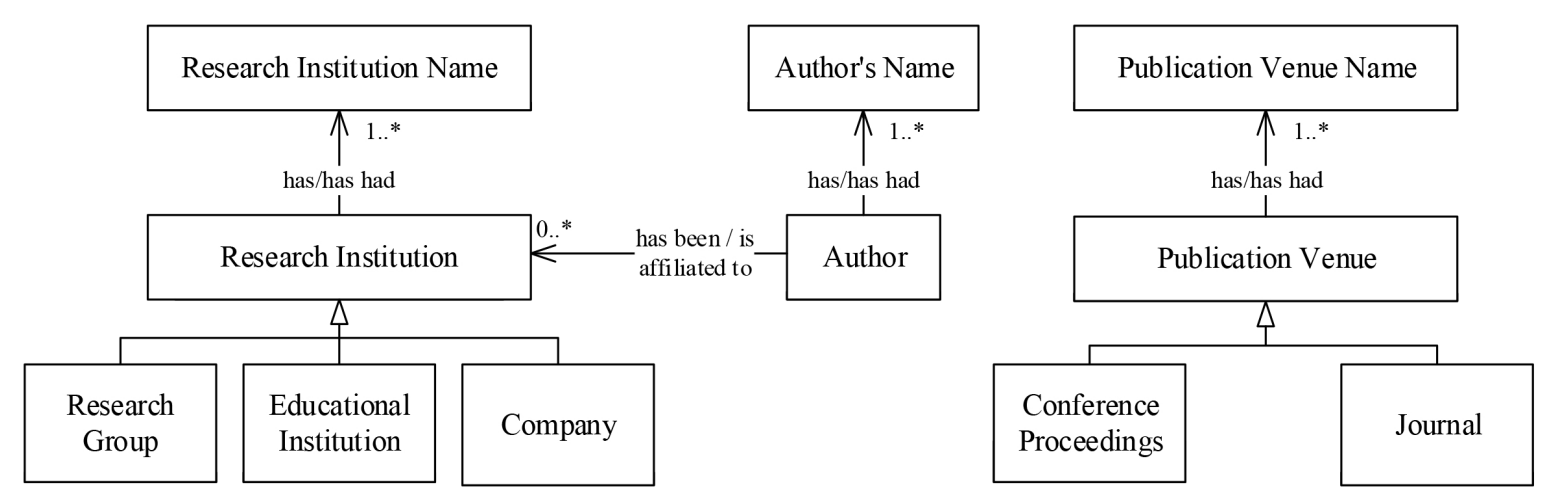

Figure 3.8 Other concepts related to research documents

Following the same approach, a distinction is also made between a publication venue and a research institution and their respective names. Indeed, the same author, publication venue or research institution may have had different names over time. For example, an author can have published some documents using his/her maiden name, and some others using his/her family name. Similarly, a publication venue or a research institution may have changed their name to adapt it to changing times in research.

Moreover, as it happens with a document, there are different types of publication venues - conference proceedings and journals - and of research institutions - research group, educational institution, and company - that are common in the investigation field.

Apart from this, Figure 3.9 reflects that documents and two of these external entities - authors and publication venues - can also have associated one or more impact metrics - like, for example, how many times they have been cited. These metrics allow CS researchers to quantify how relevant is a document, an author, or a publication venue in the scientific community, or in the context of a physical/digital local collection. This division allows to distinguish between the impact metrics that are calculated with all the public information that is available - like the number of citations, who cites what, who is cited and where, etc.-, and those that only take into consideration a subset of this information. As an example, an author can have a high impact metric because he/she has published a lot of relevant documents, but if a CS researcher only considers his/her local collection, the same author can have a lower impact metric, as only a few of these documents - those that the CS research has considered relevant to be stored in his/her local collection - are used to figure out the impact metric value. 


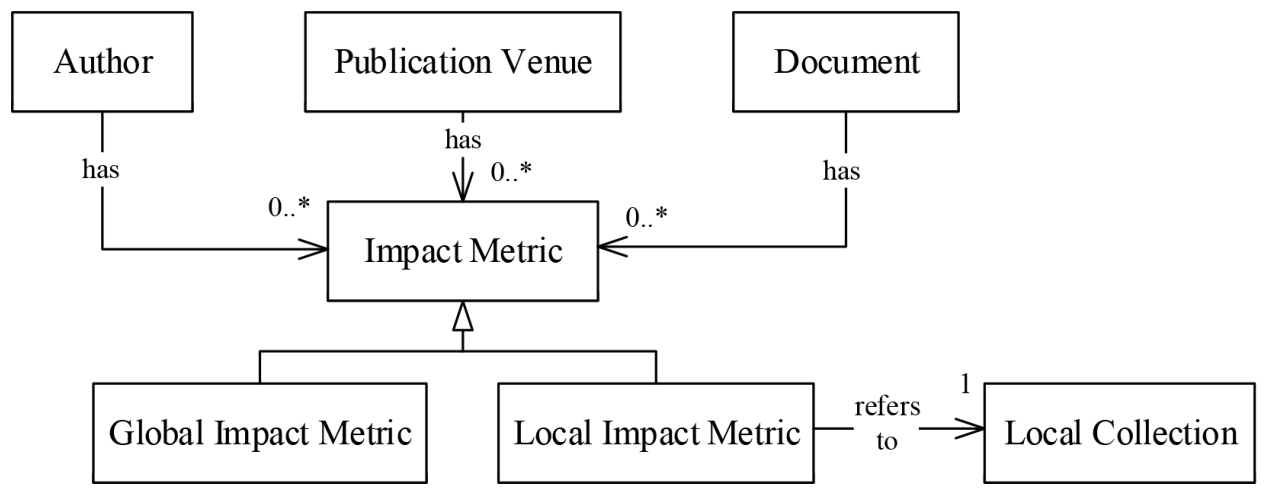

Figure 3.9 Impact metrics in the research domain

\subsubsection{Implicit Document Data}

Some of the non-written data that a document can implicitly contain are also represented in this sub-model - see Figure 3.10. To obtain them, the user has to get into the document and read it to some extent — or at least to skim it - in order to process some of the information explicitly written in it. As an example, after reading a few words of the document, like the title, the reader can identify in which language it has been written. The number of pages that has the document is also an implicit datum as its calculation is based on the range of pages, which is an explicit document datum. Besides, by having a quick look at the document, the CS researcher can recognize its structural layout, as scientific documents are usually formed by very well-defined sections like a list of keywords, an abstract, an introduction or a conclusion. In some cases, depending on the information-seeking purpose and the context of the information-seeking activity, a CS researcher may just need to read these sections, as they are - at different levelssummaries of the contribution of the document. In other cases, a CS researcher may just want to have a quick look at the general structure of a document, either through its table of contents or even by quickly overviewing which sections and content elements make up the document. For example, a CS researcher can be interested in finding documents that include some kind of figures, like graphs or diagrams, whereas another CS researcher can show more interest in a document if it contains some mathematical equations. Occasionally, a CS researcher can also want to skim a document in order to identify its content type. According to interviewees, documents contribution may be classified as primary research, when some findings are presented and sometimes validated somehow - for example through theoretical or empirical validation-, but they also can present a survey, a review or a case study, among others. 


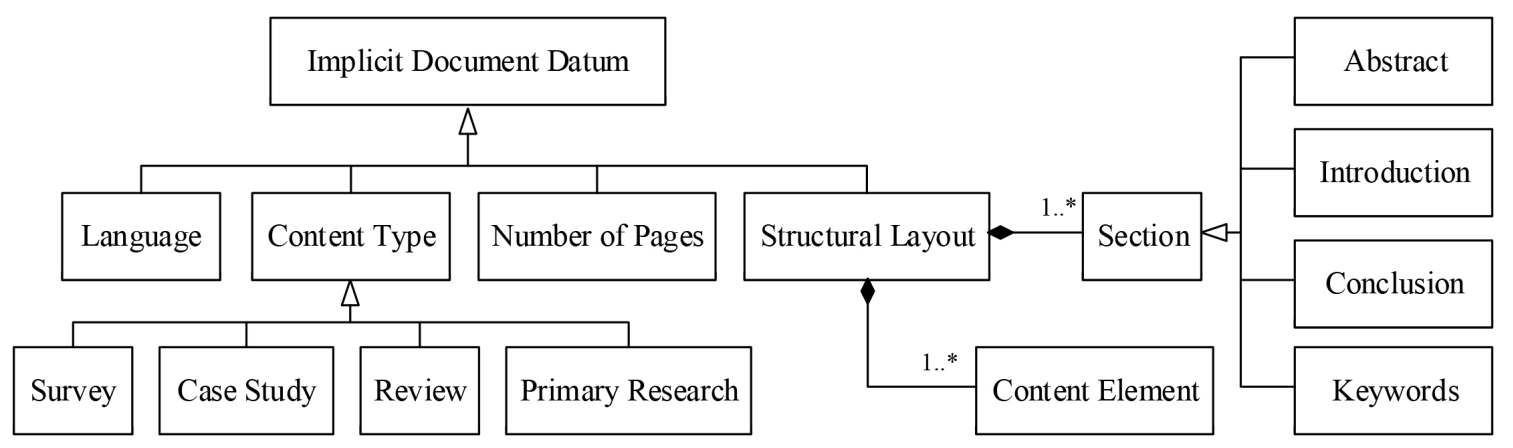

Figure 3.10 Data thata re implicitly contained in research documents

\subsection{Topic}

The document's sub-model — see Figure 3.11- also illustrates that publication venues specialize in one or more topics, and then usually publish documents related to it; research institutions and authors focus their research in some specific topics; and documents deal with one or more topics. Additionally, some of these authors, publication venues, documents and research institutions do not only address some topics, but they can also be a reference in some of them. Each of these topics can, in turn, be related to other topics - either more abstract, more concrete or complementary - and has a specific terminology associated that is used in the research context. As an example, Wilson (1999b) states that "information behavior may be seen [...] as a series of nested fields", where the information search behavior is a sub-area of the information-seeking behavior, that in turn is a sub-field of the information behavior area.

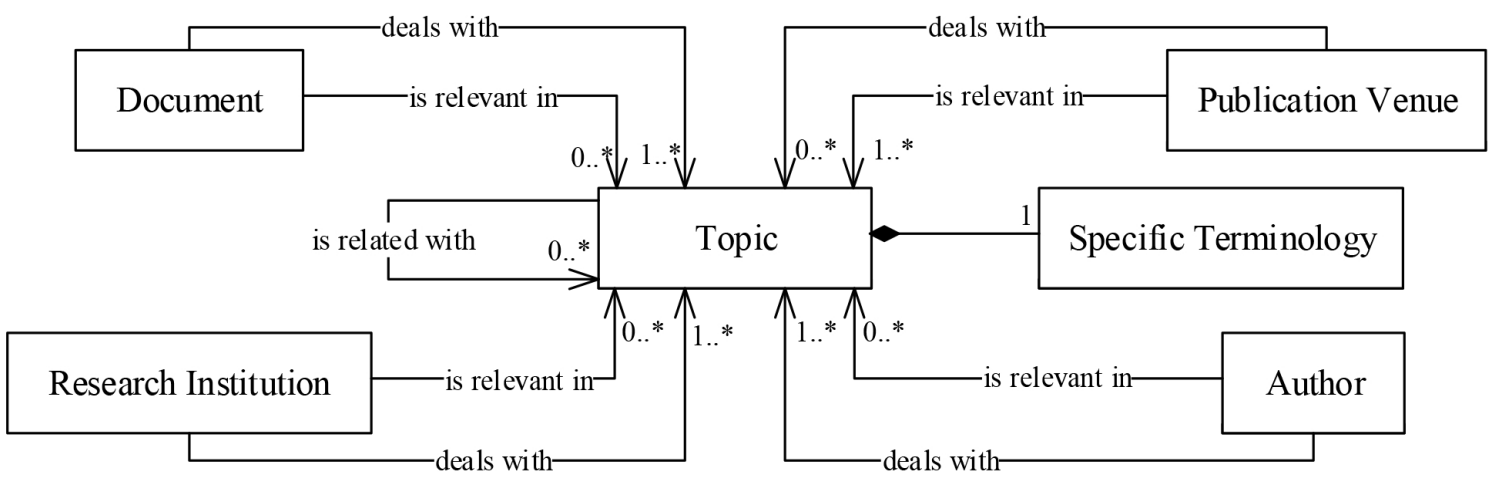

Figure 3.11 Topics in the research domain

In the proposed model, a topic is represented as a simple concept in order to better understand how it relates with other concepts, but it is actually a complex component that requires been modeled more in detail. In the first place, it is necessary to define how and from where arises a topic in the research domain. Once identified, it is required to determine which computational representations can be used to make them 
understandable and usable by a software system. At last, it is required to explain how this computational representation can be used to determine which entities are related to a topic, namely which documents address a given topic, or in which topics is interested

a CS researcher.

\subsubsection{Identification of topics}

Defining a topic is not obvious as it is an abstract concept that often depends on other aspects. In the research domain, a topic can be defined by its specific terminology. However, this terminology comes from the content of documents that address the same topic. Then, in our opinion, a topic is indirectly defined by the document that address it. Below are presented four approaches allowing to recognize a topic in the research domain, regardless the specific field of study.

\subsubsection{Use of predefined definition of topics}

The first alternative is to make use of predefined classifications carried out by external actors, without analyzing the content of the documents. This is the case, for example, of the ACM Computing Classification System ${ }^{5}$, where are defined 13 main topics that in turn are subdivided into hundreds of more specific categories. Nowadays, when an author submits an article to an ACM journal, he/she is required to indicate to which category or categories it belongs to.

Another option is to make use of a topic-specific thesaurus, lexical database or ontology to define a topic, as all of them are supposed to contain its specific terminology.

Using external resources obviously avoids having to define a topic, but it as drawback the reliability and precision of the topic definition are totally dependent on the completeness and correctness of these resources.

\subsubsection{Personal definition of topics}

The most straightforward, flexible and adaptive approach is to ask the researcher himself/herself to identify and describe the topics. To do so, the researcher has to explicitly provide the specific terminology of the topic, and even assign weights to them to better reflect their relevance.

Another possibility is to ask the researcher to classify the documents according to the topics they address according to him/her, and automatically extract the specific terminology of the created groups.

\footnotetext{
${ }^{5}$ http://dl.acm.org/ccs_flat.cfm
} 
In both cases, the classification is totally dependent on the researcher as the decision solely rests in his/her subjective opinion.

\subsubsection{Using a significant representative}

In the research field, it is quite common to find documents that are considered essential pillars in the research topic. Then, another possibility is to consider that a document - or rather its content - can properly represent the whole topic.

This approach is the simplest one, but has some drawbacks. First of all, in general, it may be too simplistic to define a whole topic by a single document, and this may result in an incorrect - or at least incomplete - definition. On the other hand, the selection of the representative document is not obvious as it may be based on objective aspects, like the amount of times it has been cited, but also on a personal — and maybe erroneous - assessment of the researcher.

\subsubsection{Emerging definition of topics}

In the last case, the absence of external resources or the lack of enough knowledge from the researcher requires defining a topic in another way. As stated before, a topic can be indirectly defined by the documents that address it, as they are supposed to share a similar terminology. The idea, then, is to cluster the documents, as done in the second approach, but in this case based only on the content of the documents, so that each cluster potentially contains documents that are thematically related, and then are supposed to address the same topic. This process is done automatically by the system and does not requires human intervention. This provides some kind of objectivity to the results, as they do not depend on humans decisions, but on an algorithm, that is supposed to be deterministic and then to always return the same result given the same input.

There are several approaches to cluster a set of documents based on their content (Manning, Raghavan, \& Schütze, 2008). The $k$ Nearest Neighbor Classification (kNN) (Silverman \& Jones, 1989), for example, calculates the clusters by defining a set of boundaries so that each document is assigned to the cluster to which it most likely belongs to according to its k nearest documents. There are also some machine learning approaches, like Support Vector Machines (SVM) (Boser, Guyon, \& Vapnik, 1992; Cortes \& Vapnik, 1995), that provide a previously trained classifier that defines the decision bounds that allow clustering a new document in one or another cluster. SVM defines these boundaries by calculating a margin that maximizes the distance between documents that belong to different clusters but whose representations are the closest in the space - the vectors representing these documents are called Support Vectors. 
Another machine learning approach is the Rocchio Classification (Rocchio, 1971), which is based on calculating the hyperplane defined by a set of points that are, two to two, equidistant from the centroids of the respective clusters - the clusters and its centroids have to be previously defined to train the classifier. The resulting hyperplanes, then, are the borders defining the surfaces associated to each cluster, and then a new document is clustered according to the surface in which its vector is projected in the space. In this work, an automatic machine learning algorithm has been implemented to analyze the set of documents that have been already tagged with the topics they address, and generate a classifier that determines which are the most common terms used in the documents that have been categorized in a given topic. This classifier, then, takes as input a new document and, after analyzing its content, to which degree the document addresses each of topics modeled in the classifier. As example, the 13 categories of the ACM classification have been used in order to train a classifier with dozens of documents published in ACM journals.

Additionally, there are other types of clustering, where the classification is not based on a training phase leading to a classifier, but in the contiguity principle: the closer two documents are, the more likely it is they belong to the same cluster. This principle, for example, is used by the k-Means algorithm (Macqueen, 1967; Steinhaus, 1956), consisting in clustering the set of documents in $\mathrm{k}$ clusters - the number has to be predefined by the user - so that the aggregate distance between the centroids of the clusters is minimized.

Finally, another option is to classify a set of documents by performing a hierarchical clustering (S. C. Johnson, 1967), that can be agglomerative - bottom-up approach-or divisive - top-down approach. In the first case, each document is initially considered as a cluster and, progressively, clusters are merged into supra-clusters, taking into account that the new fusion has to increase the aggregate similitude between all the clusters. The divisive approach, on the contrary, groups all the documents in a single cluster, and then progressively divides the clusters. In this case, the user defines until which level of depth the algorithm has to divide the clusters.

\subsubsection{Topic representation}

Once the documents addressing and defining a topic have been identified, they have to be represented in a computational way so that the software system can understand and process them. Next are presented two approaches to do it. 


\subsubsection{Using a label}

Depending on the previous knowledge and experience of the researcher, he/she may be the one providing a name to each of the identified topics. As for the personal definition of the topics, this approach is subjective as it totally depends on the user's decisions.

\subsubsection{Using a vectorial representation}

The second option consists in syntactically and semantically process, individually, each of the documents that form a cluster in order to translate them to a computational representation. In this research the Vector Space Model (VSM) (Salton, Wong, \& Yang, 1975) approach is used. In VSM, each dimension - also called feature - is associated to a term, and its content reflects its frequency of appearance in the element represented by the vector - a document, a collection of documents, the user's topics of interest... Figure 3.12 illustrates an example of vectorization using the VSM algorithm.

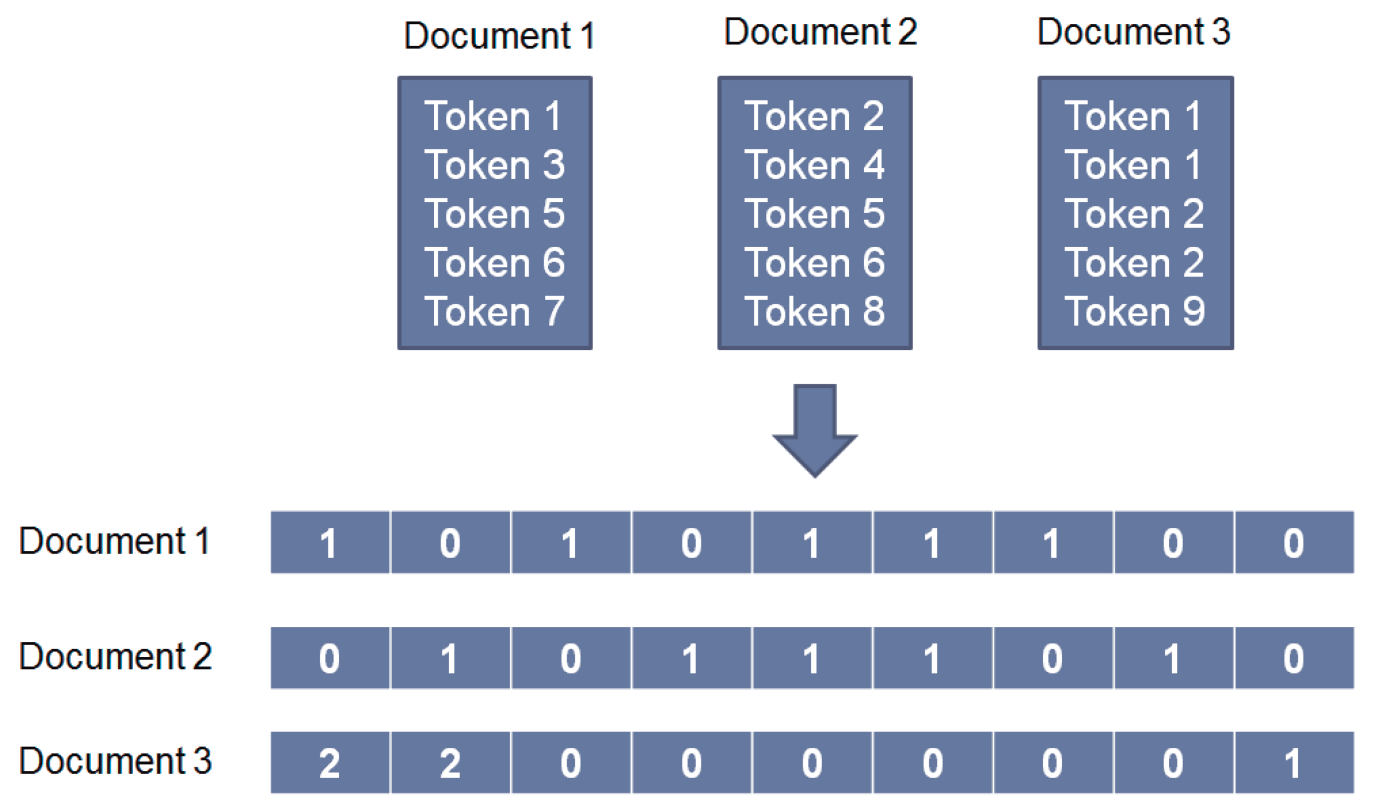

Figure 3.12 Example of vectorization of 3 documents using the Vector Space Model

In order to increase the accuracy and efficiency of the vectorization process, it is important to preprocess the document's content so that non-relevant and/or noisy terms are ignored as much as possible. To do this, it is required to make use of a set of Natural Language Processing (NLP) algorithms (Manning et al., 2008), like the ones explained below.

First of all a list of stopwords is used in order to identify terms that have no semantic load, or that are extremely common in the language and then their presence is not differential at all. This occurs, for example with the definite article the, the possessives 
- my, your, his, her, its, our, their, whose-, the demonstrative - this, that, those, these- - the general determiners - a, an, any, another, other, what-, but also some very common verbs, regardless their conjugation, like the verbs to be, to have or to get. So, if the term is recognized as a stopword, it is not inserted in the vector. In this research, a list with 335 stopwords — see Appendix B - has been used.

A second refining round can be performed by grouping the terms according to their syntactical proximity. In this research, a stemming algorithm has been used in order to reduce a word to its morphological root. By doing this, for example, the terms visualization, visualize, visualized and visual are all stemmed to visual. The idea, then, is to fill the vector with the stems instead of with the full terms. By doing this, closely related words are likely to be reduced to the same root, and then the dimensionality of the vector decreases and the weight of the dimension containing all the related terms gains weight. However, one of the biggest problems of stemming algorithms is that they do not take into account the semantics of the term, and then very often the resulting stem is not a valid term by itself. Obviously, this carries its dangers as non-related terms may share the same stem and then be threated together, reducing the precision of the results. However, the stemming process has been widely investigated, and several algorithms have been proposed, many of them providing high vocabulary compression but maintaining good precision and recall rates, that are the main features evaluated in information retrieval (Harman, 1991). A complete survey of stemming algorithms has been performed in (Moral, de Antonio, Imbert, \& Ramirez, 2014).

Alternatively, different inflections of the same term can be grouped together by using a lemmatization algorithm (Korenius, Laurikkala, Järvelin, \& Juhola, 2004; Plisson, Lavrac, \& Mladenić, 2004). As its name indicates, these kind of algorithms reduce a term to its lemma - or lexeme-, which is the base form of a term or set of terms. For example, the terms 'better' and 'best' have as lemma the term 'good'. This approach, then, solves the problem of bringing together non-related terms. However, it presents many other problems that have to be addressed. Lemmatization is usually based on dictionaries - usually implemented through ontologies, like WordNet (Miller, 1995) that allow indicating the hierarchical relationship between two terms, like for example synonymy, hiperonymy or hyponymy. Going across these relationships, it is possible to determine if two terms are related or not. However, each term can have several synonyms, hypernyms ${ }^{6}$ and hyponyms ${ }^{7}$, that can belong to the same context or not.

\footnotetext{
${ }^{6} \mathrm{~A}$ word with a broad meaning constituting a category into which words with more specific meanings fall; a superordinate. For example, colour is a hypernym of red. Contrasted with hyponym. (Oxford University Press, 2016)

${ }^{7} \mathrm{~A}$ word of more specific meaning than a general or superordinate term applicable to it. For example, spoon is a hyponym of cutlery. Contrasted with hypernym. (Oxford University Press, 2016)
} 
Then, knowing until which depth the tree is traversed, and how it is traversed - that is which relationships are considered - is not trivial at all and may result in having dozens of terms that seem to be somehow related - directly or indirectly - , but that actually are not - at least not all of them. When possible, context-specific dictionaries are used to limit this problem since, at least, all terms and relationships belong to the same context.

In any case, the final purpose is to have a vector containing semantically relevant terms in any of its forms - full term, stem or lemma-, weighted according to their frequency of appearance and, in this case, to their provenance.

At this point, it is quite common to carry out a last preprocessing stage to make the content of the vectors as representative as possible. This stage consists in applying a new weighting scheme, this time based on the frequency of appearance of the term in the vectors both individually and in aggregate. The first method, called Term Frequency (TF) (Luhn, 1957), allows assigning more importance to the terms appearing more times than to less frequent terms. The second case, named Inverse document Frequency (IDF) (Harman, 2005; Jones, 2004; S. Robertson, 2004), considers how many times a term appears in the set of vectors being compared - for example, comparing the user's vector with several topic vectors. In this case, the assumption is that the most frequent a term is in most of the vectors, the most its importance has to be reduced, as it cannot be considered as a differentiator element. Usually, the two approaches are used together so that rare and too common terms are assigned with a low weight, but on occasion only term frequency is taken into account, as common terms can represent relevant general aspects that actually exist in the vectors, and then that cannot be ignored.

In order to reduce the noise as much as possible, and then to improve the representation of documents, topics, or terms that are relevant for a researcher, some computational linguistics algorithms like the Part-Of-Speech Tagging (POS-T) (Abney, 1996; Adwait Ratnaparkhi, 1996; Brill, 1992; Martinez, 2012; Schmid, 1994) or the Named Entity Recognition (NER) (Florian, Ittycheriah, Jing, \& Zhang, 2003; Nadeau \& Sekine, 2007; Zhou \& Su, 2001) can also be used.

The first process consists in identifying the grammatical category of a term based on its definition and on the phrasal context in which it has been used. This allows to distinguish between nouns, verbs, adjectives, adverbs and so on, which can be very useful and effective when determining if a term is relevant enough to represent a document or a topic. For example, it seems reasonable to ignore some grammatical categories, like adjectives and adverbs, as they do not add information by themselves. It can be also very useful to differently weight the terms that share the same stem - for example, it can be set that stems coming from noun terms are more relevant than those 
coming from verbs-, or even to always give more weight to terms belonging to a given part-of-speech.

Similarly, NER algorithms allow identifying if a term, or set of consecutive terms, are names of specific entities, like persons, organizations, locations, quantities, percentages, or time-related expressions, among others. This approach is very interesting as some terms, by themselves, are not meaningful, or their meaning is incomplete as they are part of a bigger construct. Besides, recognizing these entities can help identifying synonyms that would otherwise be unrecognizable, and then conflate them. As an example, a NER algorithm would tag both the expressions "United States of America" and "USA" as countries, or "Barack Obama" and "President of the United States of America" as persons, which could facilitate inferring, based on the context, that they refer to the same entity. This linguistic mechanism can be also used to give more weight to the terms representing a given entity, or even to treat them separately -in research, for example, it would be very useful to separately analyze the use of names in documents, as they make reference to other authors, and then can reflect on what related works is based a document.

\subsubsection{Determining the topics addressed by a document}

At this point, as introduced before, it is possible to determine how thematically similar are two concepts of any kind, like a document and a topic, two topics, or an author or a publication venue and a topic - in the later cases, through the documents they have written or published, respectively. The only criterion that has to be met is that each of the dimensions has to be associated to the same term in both vectors. This is required as the metrics used to compare the vectors, actually compare one by one each dimension - taking into account the frequencies reflected in it-, and then integrate all the partial results to return a global value between 0 and 1 . Some of these metrics are, for example, the Canberra distance (Lance \& Williams, 1967), the Sørensen-Dice coefficient (Dice, 1945; Sorensen, 1948), the Jaccard coefficient (Jaccard, 1901), the Euclidean distance, or the Cosine metric, which is the one used in this research because of its simplicity and effectiveness, and because it is one of the most used in information retrieval. The similarity between two entities $x_{1}$ and $x_{2}$-document, collection of documents, topic, etc. - is figured out by computing the cosine of the angle $\theta$ formed by the two vectors $\vec{V}\left(x_{1}\right)$ and $\vec{V}\left(x_{2}\right)$ representing the entities in the VSM. This is equivalent, as illustrated 
in Equation 3.1 and Figure 3.13, to calculate the dot product of their normalized unit vectors.

$$
\operatorname{sim}\left(x_{1}, x_{2}\right)=\cos \theta=\vec{v}\left(x_{1}\right) \cdot \vec{v}\left(x_{2}\right)=\frac{\vec{V}\left(x_{1}\right) \cdot \vec{V}\left(x_{2}\right)}{\left|\vec{V}\left(x_{1}\right)\right|\left|\vec{V}\left(x_{2}\right)\right|}=\frac{\sum_{i=1}^{n} \vec{V}_{i}\left(x_{1}\right) \times \vec{V}_{i}\left(x_{2}\right)}{\sqrt{\sum_{i=1}^{n} \vec{V}_{i}\left(x_{1}\right)^{2} \times \vec{V}_{i}\left(x_{2}\right)^{2}}}
$$

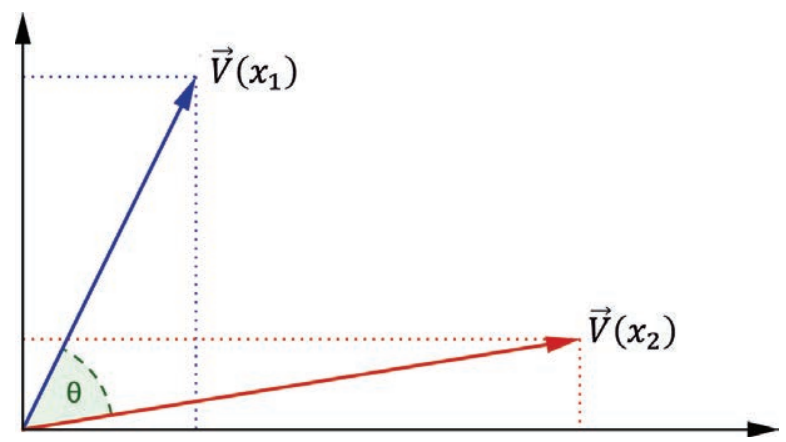

Figure 3.13 Example of similarity calculation using the cosine metric

At the end, the higher the similarity value between two vectors is, the more thematically similar are the two assessed entities. This approach, when applied to each pair of documents of a collection, allows obtaining a similarity matrix that contains all the one-to-one similarities existing between the documents of the collection. This matrix, usually, is used as input in some of the clustering algorithms explained above, like kNN.

Let's pose an example to illustrate the calculation of the similarity between a set of document. Table 3.1 contains the amount times that appear some terms in four different document. Each of the rows of this tables, then, is equivalent to the vector that represents the corresponding vector in the Vector Space Model.

Table 3.1 Example of frequency of occurrence of terms in documents

\begin{tabular}{|c|c|c|c|c|c|c|c|c|}
\hline Term & user & model & adaptation & information & seeking & task & context & visualization \\
\hline Document $_{1}$ & 15 & 10 & 15 & 0 & 0 & 0 & 0 & 0 \\
\hline Document $_{2}$ & 20 & 20 & 15 & 30 & 30 & 10 & 10 & 15 \\
\hline Document $_{3}$ & 20 & 15 & 0 & 15 & 0 & 0 & 0 & 0 \\
\hline Document $_{4}$ & 10 & 0 & 0 & 10 & 0 & 0 & 0 & 30 \\
\hline
\end{tabular}

Based on the values included in this table, the similarity measure between documents 1 and 2, for example, can be figured out as it follows: 


$$
\frac{(15 * 20)+(10 * 20)+(15 * 15)}{\sqrt{15^{2}+10^{2}+15^{2}} \cdot \sqrt{20^{2}+20^{2}+15^{2}+30^{2}+30^{2}+10^{2}+10^{2}+15^{2}+10^{2}}}=0.534
$$

If the same calculation is performed among the other pairs of documents, the similarity matrix displayed in Figure 3.14 is obtained.

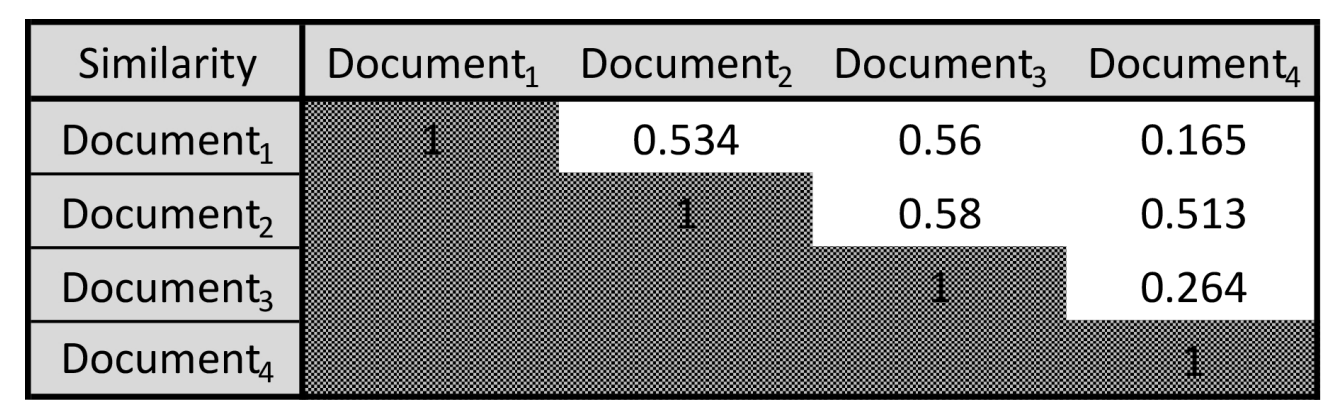

Figure 3.14 Similarity matrix of the four documents presented in the example

Considering the similarity measures reflected in the matrix, it can be stated that, for this specific set of documents, documents 1, 2 and 3 are thematically similar, whereas document 4 is only similar to document 2 . This result is coherent with the terms contained in each document, as the first three documents seems to address some kind of user modeling, whereas the last one does not.

If these values are used, for example, to spatially locate the documents based on their thematic similarity, documents 1, 2 and 3 would create a visual cluster based on their position - being documents 2 and 3 the closest ones-, and document 4 wold be located so that it is close to document 2 , but far from the rest of documents.

\subsection{Information-Seeking Tasks}

After interviewing the study participants, it was determined that the actions they perform to seek information can be classified under four main groups. The complete sub-model of the information-seeking tasks is provided in Appendix C.2.

As reflected in Figure 3.15, first of all, a CS researcher can need to carry out a filtering task in order to obtain, among a document collection, the sub-set of documents that match to a greater or a lesser extent some criteria. In other cases, a CS researcher may just want to explore a document collection in order to get a general idea of its main content and/or structure. Besides this, in order to achieve a specific information-seeking purpose, a CS researcher may need, at some point, to read, to a greater or a lesser extent, one or more documents. Finally, once a document is considered somewhat 
relevant for the current purpose, or maybe for future purposes, the CS researcher usually archives and organizes it in order to have an easier and faster access to it in the future.

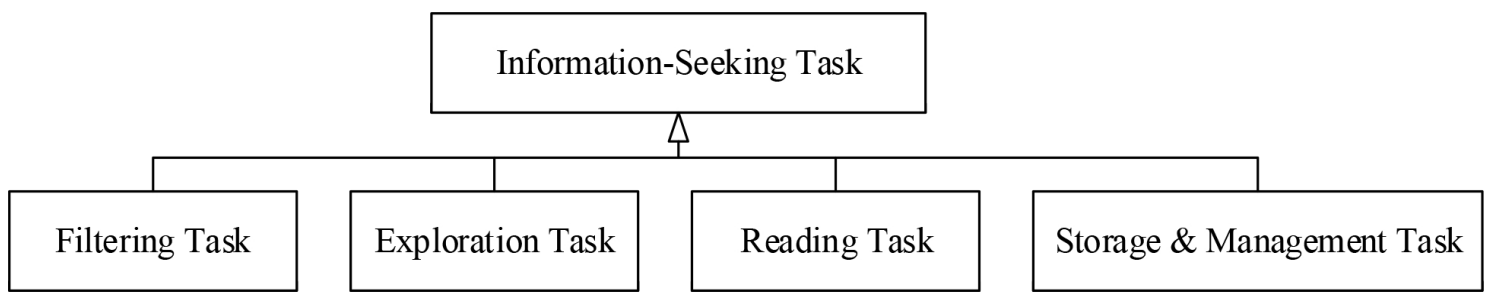

Figure 3.15 Types of information-seeking tasks

These information-seeking tasks cannot be seen as stages of a static or predefined pipeline, but as complementary tasks. In fact, a CS researcher may start exploring a document collection, then perform some kind of filtering, and finally read some of the resulting documents, but it is not the only possibility. A CS researcher may directly select or discard documents from a collection only by reading them - and then without exploring nor filtering the document collection-, or he/she may just want to obtain the list of documents written by a specific author — which can be achieved just by filtering the initial document collection. Besides, due to the variability of needs that a CS researcher may have while seeking information, and to the complexity of the information-seeking process itself, the user has to deal with a great amount of uncertainty (Wilson, 1999a). This implies that the process has to be modeled in the most flexible way possible, avoiding simple one-fits-all approaches. To achieve this, information-seeking tasks cannot be considered atomic - that is, a task can start only if the previous one has already finished - as they can interleave and complement each other. For example, while reading a document or exploring a document collection, a CS researcher may need to perform a search — which is a type of filtering task - to clarify some aspects he/she does not understand or to expand some information, or, on the contrary, after performing a filtering task, he/she may want to explore the results in order to decide if a further filtering task is needed or not. In short, a CS researcher may need to perform only a single information-seeking task to achieve his/her information-seeking purpose, but usually he/she requires carrying out a sequence of chained information-seeking tasks in order to iteratively refine the results of an information-seeking activity - see Figure 3.16.

This means that the CS researcher performs a set of information-seeking tasks that are inter-dependent, as the CS researcher may perform many tasks, even in parallel, in order to complement their results. This is usually necessary as the final purpose is too complex to be achieved in only one step, and then it has to be gradually resolved. As an example, a CS researcher may need to explore a set of documents returned after 


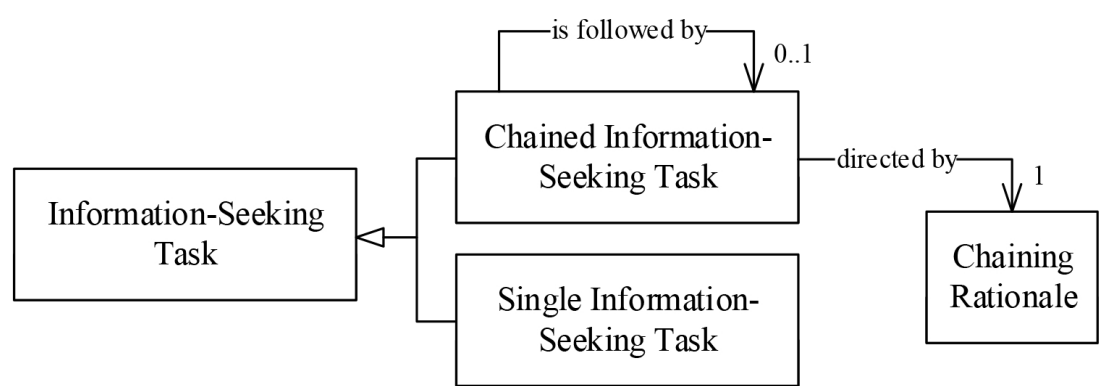

Figure 3.16 Single and chained information-seeking tasks

performing a filtering task, but he/she can also decide to perform a new filtering task after identifying new relevant information during a reading task, or simply to fully read them. The decision of performing a new information-seeking task relies uniquely on the CS researcher, who has to determine if his/her information-seeking purpose has been achieved. This decision is represented in the present model as the chaining rationale, which in case of iteration also contains which information is going to be used to chain the current and the future information-seeking tasks, and how it is going to be used. As an example, if a CS researcher wants to perform a systematic literature review, he/she will probably carry out both forward and backward snowballing in order to find and process all the documents that are cited by and that cite documents considered relevant. In this case, then, the chaining rationale consists in making use of the bibliographic references - for forward snowballing - and the publication details - for backward snowballing - of relevant documents, until no new relevant documents are found. This approach perfectly maps with the model proposed by Byström and Järvelin (1995), as they assume that the complexity of satisfying an information need is not always the same, and then an iterative and incremental approach is sometimes needed. In their model, the decision of performing another information-seeking task is defined by the user, who has to evaluate if his/her information has been satisfied.

\subsubsection{Filtering Task}

Due to the huge amount of information - both scientific and generic - that is currently available in the Web, when a CS researcher needs to find some information to achieve an information-seeking purpose, he/she often has to reduce the number of documents contained in the collection to be explored in order to keep only those that are potentially relevant for his/her current purpose. The main concepts and relationships that intervene in the filtering tasks are reflected in Figure 3.17 and are explained below.

A CS researcher can employ one or more filtering mechanisms in order to filter a document collection, but he/she typically has at his/her disposal only two filtering 


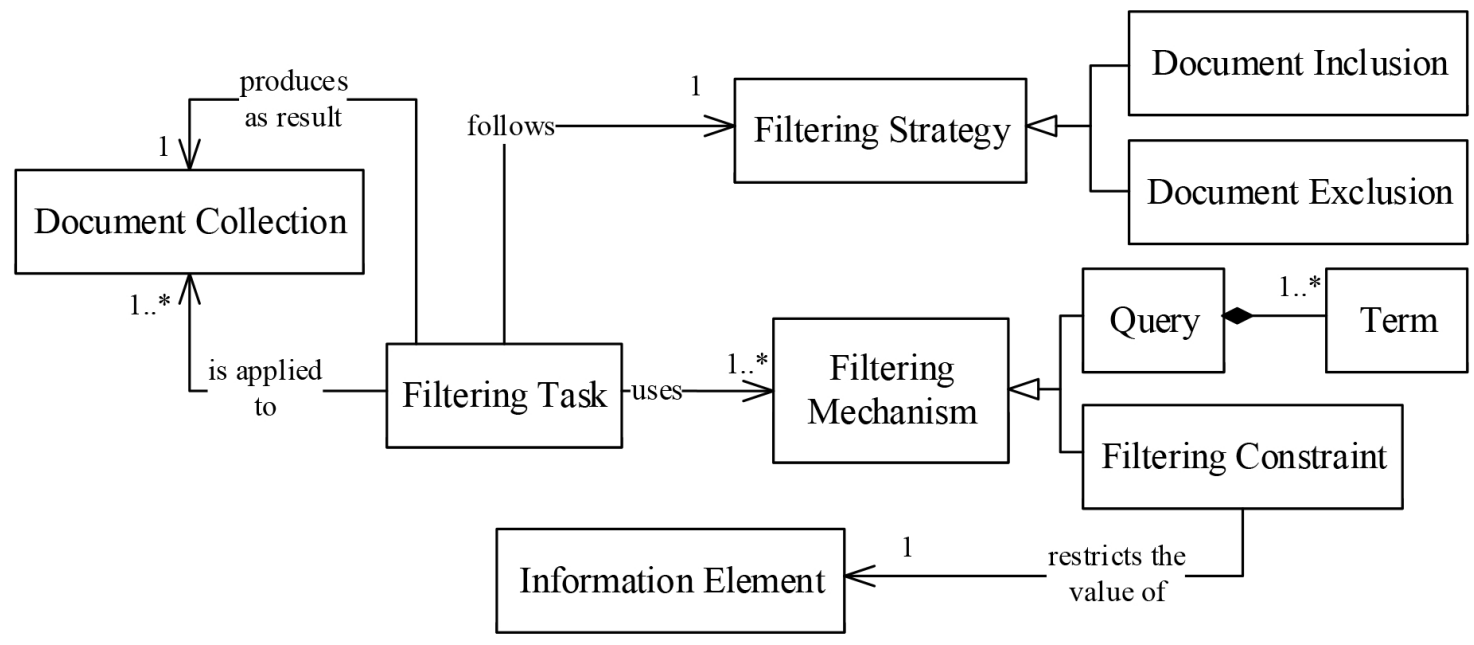

Figure 3.17 Filtering task

strategies. Both lead to same result, but using a different approach. In the first case - document inclusion-, the purpose is to identify which documents are potentially relevant to achieve his/her information-seeking purpose, and then have to be kept. The second strategy - document exclusion - consists in discarding the documents that are not relevant nor useful to achieve the CS researcher's current information-seeking purpose. In the first case, only the documents meeting the criteria defined in the filtering mechanisms are considered potentially relevant, while in the exclusive case, documents meeting these criteria are those that get discarded. For example, a CS researcher can decide to discard all the documents that are not written in English, while another CS researcher can decide to keep only the documents containing graphs, diagrams and/or tables as he/she looks for illustrated quantitative results. Even if these two strategies seem to be equivalent and can lead to the same results, they are different in terms of how the CS researcher faces the filtering task — see more details in Chapter 5.

A filtering mechanism can be implemented as a query or as a constraint. A query is typically used to retrieve information from an information source in the classical best-match approach, where the use of a search engine is required to obtain only the documents that contain the query terms - maybe not all of them, but most of them. On the other hand, a CS researcher may also prefer to filter a document collection by defining one or more filtering constraints. Each of these constraints indicates which pair of information element and specific value - or range of values - need to have the documents to be affected by the filtering - either to include or to exclude them. For example, a CS researcher may want to keep only the documents that have been published in a specific journal; or, on the contrary, he/she may want to exclude those published before 2010. Obviously, a CS researcher may also want to combine both mechanisms - that is defining both a query and one or more filtering constraints - to 
perform a more narrowed and detailed filtering task. For example, a CS researcher may want to obtain only the documents that match a given query and that have been published after a given date.

\subsubsection{Exploration Task}

As opposed to the filtering task, an exploration task does not aim at selecting one or more documents or at reducing a document collection, but just at exploring it. The main concepts and relationships that intervene in the exploration tasks are reflected in Figure 3.18 and explained below.

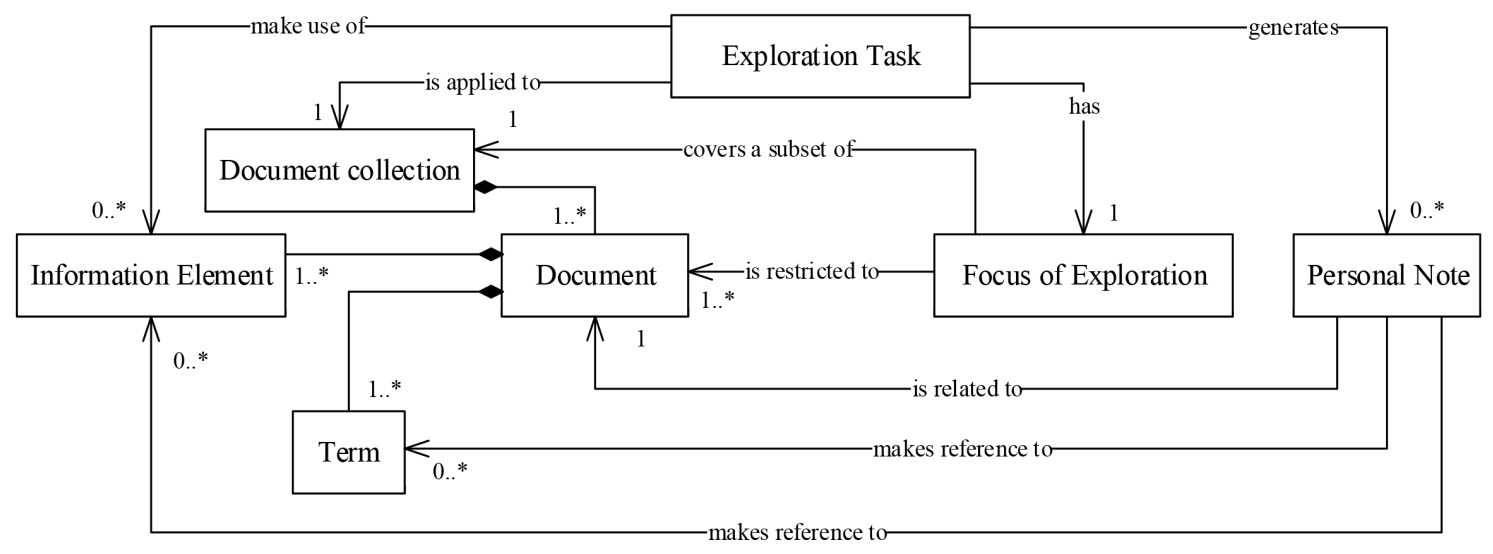

Figure 3.18 Exploration task

When exploring a set of documents, a CS researcher does not have any particular objective beyond, for example, getting a general idea of which type these documents are, which are the main topics they address or who are the most recurrent authors - among others. In order to do this, a CS researcher can manually explore one-by-one all the documents, but he/she can also perform some kind of ordering in order to create clusters according to one or more information elements. Then, the exploration is not directed by straightforward and well-defined criteria — as it occurs when using a query and/or a set of filtering constraints-, but instead by the dynamic decisions and intuition of the CS researcher while browsing the document collection. Therefore, the CS researcher is the one who decides at every moment how to proceed with the exploration and which information he/she needs to collect and use. In fact, many of the interviewees mentioned that, during their exploration tasks, they usually take some personal notes about everything they consider relevant or useful to achieve their information-seeking purpose. This relevant information can consist of any of the information elements contained in the document - like the name of its author(s), the name of the venue where it has been published, an equation or a table-, but also of a set of terms that 
are contained in the document and that the CS researcher considers relevant - for example because they are part of the specific terminology of the topic addressed in the document. In both cases, the CS researcher usually wants to clearly identify the most relevant content, either for having a summary of it - for example for speeding up further exploration or readings of the document-, or for using it — as part of the chaining rationale - in further chained information-seeking task. Besides, a personal note can be related to different documents as a CS researcher may want to relate different documents for some reason.

Given that in the exploration task no filtering is performed, it may be difficult —or even impossible - for a CS researcher to explore all the document of a big collection at the same time, and that's why he/she typically has to focus his/her attention on a reduced subset of documents at every moment. Then, for example, if a collection is formed by a hundred documents, the CS researcher may decide to explore them by tens.

\subsubsection{Reading Task}

At some point, a CS researcher may want to open and read a document - either fully or partially. While reading a document, a CS researcher can identify some relevant information and may want to highlight it - for example by marking it with some kind of symbol, by underlining it, or by coloring it with a physical or digital highlighter - or to take some personal notes about it. In this case, additionally, a CS researcher can take some personal notes about the document as a whole, but also about aspects that are not explicitly included in the document but that may have raised during or after reading it - like new promising ideas that have not been considered previously, or new approaches for solving a problem. All these reading-related concepts and relationships are illustrated in Figure 3.19.

\subsubsection{Storage \& Management Task}

Finally, the piece of model illustrated in Figure 3.20 contains the concepts and relationships that have to be taken into account to conceptually describe a storage \& management task.

Normally, if a CS researcher considers a document useful to achieve his/her present information-seeking purpose or if he/she considers it can be potentially useful in the future, he/she archives it -the document itself or the link that points to it- in a personal storage means, that can be either physical or digital. Physical storage means encompass all types of furniture or physical container that allow storing hardware documents, like a drawer, a box, a shelf or a desk table, while digital storage means include all the 


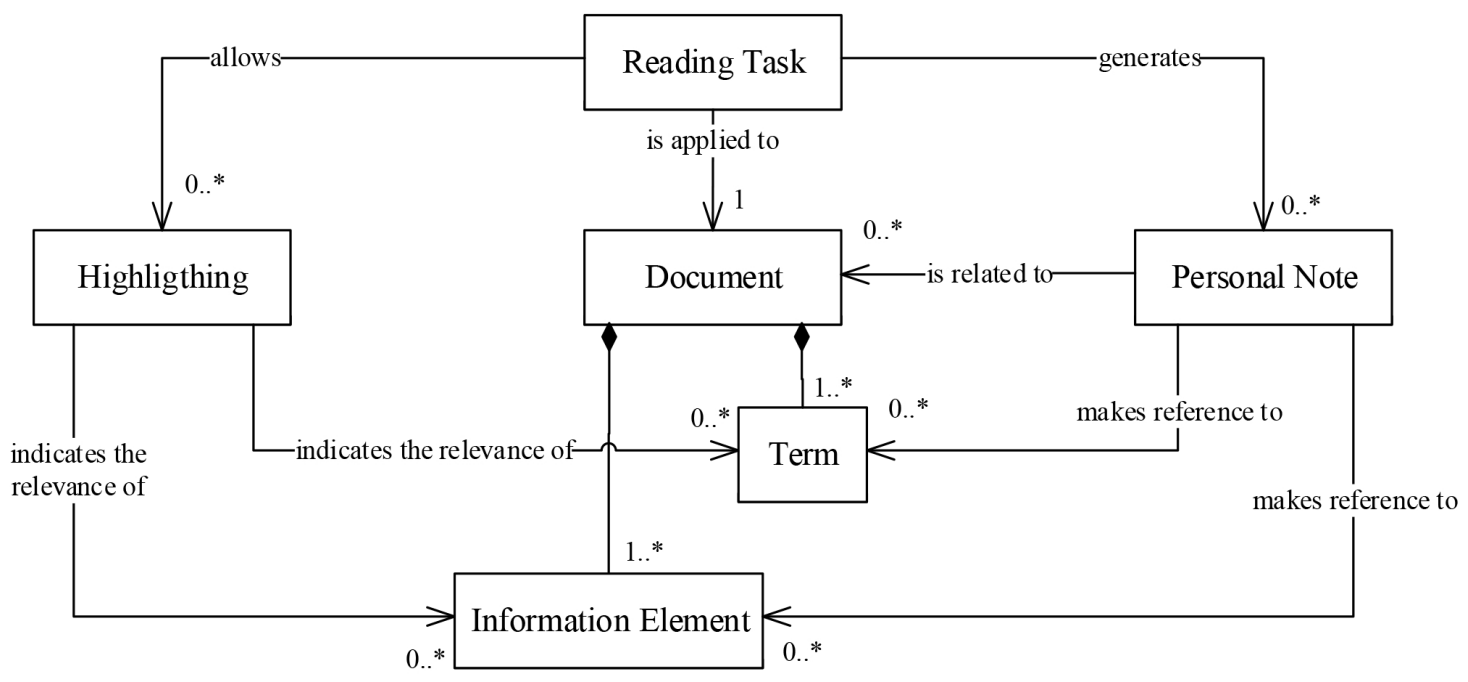

Figure 3.19 Reading task

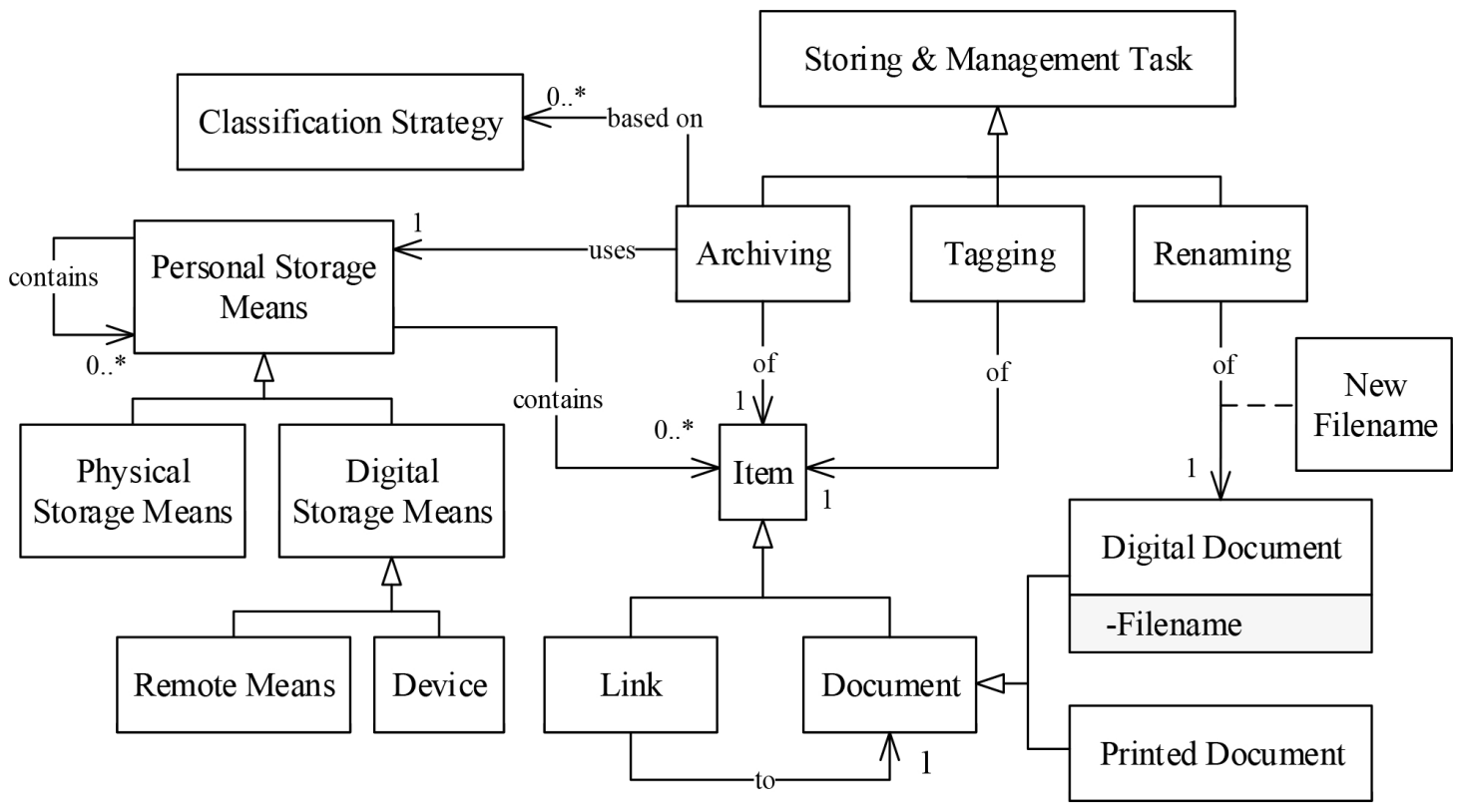

Figure 3.20 Storage \& management task

technological means -both hardware and software- allowing to store and manage digital documents or the links pointing to them. Within the latter category, CS researchers can use remote means, like cloud storage services - like Dropbox ${ }^{8}$, Google Drive ${ }^{9}$ or OneDrive $^{10}$ — or reference managers - like Refworks ${ }^{11}$, or Mendeley ${ }^{12}$ - , but docuemnts can also be archived in the storage means of a local device. In both cases, a storage

\footnotetext{
${ }^{8}$ http://www.dropbox.com

${ }^{9}$ https://www.google.com/drive/

${ }^{10}$ https://onedrive.live.com

${ }^{11}$ https://www.refworks.com

${ }^{12}$ https://www.mendeley.com
} 
means can in turn contain one or more storage means that allow to partition and structure it. As an example, a personal computer can have many partitions, and each of them can have a hierarchical structure formed by folders and sub-folders where documents are stored according to some classification criteria, or analogously, hardware documents can be archived, for example, inside different folders that in turn are stored in a set of boxes located on one or another shelf.

In order to facilitate the recognition and finding of the stored documents in future occasions, each CS researcher structures the classification in a different way, as it will be explained in Chapter 5. Usually, this classification strategy reflects the mental model of the CS researcher.

Once stored, a CS researcher may want to tag a document - or its link - in order to, for example, classify it, or he/she may prefer to assign some personal keywords to it in order to quickly summarize its content or its main contribution.

Finally, documents that are downloaded from a digital resource usually have an unrepresentative filename, and then a CS researcher may want to rename them with a new filename that, according to him/her, is more recognizable and/or representative of the document and its content. For example, the filename can simply be the real title of the document, but also a set of keywords that, according to the CS researcher, summarize its content, purpose or main contribution.

\subsection{Context}

Finally, there are some external aspects that have to be considered when modeling the information-seeking process. These aspects define the context in which an informationseeking activity is performed. The complete sub-model of the context is shown in Appendix C.3.

\subsubsection{Interaction details}

In order to perform an information-seeking task, a CS researcher has to interact somehow with the information system and with the documents. How this interaction is performed is one of the components of the context, as illustrated in Figure 3.21. To represent this interaction, it is required to know, first of all, which type of device is going to be used by the CS researcher during the information-seeking activity, both for inputting and getting information from the system.

On the other hand, it has to be defined which means of access is the CS researcher going to use to filter, explore, read or manage the documents. Figure 3.22 illustrates which are the main means of access that are used by CS researchers to seek information. 


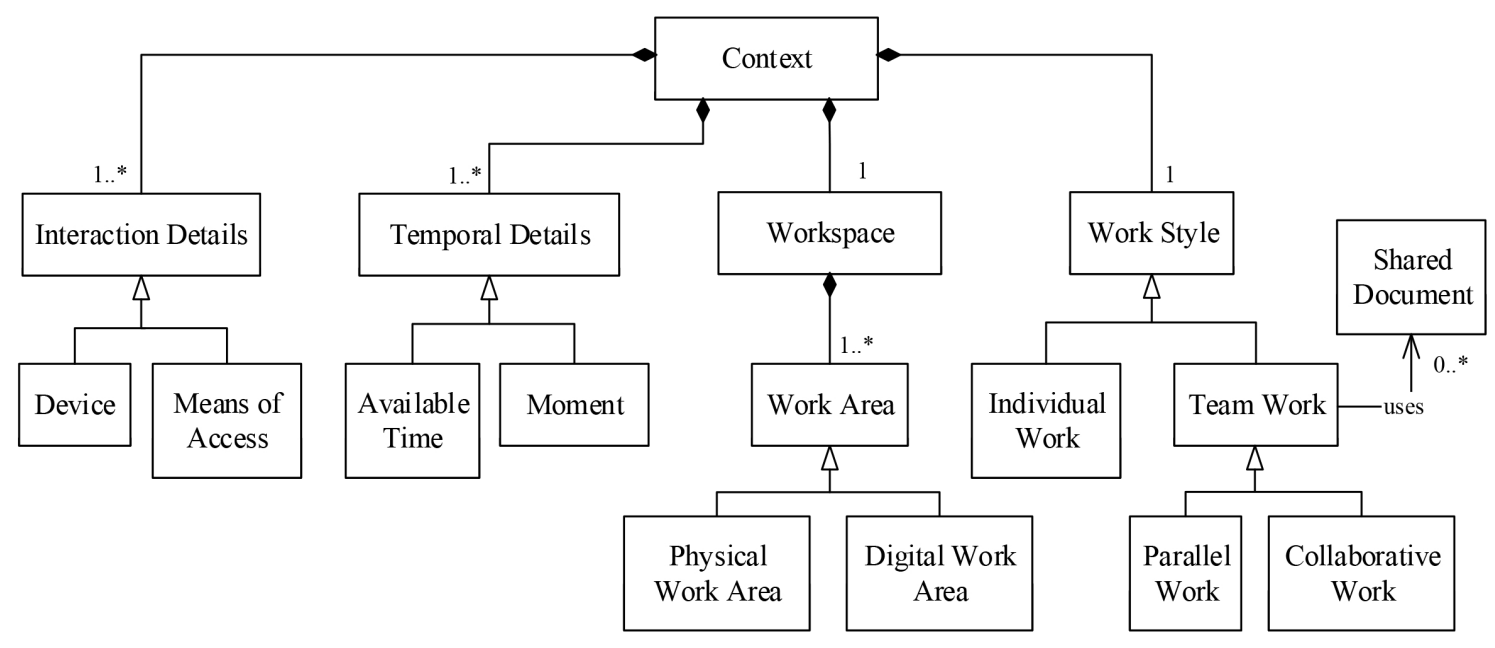

Figure 3.21 Main components of the context

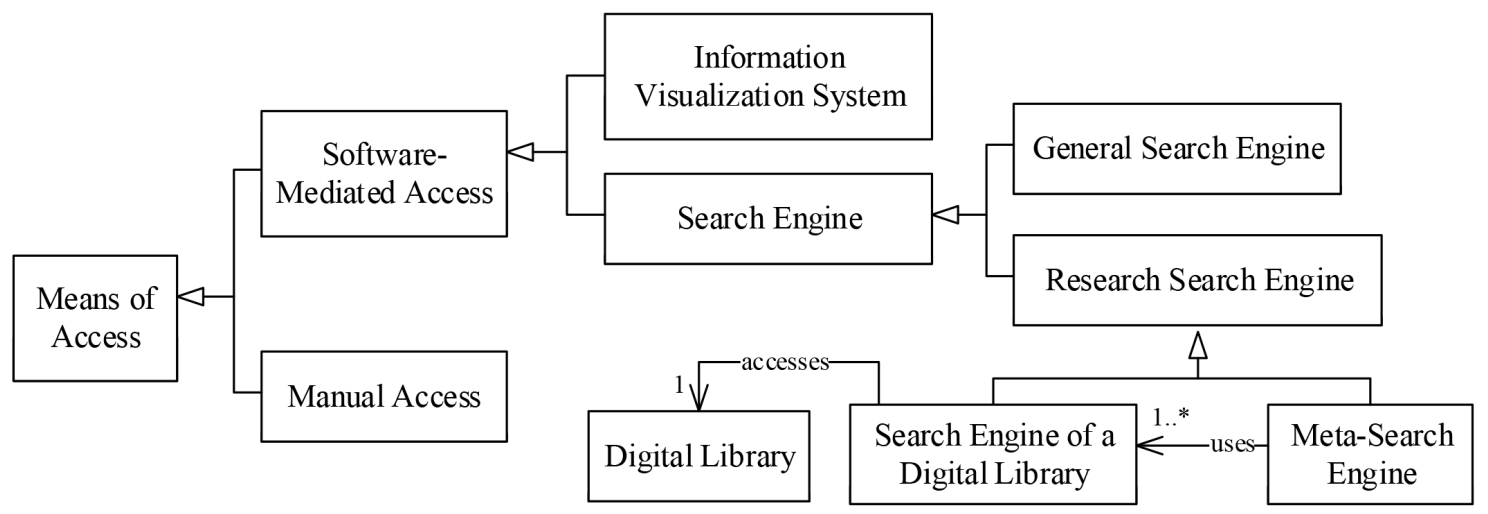

Figure 3.22 Means of access

The most basic and elementary means of access is the manual access, where the CS researcher performs the tasks without using any technological tool. In this case, the CS researcher directly interacts with the documents, usually belonging to a local document collection, in order to achieve an information-seeking purpose. This means that he/she navigates through them by manually accessing the folders that, according to their name - for example - can contain documents relevant for the current purpose. This type of access is the one used when the information-seeking activity makes use of physical collections of documents, but it also reflects when software is only used to visualize the documents - like the file explorer of an operating system does, for example - and the information-seeking tasks are performed manually by the CS researcher. As an example, in order to filter a document collection, instead of explicitly indicating a query or a filtering constraint in a software-based tool, the CS researcher is the one deciding if a document or a set of documents can be considered potentially relevant for the current purpose. This, for example, is quite common when the CS researcher looks for a book in a library. In practice, manual access can only be performed if the document collection 
is rather small, as it requires from the CS researcher to spend a high amount of time to manually and individually look over all or most the documents of a collection.

In fact, research document collections usually contain a huge amount of items, and then it becomes essential to use a software-mediated tool to perform the informationseeking activities in a reasonable amount of time. A CS researcher can use a search engine - for example - to automatically filter a document collection based on a set of criteria, or to find where a specific term has been used in a document in order to narrow the reading to this concrete part of the document. But, the CS researcher can also use an information visualization system, usually integrated in the information system itself, to facilitate observing the results of a filtering task, exploring a set of documents by allowing to visually classify them using a set of visual characteristics - like the color, the size, or the shape-, or annotating a given document while reading it. More details about the visualization of the information are provided in Chapter 4.

In the specific case of search engines - that are indisputably one of the digital tools that are more used in research-, there are two kinds that can be used depending on the aim of the search, but also on the type of information expected to be found, on the previous knowledge of the CS researcher about the topic, and/or on his/her expertise in carrying out information-seeking activities. On the one hand, general search engines like Google ${ }^{13}$, Yahoo! ${ }^{14}$ or Microsoft Bing ${ }^{15}$ are typically used to obtain a wide variety of information, even if it does not stem from scientific research sources. This kind of search engines are often used by CS researchers in rather initial exploratory phases of an information-seeking process, mainly because they intend to expand the scope of the search as much as possible; because they have little or no knowledge about a topic; because they do not know exactly which document collections could contain documents relevant for the current purpose; or because they still do not know the specific terminology used in the topic that would allow them to define good search queries.

On the other hand, there are many search engines that are intended for research purposes. Some of them are strictly associated to a single digital library, while others, called meta-search engines, provide a conceptually higher layer that allows a CS researcher to transparently perform the same search over more than one digital library, but using the same centralized interface. This is possible because, internally, a metasearch engine performs the same search over many specific search engines and integrates all the obtained results. These results are then presented in a homogeneous way, even if each of them points to its corresponding digital library, which facilitates and simplifies

\footnotetext{
${ }^{13} \mathrm{http}: / /$ www.google.com

${ }^{14} \mathrm{http}: / /$ www.yahoo.com

${ }^{15} \mathrm{http}: / /$ www.bing.com
} 
its use. Research search engines are usually employed by CS researchers that already have some relevant knowledge related to the topic - like its specific terminology — and then can perform a more directed search.

\subsubsection{Temporal details}

The second type of attributes of the context are those related with time. This implies knowing the moment when the information-seeking activity is carried out, and how much time has the CS researcher available to perform the activity. In the first case, it is important to know when the information-seeking activity takes place because there are some aspects, like the CS researcher's level of fatigue, that can influence his/her performance, concentration, motivation, and so on. As an example, a CS researcher is probably more tired late in the afternoon than early in the morning, and then he/she could perform worst. On the other hand, the amount of time that the CS researcher can spend in seeking information can also affect the performance of the information-seeking activities as, for example, it can narrow the amount of results the CS researcher is able to explore, or the amount of chained filtering tasks he/she can carry out to refine the collection as much as possible according to his/her information-seeking purpose.

\subsubsection{Workspace}

Alongside with the moment when the information-seeking activity is carried out, it is also important to take into account the workspace where it takes place. A CS researcher can work in many different workspaces - for example at home, in his/her workstation, in a laptop while flying to a conference, etc.- , and each of these workspaces can in turn be formed by many work areas, that can be categorized as digital work areas - for example a computer or a tablet - or physical work areas - for example a sheet of paper. Usually, a CS researcher uses each of these areas for a different activity, like searching, exploring, reading or writing. As an example, a CS researcher can use two screens while seeking information, using one of them to perform filtering tasks, and the other one to take notes about the obtained results. Alternatively, he/she can take some notes in a paper notebook and, at the same time, make use of a digital word processor to copy and paste relevant references. Analogously, a CS researcher can filter a document collection using a search engine, but he/she also can manually look for a specific article in a printed journal issue. 


\subsubsection{Work style}

Finally, a CS researcher may seek information individually, but he/she also may be part of a research group, and then it is highly probable that he/she has to coordinate with other CS researchers to properly carry out the information-seeking activities. In this case, the team can work collaboratively so that each member performs a separate part of an information-seeking activity and then they integrate their respective results. On the other hand, the team can work in parallel so that each member seeks the same information - but probably by different means, using a different sequence of information-seeking tasks, and using, for example, different mechanisms to filter the collection, or different information elements to cluster the documents - in order to dynamically share, compare and complement their results.

In both cases, the team shares the same final information-seeking purpose, but in the first case each member is in charge of fulfilling a different part of it, while in the second case a more holistic approach is undertaken and everybody tries to achieve the whole information-seeking purpose. Then, for example, if the information-seeking purpose is to elaborate the state-of-the-art of a topic, each member of the research team can take care of looking for relevant documents published within different ranges of years so that, in sum, they cover the whole desired period. Alternatively, all of them can perform the information-seeking activity considering the whole period of time. In terms of information retrieval, both approaches differ in terms of precision and recall, which are the most common measures of effectiveness in this field (Manning et al., 2008). Collaborative work can potentially provide a higher recall as the number of documents that have to be processed by each CS researcher is smaller and then it is more difficult to let a relevant document unidentified, but the precision can be lower as determining if a document is relevant or not depends only on the criterion of one CS researcher. On the contrary, results obtained by teams working in parallel can potentially be more precise as the findings can be contrasted: if all or most of the CS researchers have found the same document and have considered it relevant, then it is almost sure that the document is truly relevant. In this case, however, it is more probable for some relevant documents to remain unidentified at the end of the process as the document collection is bigger, and then the CS researcher potentially has to perform more and more complex information-seeking tasks and spend more time in each of them.

In both cases, CS researchers that are part of a team usually establish one or more shared documents - for example a digital word processor's file stored in the cloud - as a meeting point where they write their comments, results, summaries and/or interesting ideas, so that the rest of the team members can be aware of them. 


\subsection{Related works}

There are many authors in the literature who have tried to model, from different points of view, the information-seeking process undertaken by users of different profiles, working in different contexts and/or in different fields (Case, 2012; Ford, 2015; Wilson, 1999a). To begin with, Bates (1989) states that the typical information retrieval model based on the best-match approach is not valid, as fulfilling an information need is a complex activity that requires more than a query. This need evolves during the process and the context of use greatly affects how the process is performed. Bates concludes that each search provides the user with a small chunk of the information he/she needs, and that the user uses different search strategies and different sources of information in order to fulfill an information-seeking purpose. Then, it seems essential to understand both the user and the tasks he/she carries out, as well as the context in which he/she carries them out in order to properly model the information-seeking process. the results presented in this thesis completely match these findings, first of all because it considers that there are five main aspects that influence the performance of an information-seeking activity by a researcher. The main ones are the documents in which the researcher has to look for information, and the researcher himself/herself. The rest revolve around the latter: the final purpose the researcher wants to achieve, the tasks he/she needs to perform for this achievement, and the context in which he/she is while looking for the information. Similarly, the proposed solution also considers that the information-seeking process is an iterative process that requires a progressive refinement of the solution that cannot be simply defined as a predefined sequence of tasks.

Many authors have derived information-seeking models detailing which are the stages through which a user usually passes during an information-seeking activity. One of the most relevant and referred models, proposed by Ellis (1989), firstly consisted of 6 stages - Starting, Chaining, Browsing, Differentiating, Monitoring, and Extracting and was derived from the study of academic researchers in social sciences like psychology, sociology, politics or geography. However, the model has been also validated in other fields like Physics, Chemistry, and English Literature (Ellis et al., 1993; Ellis, 1993). Later, Ellis updated his model with two new stages - Filtering and Ending - (Ellis \& Haugan, 1997) after studying the behavior of professionals - non-academic researchersand research scientists in an industrial environment - an oil research center. More recently, Meho and Tibbo (2003) proposed to complete the Ellis' initial model with four new stages - Accessing, Networking, Verifying, and Information Management - after analyzing a set of structured and semi-structured interviews performed to sixty social sciences researchers. Later on, Makri et al. (2008) modeled the information-seeking 
behavior using 14 low-level stages - among which can be found most of those proposed by Ellis - grouped into three higher-level stages - Identifying and locating, Accessing, and Selecting and Processing. In this case, the study targeted academic lawyers. In all these cases, authors assign to some level a dependence between these stages as they have some kind of precedence when carrying them out. However, all them also argue that the process cannot be perceived as a linear process where a set of atomic and sequential tasks are performed to fulfill the information need, but instead it must be described as a non-linear and iterative process with a great complexity that has to be iteratively reduced through a set of tasks that may be carried out in an unordered fashion, that may complement each other, and that may even be performed simultaneously. The proposed model also tries to reflect this complexity and uncertainty by avoiding defining the process as a sequence of stages or tasks, from which some kind of precedence or dependence could be derived. However, it is essential to note that, despite this structural difference in the model, most of the concepts presented by these authors have been also derived from the analysis of the qualitative study - for example chaining, browsing, differentiating, extracting, filtering, accessing, or examination of results.

There are many other authors that, instead of defining the process only by the set tasks that are performed by the user, they also include the stages through which a user passes during the information-seeking process. This is usually called information behavior. As an example, Marchionini (1997) provides a behavioral model of the information-seeking process by defining a set of progressive and iterative tasks - Problem formulation, Express the information need, Examination of results, Reformulation, and Use of the found information - together with a set of stages that are more related to the user - Recognize a need and Accept a challenge. In the same direction, Foster (2004) identifies a set of tasks that he calls core processes - Breadth exploration, Keyword searching, Browsing, Chaining, Reviewing, Identifying keywords, Refining or Verifying - and categorizes them into three main activities - Opening, Orientation, and Consolidation. Foster finds that these tasks and activities take place in three levels of contextual interaction: in the Cognitive Approach level, where the user processes the information and takes decisions; the Internal Context is related with the user's feelings and thought; and the External Context deals with the social aspects involving the user while seeking information. Finally, Kuhlthau (1991) also models the information-seeking process as a sequence of six user-centered stages: Initiation, Selection, Exploration, Formulation, Collection, and Presentation. This model, which is one of the most relevant and cited in the literature, focuses in trying to understand the user's behavior while seeking information from a psychological and sociological point of view. Even if the proposed model shares many of the concepts presented in these behavioral models, the 
point of view from which has been raised and the type of information it is intended to convey are totally different as, even if there is an agreement on the importance of taking into account the specificities of the user during the process, the analysis made in this work does not focus on how the user feels, what are his/her thoughts during the process, or how he/she acquires and consolidates knowledge during the process. In this work, we follow a more holistic approach in order to try to clearly and unambiguously illustrate by visual means which are the main concepts that intervene in an information-seeking process.

In our opinion, it can be intuitively stated that representing a model visually is probably easier and faster than explaining it extensively, especially if the final aim is to allow the reader creating his/her own mental models about a given situation or process. In fact, even if many of the models that can be found in the literature have been explained by a more or less extensive and more or less detailed verbal description - like for example those presented just above-, there are some authors that have adopted this approach to present their information-seeking models. One of the best representatives of this approach is the pictorial model of the user's behavior while seeking information proposed by Wilson (1981) as he summarizes the process using a graphical diagram where only the main actions and objects are represented. Some years later, Wilson expanded his model including other external aspects - economical, sociological, situational, and information sources - that can also intervene in the information-seeking process (Wilson, 1997). However, as it can be seen in Figure 3.23, the Wilson's revised model still contains only very high-level concepts and relationships, and as a result the pictorial model is just a support material that cannot be understood without the textual explanation.

Later on, Niedźwiedzka (2003) proposed a new information behavior model based on Wilson's revised model. In this new proposal, Niedźwiedzka maintained all the components proposed by Wilson, but she reorganized and refactorized them, especially the intervening variables - personal, role-related, and environmental - that in her model are part of the context, which in turn affect all the process stages. Additionally, Niedźwiedzka's model reflects that the process can be activated at any of its stages by different mechanisms, and not only at the beginning. Leckie et al. (1996) also derived a graphical information-seeking behavior model for researchers in general - even if the study focused on engineers, health care professionals and lawyers, they claim that the model can be generalized. In their case, the information-seeking process starts in a specific stage - Work Roles - and, after performing a set of intermediary stages, it ends up with the Outcomes stage. 


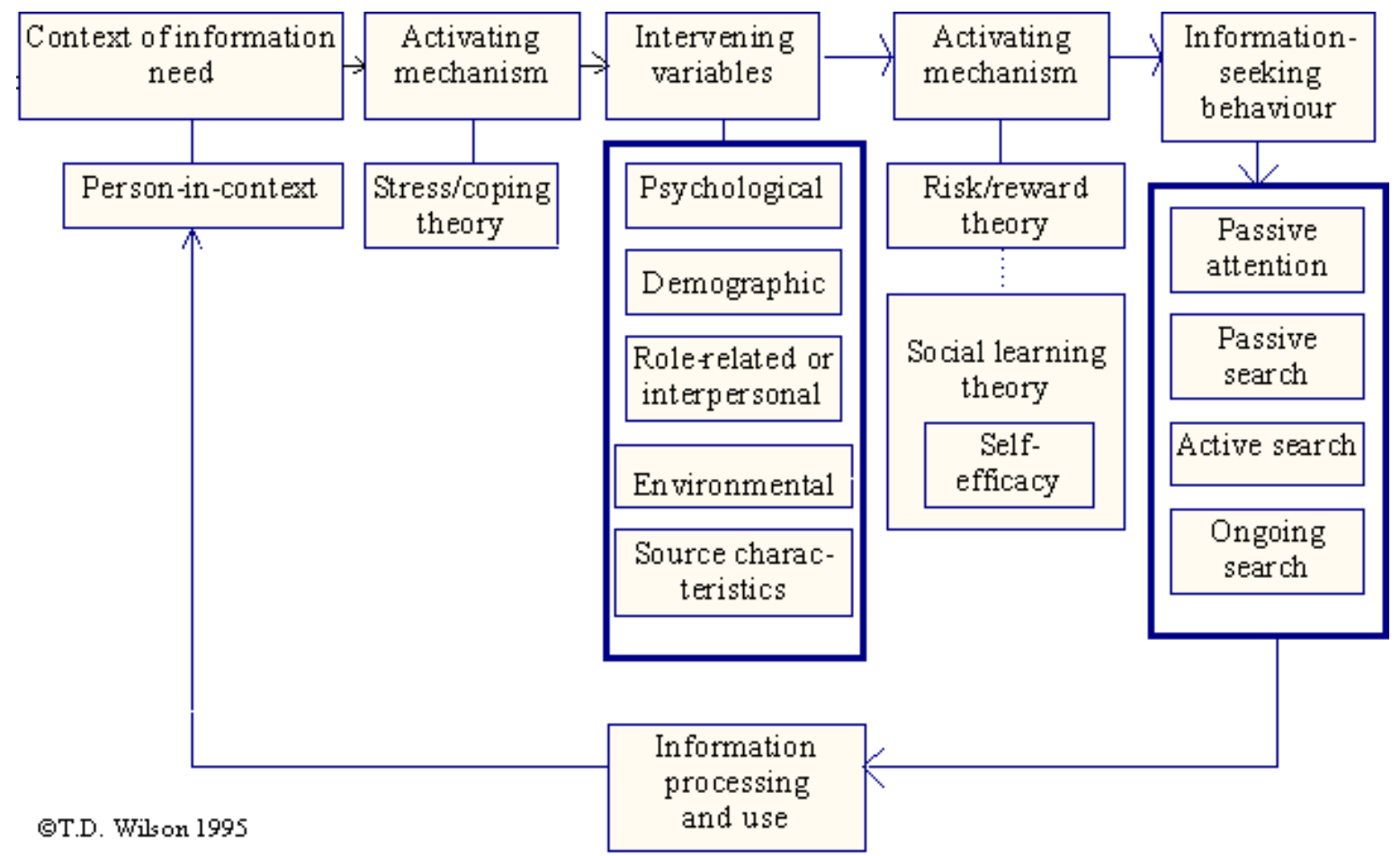

Figure 3.23 Wilson's revised general model of information behaviour ${ }^{16}$

In all three cases, even if some concepts related to the information-seeking process are presented, their relationships are defined in terms of precedence, and therefore they better can be defined as sequence or activity models allowing the reader to navigate through the temporal sequence stages through which a researcher has to pass when seeking information. The proposed conceptual model, however, is timeless as it intends to illustrate the relationships as semantic and functional interactions between concepts - reflected by association relationships - , where dependence between concepts is only reflected by structural relationships - like in the composition and generalization relationships.

To the best of our knowledge, only Krikelas (1982) and Benardou et al. (2010) have used something similar to a conceptual model to visually describe the informationseeking activities. In both cases, even if the representation is not framed in a standard representation like UML, their approach is very similar, and they visually illustrate concepts and relationships in a similar way. In the first case, as reflected in Figure 3.24, Krikelas describes the main high-level concepts and actions related to the informationseeking behavior - like information needs, sources of information, information gathering and information giving - and then illustrates them in a pictorial conceptual model relating them in terms of association - for example, information gathering occurs when

\footnotetext{
${ }^{16}$ Copyright from T.D. Wilson (1995). Reused free-of-charge under Creative Commons license. Extracted from http://www.informationr.net/tdw/publ/infbehav/chap7.html.
} 
the user's information need does not have to be satisfied immediately and can be deferred - or of generalization - a source preference can be of two types, internal or external.

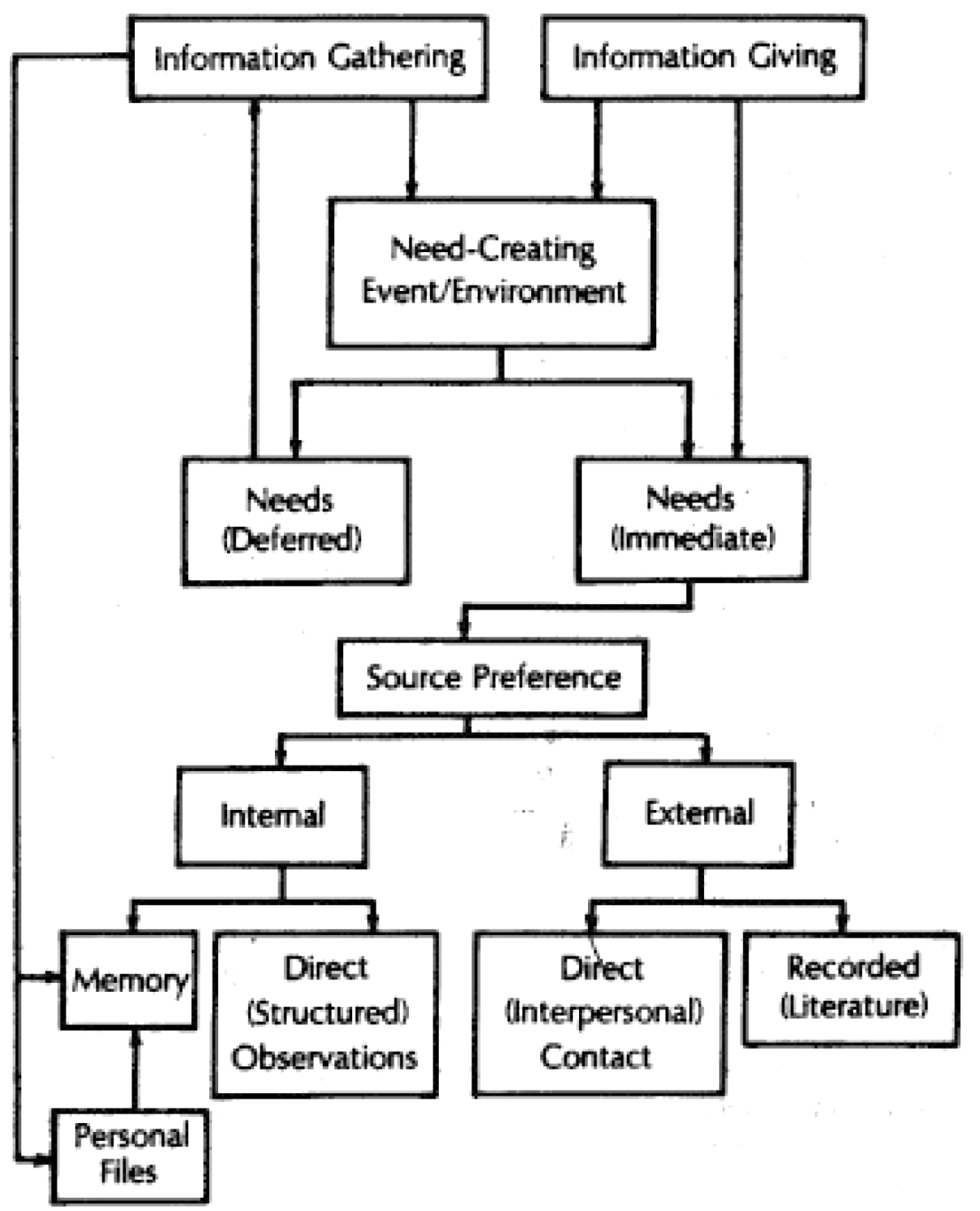

Figure 3.24 Krikelas' information behaviour model ${ }^{17}$

In turn, Benardou proposes a pictorial conceptual model, illustrated in Figure 3.25, containing very high-level concepts, like actor, information object, or method that are related through a set of tagged relationships — as done in the association relationships in UML. In this case, moreover, the model aims at conceptualizing the overall research activity performed by scholars, including a lot of other sub-activities apart from seeking information, like, for example, writing a paper.

However, in both cases, the information-seeking process is over-simplified and the presented concepts are so abstract that the model is not comprehensive nor self-sufficient,

\footnotetext{
${ }^{17}$ Copyright from J. Krikelas (1982). Extracted from (Krikelas, 1982).
} 


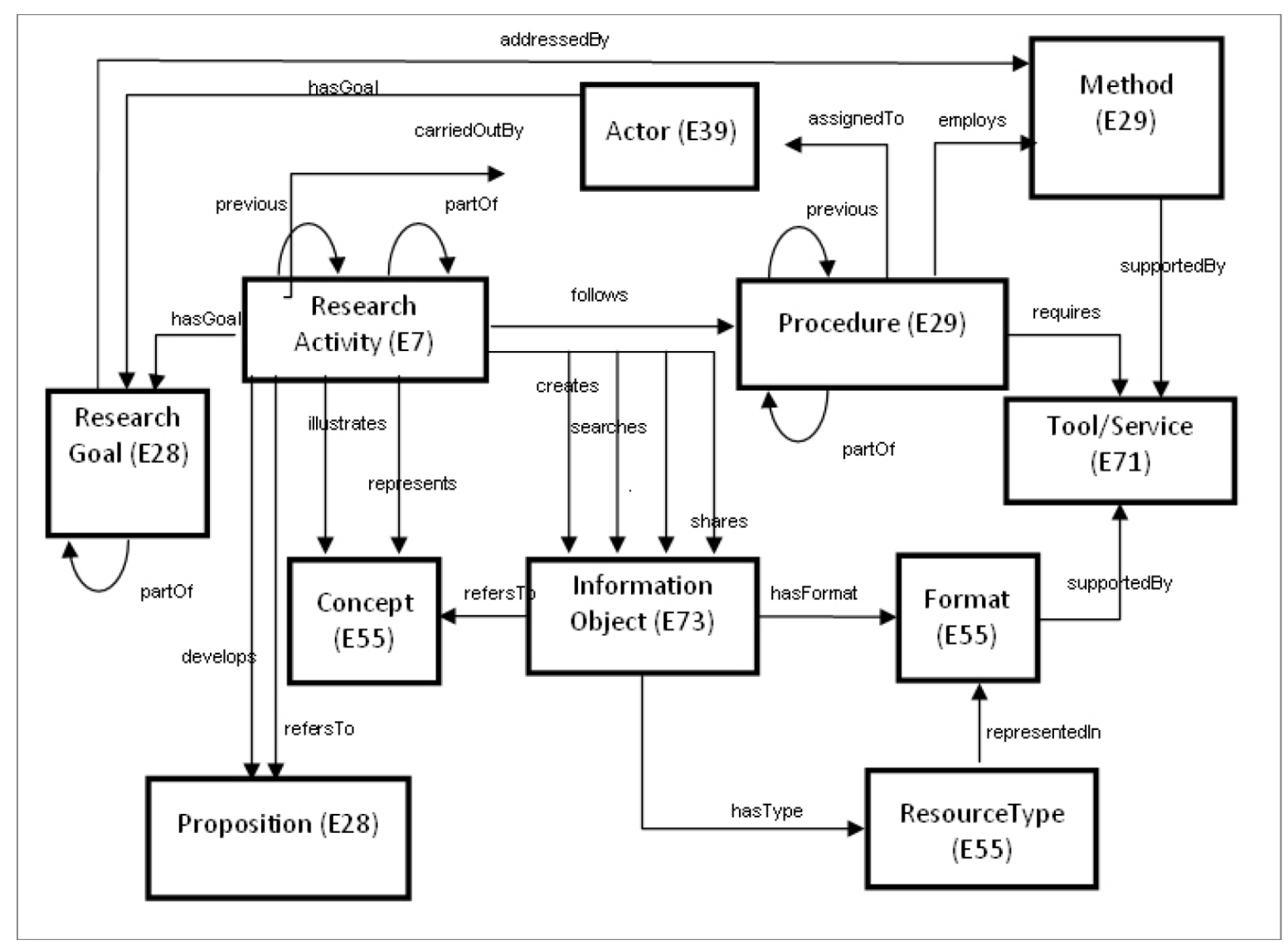

Figure 3.25 Scholarly research activity model from Benardou, Constantopoulos, Dallas, and Gavrilis $(2010)^{18}$

and then the reader may have several questions about the model that remain unasked even after reading the explanations provided by the authors, as the concepts and their relationships are not always explained in very much depth. The present model tries to be not only comprehensive, but also absolutely self-explainable and self-contained, so that reading the textual explanation is a complementary task whose only aim is to facilitate and improve the understanding of the model by providing more in-depth details or by providing some examples illustrating the concepts and their relationships.

Some authors have proposed theoretical information-seeking or information behavior models, that are meant to be general (Bates, 1989; Godbold, 2006; Marchionini, 1997; Wilson, 1997). The premise adopted in this work, however, is that the information-seeking process is dependent on many factors, like the user - in this case a CS researcher-, his/her information-seeking purpose, the context in which the seeking is carried out, and the information-seeking tasks that are performed during the process to reach the mentioned purpose. Cheuk and Dervin (1999) reached the same conclusion after analyzing how auditors, engineers and architects perform their

\footnotetext{
${ }^{18}$ Copyright from A. Benardou et al. (2010). Reused free-of-charge under Creative Commons license. Extracted from http://www.ijdc.net/index.php/ijdc/issue/view/11.
} 
information-seeking activities using the Sense-Making Methodology (Dervin \& Nilan, 1986; Dervin, 1983, 1992). The analysis of the study, based on the identification of three aspects - the Contextual time-space situation in which the process is performed; the information need or Gap; and how the user makes Use of the obtained information to construct new knowledge - resulted in the identification of ten different contexts - called Information-seeking situations. Seven of these situations - Task initiating, Focus forming, Idea assuming, Idea rejecting, Idea confirming, Idea finalizing, and Idea sharing - were commonly experienced by the three types of participants, while the other three - Approval granting, Design generating, and Approval seeking - were primarily experienced only by architects. Then, they concluded that, even if there exist many commonalities between different workplace domains, there also exist specificities that can affect the information-seeking process. Byström and Järvelin (1995) also propose an information-seeking model that reflects the dependence of the information-seeking process on the researcher characteristics and preferences - called Personal factors and Personal style of seeking - and on the context — called Situational factors. Additionally, they categorize the tasks into five categories based on their determinability, which is closely related with their levels of uncertainty and complexity. In these cases, the performance of several activities is generally needed to iteratively reduce the complexity and uncertainty of the problem, and that's why the model is structured as a feedback loop so that the result of each activity is used as input in the following activity. This approach corresponds to solution presented in this work as the achievement of an information-seeking purpose requires performing one or more chained tasks that interleave in a non-deterministic way. Similarly, Domik and Gutkauf (1994) stated that, in order to improve the information-seeking process performed through information visualization systems, there are four factors that have to be taken into account. The models proposed in this thesis also reflect the relevance of these factors when describing the information-seeking process. First of all, the data model proposed by Domik \& Gutkauf is comparable to the document sub-model. Then, their problem domain/task model is equivalent to the information-seeking purpose concept, which is directly related to the information-seeking tasks performed by the user - in this case, the researcher-, who also has to be modeled, as done in the presented model. Finally, their resource model directly maps with part of the context sub-model presented here, as it deals with the hardware and software used by the user to carry out the information visualization process.

Focusing on the studied area, to the best our knowledge, no models related to the information-seeking process performed by CS researchers have been proposed until now. Some authors have analyzed or statistically surveyed how engineers seek 
information (Freund et al., 2006; Hertzum \& Pejtersen, 2000; Kwasitsu, 2003; Leckie et al., 1996; Peterson Holland \& Kelleher Powell, 1995; Pinelli, 1991), but none of them has derived a model from the obtained results. Additionally, none of them focused on researchers with a strong technical education background, especially in information and communication technologies, like CS engineers. Ellis and Haugan (1997) studied how engineers and research scientists performed their information-seeking activities in an industrial environment, but among the 26 participants of the study, only one of was a scientist with a technical education background - mechanical engineering. Similarly, Anderson, Glassman, McAfee, and Pinelli (2001) also studied how 872 aerospace engineers and scientists looked for information. To the best of our knowledge, only O'Brien and Buckley (2005) have partly studied this user profile, as they propose an information-seeking behavior model for programmers involved in software maintenance. Their model is based on some of the models mentioned above in order to adapt it to the specific needs of the studied context - for example, seeking information is presented as an iterative process, or the stage leading to the identification of the problem is omitted as in the software maintenance context the problem is usually defined in advance by somebody. At the end, this non-linear model proposes five stages. First of all, the user has to be "Aware of the Problem", which requires an initial understanding of it. Then, the information seeker has to "Focus the Formulation" and narrow the problem to formulate specific queries. At this point the user has to start the "Information Collection" stage where he/she tries to identify what sources can be relevant, which usually implies performing chained searches based on who refers to these sources - forward snowballing - , or who is referred to in the sources - backward snowballing. Once relevant sources have been identified, their content is browsed in order to differentiate which information is potentially relevant and has to be extracted, and which one seems to be non-relevant and then has to be omitted. After this, the seeker has to "Examine these Results" more in detail to determine if they are actually relevant for his/her information need. Finally, the process ends up when the user considers that his/her information need has been satisfied - "Problem Solution". Shortly after, Buckley, O'Brien, and Power (2006), after empirically evaluating their model with two maintenance programmers, extended their model with a sixth stage, "Information Prompted Action", between "Examine Results" and "Problem Solution" in order to accommodate the actions allowing to provide directional information that can be used as a base to facilitate the performance of further information-seeking activities.

However, programmers, even if they have a strong background in technical aspects and in information and communication technologies, cannot be considered CS researchers, as they have different objectives and focus on different aspects - in con- 
crete, the type of information-seeking purposes they have to achieve are quite different, and the type of documents and information they seek are, probably, also different. This, together with the incredible advancement of the technology in the last years, has motivated us to study how CS researchers - that are supposed to master the use of technology - actually perform their information-seeking processes, and evaluate if there are differences with respect to researchers with a different profile. In this sense, even if the proposed model has not been compared exhaustively with other models derived from other contexts, there are numerous similarities that make us think that the variability of the model is not related to field in which the seeking is performed, but to the other aspects that have been already mentioned before. As discussed in Chapter 9 , in the future it is planned to formally evaluate to what extent the proposed model is valid in other research fields.

Figure 3.26 illustrates the comparison between the generated model and the models existing in the literature, paying particular attention to the four aspects aforementioned:

- Methods used to obtain the model

- Type of representation used to present the model

- Type of model

- Domain from which the model has been derived

Then, after analyzing all the aspects presented below, we claim that our contribution is very interesting as nobody, to the best of our knowledge, has conceptualized the information-seeking process in the specific domain of CS researchers so comprehensively in order to provide a solid, flexible and complete framework, and then it can be of great utility for professionals - researchers, designers, software programmers, etc.- - working in the the computer science field, especially in research-oriented activities. 


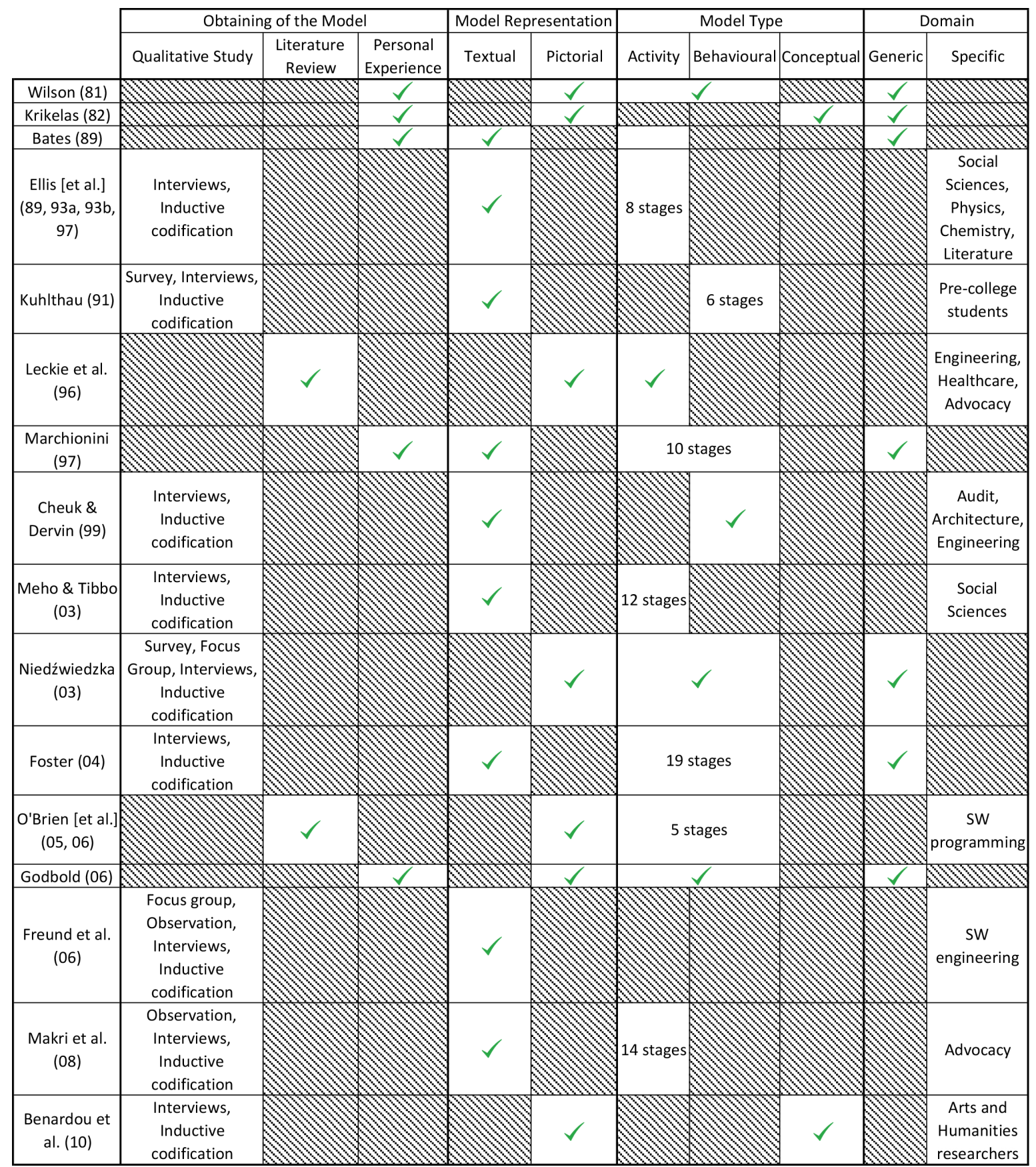

Figure 3.26 Comparing the obtained ISP conceptual model vs. models existing in the literature 